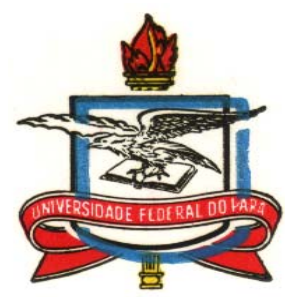

UNIVERSIDADE FEDERAL DO PARÁ

CENTRO DE GEOCIÊNCIAS

CURSO DE PÓS-GRADUAÇÃO EM GEOFÍSICA

\title{
APROXIMAÇÕES HIPERBÓLICAS DOS TEMPOS DE TRÂNSITO COM TOPOGRAFIA
}

Manuel de Jesus dos Santos Costa

Belém - Pará

2005 


\title{
UNIVERSIDADE FEDERAL DO PARÁ CENTRO DE GEOCIÊNCIAS CURSO DE PÓS-GRADUAÇÃO EM GEOFÍSICA
}

\author{
DISSERTAÇÃO DE MESTRADO POR \\ Manuel de Jesus dos Santos Costa
}

\section{APROXIMAÇÕES HIPERBÓLICAS DOS TEMPOS DE TRÂNSITO COM TOPOGRAFIA}

\section{COMO REQUISITO PARCIAL A OBTENÇÃO DE GRAU DE MESTRE EM CIÊNCIAS NA ÁREA DE GEOFÍSICA}

Data de Aprovação: 23/05/2005

Nota: 86\% (Excelente)

Comitê de Tese:

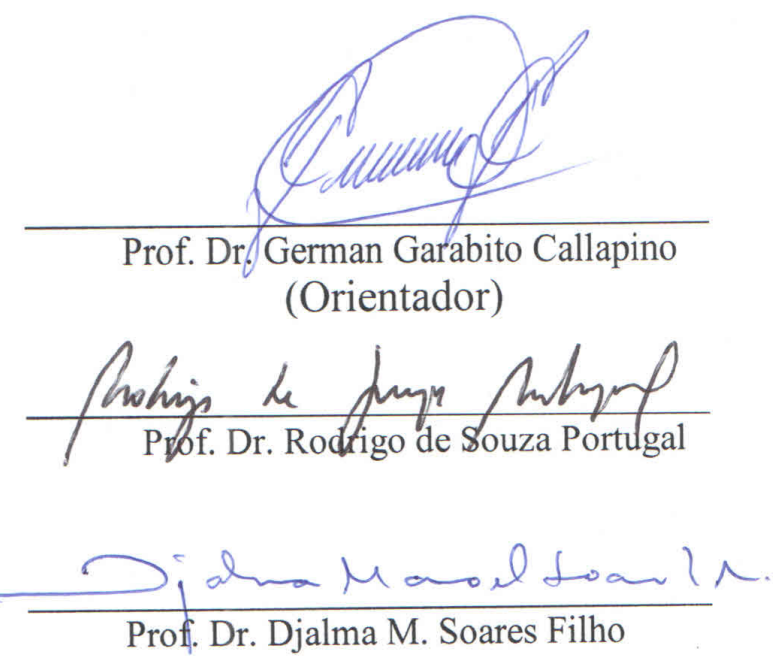

Belém - Pará 
Aos meus pais,

Á minha esposa Clenir e minha filha Emanuelle 


\section{AGRADECIMENTOS}

Agradeço primeiramente a Deus por ter proporcionado saúde, confiança e determinação para terminar esta dissertação.

Aos meus pais, esposa e filha pela compreensão nos momentos de ausência necessários para a concretização desta dissertação.

Ao Prof. Dr. German Garabito que me apresentou o tema desta dissertação, bem como pelo apoio e orientação dispensados durante toda sua realização.

Aos membros da banca examinadora pelas suas valorosas sugestões.

Aos professores do CPGF.

A Sr ${ }^{\mathrm{a}}$ Benildes Lopes por seu apoio e amizade constate.

A todos os amigos que de uma forma direta ou indireta cooperaram para a conclusão desta dissertação. 


\section{SUMÁRIO}

p.

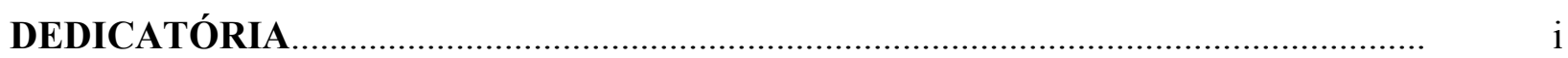

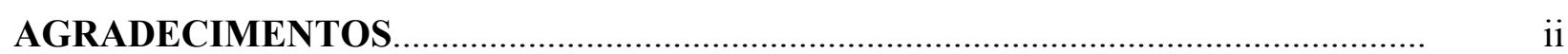

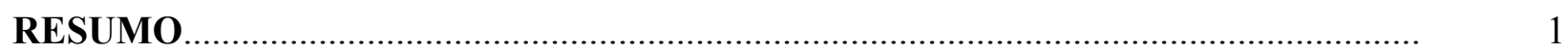

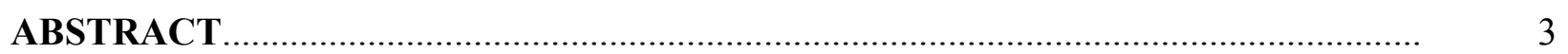

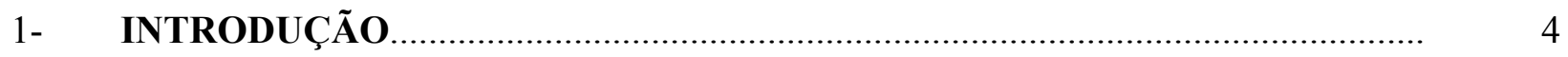

2- TEORIA DO RAIO: UMA BREVE REVISÃO ................................................. 8

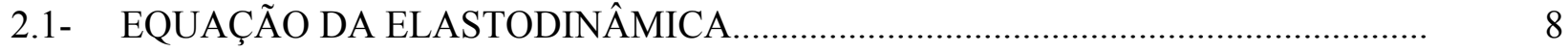

2.2- EQUAÇÃO DA ONDA ACÚSTICA.................................................................... 10

2.3- EQUAÇÕES EIKONAL E DE TRANSPORTE..........................................................

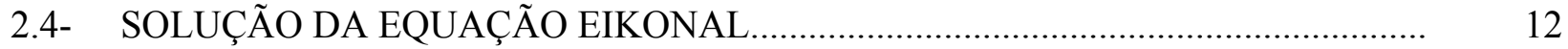

2.5- SOLUÇÃO DA EQUAÇÃO DE TRANSPORTE....................................................... 13

2.6- TEORIA PARAXIAL DO RAIO E TRAÇAMENTO DINÂMICO DO RAIO.......... 14

3- TEMPOS DE TRÂNSITO DE RAIOS PARAXIAIS PARA UMA LINHA DE MEDIÇÃO COM TOPOGRAFIA RUGOSA 20

3.1- SISTEMA DE COORDENADAS DO RAIO........................................................... 20

3.2- SISTEMA DE COORDNADAS CENTRADO NO RAIO....................................... 21

3.3- $\quad$ SISTEMA CARTESIANO LOCAL DE COORDENADAS.......................................

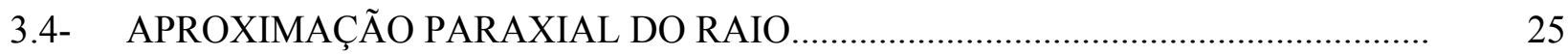

3.4.1 - Sistema Dinâmico da Trajetória do Raio................................................................. 26

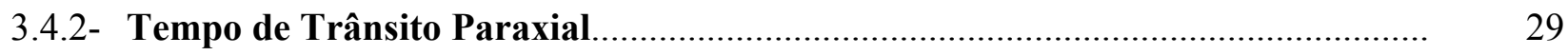

3.5- FORMALISMO PARA O MÉTODO DE EMPILHAMENTO SRC

BIDIMENCIONAL COM AFASTAMENTO-NULO PARA UMA LINHA

DE MEDIÇÃO COM TOPOGRAFIA RUGOSA.................................................... 32

4- TEMPOS DE TRÂNSITO DE RAIOS PARAXIAIS PARA UMA SUPERFÍCIE DE MEDIÇÃO COM TOPOGRAFIA SUAVE............................ 34

4.1 - TEORIA GEOMÉTRICA DO RAIO ......................................................................... 


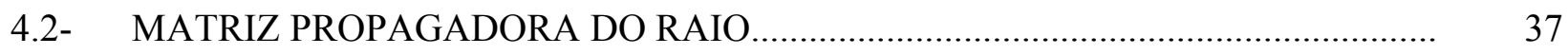

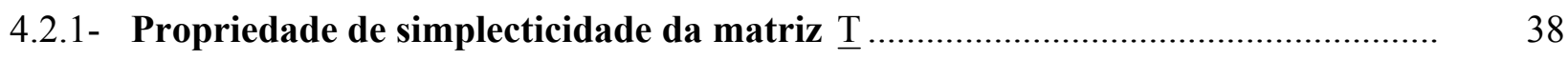

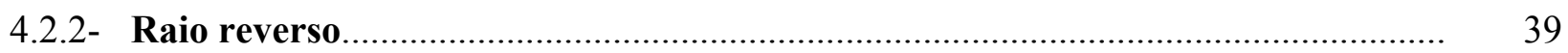

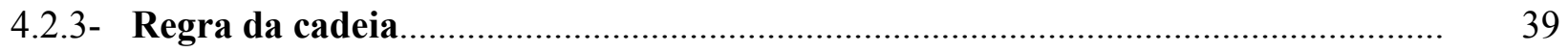

4.3- DERIVAÇÃO DO TEMPO DE TRÂNSITO PARAXIAL ........................................... 40

4.3.1- Tempo de trânsito de um raio paraxial..........................................................................

4.4- INFLUÊNCIA DA TOPOGRAFIA DE AQUISIÇÃO COM NÃO-HOMOGENEIDADE NO MODELO....................................................... 44

4.5- CASO DO RAIO CENTRAL COM AFASTAMNETO-NULO (AN) ......................... 47

5- COMPARAÇÃO DOS TEMPOS DE TRÂNSITO PARAXIAIS COM TOPOGRAFIA SUAVE E RUGOSA...................................................... 50

5.1- SUPERFÍCIE DE EMPILHAMENTO SRC PARA UMA LINHA DE MEDIÇÃO COM TOPOGRAFIA SUAVE ..................................................................... 50

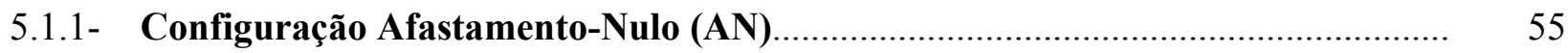

5.2- SUPERFÍCIE DE EMPILHAMENTO SRC PARA UMA LINHA DE MEDIÇÃO COM TOPOGRAFIA RUGOSA......................................................................... 56

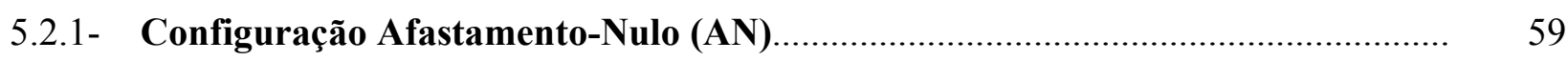

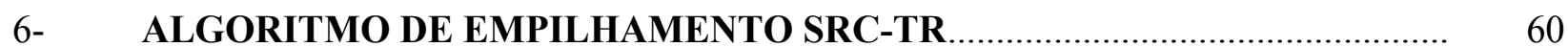

6.1- ESTUDO DE SENSIBILIDADE DOS ATRIBUTOS DE FRENTES DE ONDAS... 60

6.2- $\quad$ ALGORITMO DO EMPILHAMENTO SRC-TR .......................................................

7- CONCLUSÕES E PERSPECTIVAS.................................................................... 72

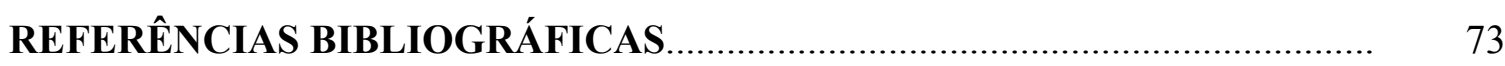

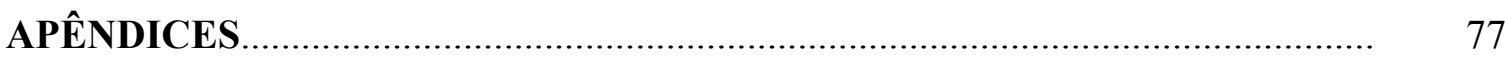
APÊNDICE A - DERIVAÇÃO DO TEMPO DE TRÂNSITO PARABÓLICO... 78 APÊNDICE B - PARÂMETRO CINEMÁTICOS DAS AUTO-ONDAS: PONTO DE INCIDÊNCIA NORMAL E ONDA NORMAL ................................. 81

APÊNDICE C - MATRIZ PROPAGADORA ח ${ }_{\mathrm{AN}}$ EM FUNÇÃO DOS PARÂMETROS CINEMÁTICOS DAS AUTOÓNDAS PIN E N. 


\section{RESUMO}

A simulação de uma seção sísmica de afastamento-nulo (AN) a partir de dados de cobertura múltipla pode ser realizada através do empilhamento sísmico, o qual é um método de imageamento de reflexão sísmica muito utilizado na industria. $\mathrm{O}$ processo de empilhamento sísmico permite reduzir a quantidade de dados e melhorar a razão sinal / ruído.

Baseado na aproximação hiperbólica dos tempos de trânsito dependente de três parâmetros ou atributos cinemáticos de frentes de onda. Recentemente, vem desenvolvendo-se um novo método para simular seções (AN) chamado método de empilhamento sísmico por Superfície de Reflexão Comum (ou empilhamento SRC). Este novo formalismo pode ser estendido para construir seções de afastamento-nulo (AN) a partir de dados de cobertura múltipla, usando aproximações dos tempos de trânsito paraxiais na vizinhança de um raio central com afastamento-nulo (AN), para o caso de uma linha de medição com topografia suave e rugosa. Essas duas aproximações de tempos de trânsito também dependem de três atributos cinemáticos de frentes de ondas.

Nesta dissertação, apresenta-se uma revisão teórica da teoria paraxial do raio para a obtenção das aproximações dos tempos de trânsito paraxiais considerando uma linha de medição com topografia rugosa e suave.

A partir das aproximações dos tempos de trânsito paraxiais em relação a um raio central com afastamento-nulo (AN), foram obtidas duas novas aproximações de tempos de trânsito usando a condição de um ponto difrator em profundidade, reduzindo as equações originais para dois parâmetros.Também foram obtidas as aproximações para o caso de raios paraxiais com afastamento-nulo (AN).

Para as aproximações de reflexão e difração utilizando um mesmo modelo sintético, foram comparadas através da representação gráfica as superfícies de empilhamento das aproximações dos tempos de trânsito para a topografia suave e rugosa.

Em seguida, para analisar o comportamento dos operadores associados a reflexão e a difração, quando estes são perturbados, discutimos suas sensibilidades em relação a cada um dos três parâmetros ( $\left.\beta_{0}, K_{P I N}, K_{N}\right)$. Esta análise de sensibilidade foi realizada em duas formas: Sensibilidade através da perturbação de cada parâmetro visualizado nas superfícies de 
empilhamento SRC-TR e SDC-TR e da primeira derivada dos tempos de trânsito SRC-TR e SDC-TR.

Finalmente, usando essas aproximações hiperbólicas em função de três e dois parâmetros e com base nos resultados da análise de sensibilidade, foi proposto um algoritmo para simular seções AN a partir de dados de cobertura múltipla. 


\begin{abstract}
The simulation of a zero-offset seismic section $(\mathrm{ZO})$ from multicoverage data can be carried through the seismic stacking, which is a very used method of seismic reflection imaging in the oil industry. Seismic stacking process allows to reduce the amount of data and is aimed to improve the signal/noise ratio. Based in the hyperbolic approach of the traveltime, dependent on three parameters or kinematic attributes of wavefronts, recently it was developed a new method to simulate zero-offset sections (ZO), called seismic stack for Common Reflection Surface method (or SRC stack). This new formalism can be extended to construct $\mathrm{ZO}$ sections from multicoverage data, using the approach of the paraxial traveltimes in the neighborhood of a central ray with zero offset, for the case of a line of measurement with soft and rugged topography. These two approaches of traveltime also depend on three kinematic attributes of wavefronts. In this work, a theoretical revision of the paraxial theory of the ray for the attainment of the approaches of the paraxial traveltimes is presented, considering a line of measurement with rugged and soft topography. From the approaches of the paraxial traveltimes with relation to a central ray with zero-offset (ZO), two new approaches had been derived from traveltimes using the condition of a diffraction point in depth, reducing the original equations for two parameters. For the approaches of reflection and diffraction, using the same synthetic model, a graphical representation of their respective stacking surfaces were compared, using the traveltime approaches for the soft and rugged topography. After that, we analyze the behavior of the operators associated with the reflection and the diffraction surfaces when these are disturbed, where we investigate the sensibilities in relation to each one of the three parameters $\left(\beta_{0}, K_{N I P}\right.$, $\mathrm{K}_{\mathrm{M}}$ ). This sensibility analysis was perfomed in two ways: Sensibility through the disturbance of each parameter visualized in the stacking surfaces SRC-TR and SDC-TR, and the first derivative of the traveltimes SRC-TR and SDC-TR. Finally, using these hyperbolic approaches as a function of three and two parameters, and based on the results of the sensibility analysis, were considered an algorithm to simulate $\mathrm{ZO}$ sections from data of multi coverage.
\end{abstract}




\section{1- INTRODUÇÃO}

Os métodos de imageamento de reflexões sísmicas têm sua aplicação concentrada na exploração de petróleo, pois os mesmos têm o objetivo de produzir uma melhor imagem das regiões de interesse em subsuperfície, mapeando as estruturas geológicas através do processamento e interpretação dados sísmicos, com uma essencial contribuição para a industria no que diz respeito à procura de jazidas de petróleo.

Dentre os métodos de imageamento sísmico utilizado na industria de petróleo para produzir uma imagem da subsuperfície, destacam-se o empilhamento sísmico no domínio do tempo, a migração pré e pós-empilhada no domínio do tempo e em profundidade. Nesta dissertação, será tratado o processo de empilhamento sísmico $2 \mathrm{D}$, o qual permite simular seções sísmicas com afastamento-nulo (AN) entre a fonte e o receptor, baseadas em empilhar (somar) através das trajetórias de empilhamento os eventos sísmicos, tais como, reflexões, difrações, múltiplas entre outros, que estão contidos nos dados de cobertura múltipla. O processo de empilhamento para simular seções AN, permiti a redução na quantidade dos dados e a melhoria na razão sinal-ruído, proporcionando assim uma melhor imagem dos refletores. No imageamento sísmico, a simulação de uma seção com afastamento-nulo (AN) é realizada freqüentemente por meio do método de empilhamento sísmico denominado ponto-médio-comum (PMC), cuja seqüência de processamento compreende: análise de velocidade, correção normal moveout (NMO), correção dip moveout (DMO) e da soma dos traços. Este método empilha os dados ao longo das famílias PMC, isto é, famílias de par fonte-receptor simétricos localizados em relação ao PMC considerando o tempo de trânsito NMO, cuja forma hiperbólica depende de um parâmetro denominado velocidade NMO ou de empilhamento. É valido salientar que este método não produz resultados satisfatórios quando aplicados a meios com fortes variações laterais de velocidades, pois o mesmo foi desenvolvido baseado em suposições simplificadas do meio.

Nos últimos anos, foram desenvolvidos vários métodos para obter seções simuladas com afastamento-nulo (AN) a partir dos dados de cobertura múltipla correspondentes a meios heterogêneos. Estes métodos utilizam como informação à priori o conhecimento da velocidade próximo à superfície, produzindo resultados satisfatórios. Dentro desses métodos, destacam-se o método de empilhamento Multifoco (Gelchinsky et al., 1999a, b) e o Empilhamento por Superfície de Reflexão Comum (SRC) (Müller,1999; Jäger et al., 2001; Garabito, 2001). Devido 
ao fato destes métodos precisarem apenas do conhecimento da velocidade próxima à superfície, os mesmos são referidos na literatura como métodos independentes do modelo de macrovelocidades (Hubral, 1999). Como resultados adicionais, esses métodos fornecem atributos de frentes de ondas hipotéticas que podem ser usados para a determinação do modelo de velocidades (Biloti, 2001; Duveneck, 2004), análises de amplitude versos afastamento (AVO) bem como amplitude versos ângulo (AVA) (Biloti et al., 2001), cálculos das Zonas de Fresnel projetadas, calculo do fator de espalhamento geométrico, migração no tempo baseado nos atributos (Mann et al., 2000), entre outra aplicações.

Para a simulação de seções AN através do método de Empilhamento por Superfícies de Reflexão Comum (SRC), a fórmula de aproximação hiperbólica dos tempos de trânsito é usada para calcular as superfícies ou curvas de empilhamento, sendo que para meios 2D o operador ou superfície de empilhamento SRC depende de três atributos cinemáticos de frentes de onda ou parâmetros que são: o ângulo de emergência do raio central com afastamento fonte-receptor nulo $\left(\beta_{0}\right)$, a curvatura da onda ponto de incidência normal $\mathrm{K}_{\mathrm{PIN}}$ e a curvatura da onda normal $\mathrm{K}_{\mathrm{N}}$, definidas em Hubral (1983). Estes três parâmetros, que estão associados a cada ponto de amostragem da seção AN, são determinados, a partir dos dados sísmicos de cobertura múltipla, por meio de processos de otimização e análise de coerência utilizando estratégias que envolvem processos de busca de um, dois ou três parâmetros. Este novo método de empilhamento pode ser estendido para construir seções de afastamento-nulo (AN) a partir de dados de cobertura múltipla, usando aproximações dos tempos de trânsito paraxiais na vizinhança de um raio central com afastamento-nulo (AN), considerado uma linha de medição com topografia suave e rugosa, seguindo as linhas de Chira e Hubral (2003) e Zhang et al. (2002). Estas novas aproximações hiperbólicas (topografia suave e rugosa) também dependem dos três atributos de frentes de ondas $\left(\beta_{0}, \mathrm{~K}_{\mathrm{PIN}}, \mathrm{K}_{\mathrm{N}}\right)$.Neste sentido, com base nessas duas aproximações, já foram propostos algoritmos de empilhamento SRC para simular seções AN a partir de dados adquiridos em uma linha de medição com topografia suave visto em Chira (2003) e também a partir de dados adquiridos em uma linha de medição com topografia rugosa (Zhang et al., 2002). Recentemente, dentro desta categoria, métodos de empilhamento que consideram topografia (Gurevich et al., 2002) apresentaram uma extensão do tempo de trânsito Multifoco, para ser aplicado em dados adquiridos em uma linha de medição com topografia irregular. 
Neste trabalho, será apresentada uma revisão detalhada das fórmulas de empilhamento SRC para os casos de uma topografia rugosa e suave no que diz respeito a seus fundamentos teóricos. Também são apresentadas particularizações das mesmas para os casos de um ponto difrator em profundidade e da configuração afastamento-nulo (AN). Por outro lado, serão realizadas as comparações gráficas dos operadores SRC com topografia suave e rugosa, para eventos de reflexão e difração, utilizando um modelo sintético $2 \mathrm{D}$. Um primeiro trabalho comparativo dos operadores de empilhamento com topografia foi apresentado em (Garabito et al., 2003). Sendo assim, o objetivo principal desta dissertação é apresentar um novo algoritmo de empilhamento SRC com topografia rugosa, baseado em estudos de sensibilidade dos parâmetros SRC. Apresentam-se então, os resultados da análise de sensibilidade dos atributos da aproximação hiperbólica para topografia rugosa.

Portanto, para analisar as sensibilidades dos operadores Superfície de Reflexão Comum (SRC-TR) e Superfície de Difração Comum (SDC-TR) com topografia rugosa, quando estes são perturbados, será discutido seus comportamentos em relação a cada um dos três parâmetros $\left(\beta_{0}, \mathrm{~K}_{\mathrm{PIN}}, \mathrm{K}_{\mathrm{N}}\right)$. Esta análise de sensibilidade é realizada em duas formas: Sensibilidade através da perturbação de cada parâmetro visualizado nas superfícies de empilhamento SRC-TR e SDC-TR e da primeira derivada dos tempos de trânsito SRC-TR e SDC-TR. Neste sentido, como conseqüência da análise de sensibilidade será proposto um algoritmo de empilhamento SRC para topografia rugosa utilizando os tempos de trânsito SRC-TR e SDC-TR, objetivando a simulação de seções $\mathrm{AN}$, a partir de dados de cobertura múltipla adquiridos sobre uma linha sísmica com topografia rugosa.

\section{ESTRUTURA DA TESE:}

Além deste capítulo introdutório, o corpo desta tese é composto pelos seguintes capítulos:

Capítulo 2: Neste capítulo, são apresentadas as idéias básicas e fórmulas estabelecidas pela teoria do raio, num contexto resumido.

Capítulo 3: No presente capítulo, são apresentadas as aproximações dos tempos de trânsito parabólico e hiperbólico de raios paraxiais em um sistema cartesiano local de coordenadas, dando ênfase à fórmula de aproximação hiperbólica dos tempos de trânsito refletidos, associados a um 
raio central (normal) em função de três parâmetros cinemáticos para o caso de uma linha de medição com topografia rugosa.

Capítulo 4: É apresentada uma revisão da teoria geométrica do raio, para desenvolver as equações dos tempos de trânsito parabólico e hiperbólico para raios paraxiais na vizinhança de um raio central refletido com afastamento fonte-receptor finito, sendo particularizado o tempo de trânsito hiperbólico para o caso do raio central com afastamento-nulo (AN), considerando-se uma linha de medição com topografia suave.

Capítulo 5: São mostrados graficamente os dois operadores de empilhamento tratados nos dois capítulos anteriores, onde o operador SRC-TS do capítulo 4 é mostrado com um formalismo ligeiramente modificado recorrente ao um sistema de coordenada global com origem arbitrária, além de realizar um estudo comparativo desses operadores. Por outro lado, é realizada uma particularização desses operadores para o caso de eventos de difração, como também, de uma configuração afastamento-nulo (AN), sendo apresentadas graficamente.

Capítulo 6: É feita uma análise de sensibilidade através da perturbação de cada parâmetro visualizado na superfície de empilhamento e da primeira derivada dos tempos de trânsito SRCTR e SDC-TR. Finalmente, com base nesta análise de sensibilidade foi proposto um algoritmo de empilhamento Superfície de Reflexão comum com topografia rugosa (SRC-TR) para a simulação de seções AN a partir dos dados de cobertura múltipla.

Capítulo 7: Conclusões e as perspectivas referentes ao algoritmo de empilhamento SRC-TR proposto nesta dissertação.

Apêndice A: Derivação do tempo de trânsito parabólico.

Apêndice B: Parâmetros cinemáticos das auto-ondas PIN e N.

Apêndice C: Matriz propagadora $\Pi_{\mathrm{AN}}$ em função dos parâmetros cinemáticos das auto-ondas PIN e N. 


\section{2- TEORIA DO RAIO: UMA BREVE REVISÃO}

A Teoria dos Raios consiste na aproximação da solução da equação da onda elástica utilizando uma série assintótica, sendo efetivamente aplicada em meios suaves, onde o comprimento de onda envolvido seja muito menor quando comparados com as dimensões características do meio, das quais se deseja obter informações. Em contra partida, se o meio for estratificado, esta condição se reduz na hipótese de que os raios de curvatura das interfaces do modelo sejam relativamente maiores que os comprimentos de onda. Assim, de um modo geral, nosso interesse está evidenciado aos aspectos cinemáticos de um referido problema, com ênfase nas equações que descrevem as frentes de ondas e as trajetórias dos raios.

\section{1- EQUAÇÃO DA ELASTODINÂMICA}

A equação da elastodinâmica descreve o movimento e a mecânica do movimento de uma partícula num meio, onde as propriedades e os parâmetros físicos são tratados como funções contínuas e suficientemente suaves. Assim, seja uma partícula dentro de um corpo sólido com um volume W e uma superfície limite $\psi$, nestas condições podemos escrever a segunda lei de Newton da mecânica na forma:

$$
\iiint_{W} \rho \frac{\partial^{2} \overrightarrow{\mathrm{u}}}{\partial \mathrm{t}^{2}} \mathrm{dW}=\iiint_{W} \overrightarrow{\mathrm{f}} \mathrm{dW}+\iiint_{\psi} \overrightarrow{\mathrm{T}}(\overrightarrow{\mathrm{n}}) \mathrm{d} \psi
$$

onde, $\overrightarrow{\mathrm{u}}(\overrightarrow{\mathrm{x}}, \mathrm{t})$ é o vetor deslocamento, $\mathrm{t}$ é o tempo, $\rho(\overrightarrow{\mathrm{x}})$ é a densidade do corpo sólido, $\overrightarrow{\mathrm{f}}$ é a densidade das forças externas, e $\overrightarrow{\mathrm{T}}(\overrightarrow{\mathrm{n}})$ é a tração que age no volume W da partícula pela superfície limite $\psi$, sendo $\vec{n}$ normal a superfície limite. Na forma diferencial a equação (2.1) é dada por (ver, por exemplo, Aki \& Richards (1980), capítulo 2):

$$
\rho \frac{\partial^{2} u_{j}}{\partial t^{2}}=f_{j}+\frac{\partial \sigma_{i j}}{\partial x_{i}} ; i, j=1,2,3,
$$


onde, o tensor $\sigma$, denominado de tensão, é um tensor simétrico de segunda ordem, que descreve a condição de tensão em qualquer ponto $\overrightarrow{\mathrm{x}}=\left(\mathrm{x}_{1}, \mathrm{x}_{2}, \mathrm{x}_{3}\right)$ em subsuperfície sob a condição de deslocamento infinitesimal.

O conjunto das três equações (2.2) é denominado de equação do movimento para um meio contínuo. Para resolver esta equação matemática que descreve a propagação das ondas, é necessário que a mesma seja especificada em termos do deslocamento $u_{j}$, fazendo para tal relações entre a tensão e a deformação. A tensão e a deformação são mutuamente dependentes, neste sentido, supondo deformações lineares pequenas e um sólido anisotrópico perfeitamente elástico, a lei de Hooke generalizada é determinada por:

$$
\sigma_{\mathrm{ij}}=\mathrm{c}_{\mathrm{ijkl}} \mathrm{e}_{\mathrm{kl}} \text {, }
$$

que relaciona o tensor tensão $\sigma_{\mathrm{ij}}$ linearmente com o tensor deformação $\mathrm{e}_{\mathrm{kl}}$ através do tensor de parâmetros elásticos de quarta ordem $\mathrm{c}_{\mathrm{ijk}}$, que especifica as propriedades elásticas do meio. Os tensores tensão e deformação são simétricos, isto é:

$$
\sigma_{\mathrm{ij}}=\sigma_{\mathrm{ji}} ; \mathrm{e}_{\mathrm{ij}}=\mathrm{e}_{\mathrm{ji}},
$$

tendo como conseqüência imediata as seguintes simetrias:

$$
\mathrm{c}_{\mathrm{ijkl}}=\mathrm{c}_{\mathrm{jikl}}=\mathrm{c}_{\mathrm{ijlk}}=\mathrm{c}_{\mathrm{klij}} .
$$

Assim, o número de componentes independentes do tensor de parâmetros elásticos $\mathrm{c}_{\mathrm{ijkl}}$ reduz-se de 81 para 21, podendo assim representar os nove elementos do tensor deformação por:

$$
\mathrm{e}_{\mathrm{kl}}=\frac{1}{2}\left(\frac{\partial \mathrm{u}_{\mathrm{k}}}{\partial \mathrm{x}_{1}}+\frac{\partial \mathrm{u}_{1}}{\partial \mathrm{x}_{\mathrm{k}}}\right) .
$$

Note que as componentes de deformação dependem linearmente das derivadas das componentes de deslocamento. Substituindo (2.6) em (2.3), obtemos:

$$
\frac{\partial \sigma_{i j}}{\partial x_{i}}=\frac{1}{2} \frac{\partial}{\partial x_{i}}\left(c_{i j k l} \frac{\partial u_{k}}{\partial x_{1}}+c_{i j k l} \frac{\partial u_{1}}{\partial x_{k}}\right) .
$$

Simplificando a equação (2.7), usando a propriedade de simetria $c_{i j \mathrm{kl}}=\mathrm{c}_{\mathrm{ij \textrm {k } k}}$ e inserindo o resultado na equação (2.2), obstem-se:

$$
\rho \frac{\partial^{2} u_{j}}{\partial t^{2}}-\frac{\partial}{\partial x_{i}}\left(c_{i j k l} \frac{\partial u_{k}}{\partial x_{1}}\right)=f_{j} .
$$


A ultima equação é denominada equação da elastodinâmica para um meio anisotrópico não homogêneo perfeitamente elástico, estando implícito um sistema hiperbólico de três equações diferenciais parciais de segunda ordem, não admitindo solução analítica em sua forma geral.

Felizmente, as propriedades elásticas para muitos materiais são independentes de direção ou orientação, deste modo, considerando um meio isotrópico, o tensor $\mathrm{c}_{\mathrm{ijkl}}$ pode ser expressado por apenas dois parâmetros elásticos e independentes, $\lambda$ e $\mu$, denominados parâmetros de Lamé, isto é:

$$
\mathrm{c}_{\mathrm{ijkl}}=\lambda \delta_{\mathrm{ij}} \delta_{\mathrm{kl}}+\mu\left(\delta_{\mathrm{ik}} \delta_{\mathrm{jl}}+\delta_{\mathrm{il}} \delta_{\mathrm{jk}}\right)
$$

onde, $\delta_{\mathrm{ij}}$ é o delta de Kronecker, i.e., $\delta_{\mathrm{ij}}=\left\{\begin{array}{lll}1 & \text { se } & i=j \\ 0 & \text { se } & i \neq j\end{array}\right.$.

Nestas condições, a equação da onda elástica para um meio isotrópico não homogêneo perfeitamente elástico, não considerando o termo que representa a fonte, ou seja, $\vec{f}=0$ pode ser expressa por:

$$
(\lambda+\mu) \nabla(\nabla \cdot \overrightarrow{\mathrm{u}})+\mu \nabla^{2} \overrightarrow{\mathrm{u}}+\nabla \lambda(\nabla \cdot \overrightarrow{\mathrm{u}})+\nabla \mu \times(\nabla \times \overrightarrow{\mathrm{u}})+2(\nabla \overrightarrow{\mathrm{u}} \cdot \nabla) \overrightarrow{\mathrm{u}}=\rho \frac{\partial^{2} \overrightarrow{\mathrm{u}}}{\partial \mathrm{t}^{2}}
$$

sendo, $\nabla, \nabla$. e $\nabla \times$ os operadores matemáticos do gradiente, do divergente e do rotacional, respectivamente.

\section{2- EQUAÇÃO DA ONDA ACÚSTICA}

Um fluido é caracterizado por $\mu=0$, sendo uma aproximação para um meio sólido (caso acústico), muito utilizado na prospecção sísmica . Neste caso, a equação (2.10) reduz-se em:

$$
\nabla(\lambda \nabla \cdot \vec{u})=\rho \frac{\partial^{2} \vec{u}}{\partial t^{2}}
$$

No entanto, faz-se necessário a substituição do vetor deslocamento $\vec{u}(x, t)$, pela pressão definida por:

$$
\mathrm{p}(\overrightarrow{\mathrm{x}}, \mathrm{t})=-\lambda \nabla \cdot \overrightarrow{\mathrm{u}}(\overrightarrow{\mathrm{x}}, \mathrm{t})
$$

Agora, substituindo (2.12) em (2.11) obtemos: 


$$
\nabla\left(\frac{1}{\rho} \nabla p\right)=\frac{1}{\lambda} \frac{\partial^{2} p}{\partial t^{2}}
$$

denominada como equação da onda acústica. Para um meio com densidade constante $\rho$, a equação (2.13) transforma-se em:

$$
\Delta \mathrm{p}=\frac{1}{\mathrm{v}^{2}} \frac{\partial^{2} \mathrm{p}}{\partial \mathrm{t}^{2}}
$$

onde, $\Delta$ é o operador matemático denominado Laplaciano, e $v=\sqrt{\frac{\lambda}{\rho}}$, definindo a velocidade de propagação da onda acústica.

\section{3- EQUAÇÕES EIKONAL E DE TRANSPORTE}

Considerando uma região do espaço onde os efeitos ondulatórios podem ser observados (campo de onda) com um tempo harmônico, temos:

$$
\mathrm{p}(\mathrm{x}, \mathrm{t})=\mathrm{e}^{-\mathrm{i} \omega \tau} \mathrm{U}(\mathrm{x}),
$$

onde, $\omega$ é uma freqüência angular. Dessa forma, inserindo esta equação na equação (2.14), obtemos a equação da onda reduzida, denominada de equação de Helmholtz para o domínio da freqüência, ou seja:

$$
\left(\Delta+\frac{\omega^{2}}{\mathrm{v}^{2}}\right) \mathrm{U}=0 .
$$

Para determinação das equações eikonal e de transporte, devemos assumir uma densidade constante $\rho$ e uma velocidade variável $\mathrm{v}=\mathrm{v}(\mathrm{x})$, buscando assim uma solução na forma:

$$
\mathrm{U}=\mathrm{e}^{\mathrm{i} \omega \tau} \mathrm{A}(\mathrm{x}),
$$

onde, $\tau=\tau(\mathrm{x})$ é denominado de eikonal e $\mathrm{A}(\mathrm{x})$ amplitude. Supondo que a freqüência angular seja alta e inserindo a equação (2.17) na equação reduzida da onda (2.16), obtém-se:

$$
\mathrm{e}^{\mathrm{i} \omega \tau}\left\{\omega^{2}\left(\frac{1}{\mathrm{v}^{2}}-(\nabla \tau)^{2}\right) \mathrm{A}+\mathrm{i} \omega(2 \nabla \tau . \nabla \mathrm{A}+\Delta \tau \mathrm{A})+\Delta \mathrm{A}\right\}=0
$$

em que, $\nabla$ e $\Delta$, são os operadores matemáticos do gradiente e do Laplaciano.

Posteriormente, igualando a zero os coeficientes do polinômio do segundo grau em $\omega$ da equação acima, obtemos:

$$
\omega^{0}: \Delta \mathrm{A}=0
$$




$$
\begin{gathered}
\omega^{1}: 2 \nabla \tau . \nabla \mathrm{A}+\Delta \tau \mathrm{A}=0, \\
\omega^{2}:(\nabla \tau)^{2}=\frac{1}{\mathrm{v}^{2}} .
\end{gathered}
$$

Assumindo-se que a equação (2.19) é satisfeita, temos que as equações (2.20) e (2.21) denominam-se respectivamente equação de transporte e equação eikonal, onde a eikonal resolve a parte cinemática do problema enquanto que a equação de transporte soluciona a parte dinâmica, desse modo, o procedimento natural para achar à solução, tem como primeira etapa determinar a solução da equação (2.21) e em seguida inseri-la na equação (2.20) determinando assim uma solução para amplitude.

É valido salientar que a equação (2.16) não satisfaz de forma exata os restos da equação (2.18). Sendo $\Delta \mathrm{A}$ pequeno, a equação da onda é aproximada localmente pelas equações eikonal e de transporte, porém pode acontecer que o termo $\Delta \mathrm{A}$ aumente ao longo do raio. Neste sentido, para diminuir uma provável discrepância uma série infinita para U é introduzida, denominada série do raio, isto é:

$$
\mathrm{U}=\mathrm{e}^{\mathrm{i} \omega \tau} \sum_{\mathrm{n}=0}^{\infty} \frac{\mathrm{A}(\overrightarrow{\mathrm{x}})}{(-\mathrm{i} \omega)^{\mathrm{n}}}
$$

Agora, substituindo a equação (2.22) na equação (2.16), obstem-se novamente a equação eikonal (2.18) e um conjunto periódico de equações de transporte, ou seja:

$$
2 \nabla \tau \cdot \nabla \mathrm{A}_{\mathrm{n}+1}+\Delta \tau \mathrm{A}_{\mathrm{n}+1}=\Delta \mathrm{A}_{\mathrm{n}}, \mathrm{n}=-1,0,1 \ldots, \mathrm{A}_{-1}=0 .
$$

O termo de amplitude de ordem-zero é caracterizado para $n=-1$ na equação (2.23), obtendo-se (2.20). A maioria dos trabalhos científicos vinculam-se a teoria do raio de ordem zero, pois é muito difícil controlar condições de ordem mais altas. Sem contar, que as equações (2.20) e (2.21) nesse formalismo permanecem simples até mesmo se a equação da onda acústica possuir uma densidade variável $\rho$.

\section{4- SOLUÇÃO DA EQUAÇÃO EIKONAL}

A equação eikonal representa uma equação diferencial parcial não-linear de primeira ordem para o tempo de trânsito $\tau(\mathrm{x})$, denominado o eikonal da equação (2.17). A equação eikonal tendo como curvas características os raios e a frente de onda num instante $t$ definida pela relaçãot $=\tau(\mathrm{x})$, pode ser resolvida através do método das características (Bronstein \& Semendjajew, 1991), o qual tem como objetivo principal converter uma equação diferencial 
parcial em um sistema de equações ordinárias (sistema de traçamento de raios), que descrevem a trajetória do raio, sendo que esta conversão é determinada através de quantidades auxiliares que não pertencem às quantidades originais do problema. O sistema de traçamento de raios em coordenadas cartesianas é formado pelas equações (Červený, 2001):

$$
\begin{gathered}
\frac{\mathrm{dx}_{\mathrm{i}}}{\mathrm{d} \tau}=\mathrm{v}^{2} \mathrm{p}_{\mathrm{i}} ; \mathrm{i}=1,2,3, \\
\frac{\mathrm{dp}_{\mathrm{i}}}{\mathrm{d} \tau}=-\frac{1}{\mathrm{v}} \frac{\mathrm{dv}}{\mathrm{dx}} ; \mathrm{i}=1,2,3,
\end{gathered}
$$

onde, $\mathrm{p}_{\mathrm{i}}$ são as componentes do vetor vagarosidade $\mathrm{p}=\nabla \tau$, em coordenadas cartesianas, e $\mathrm{v}$ a velocidade da onda.

\section{5- SOLUÇÃO DA EQUAÇÃO DE TRANSPORTE}

A equação de transporte representa uma equação diferencial linear de primeira ordem para a propriedade dinâmica da onda $\mathrm{A}(\mathrm{x})$ (amplitude), cuja solução permite avaliar o deslocamento da partícula. Esta equação pode ser rescrita como uma equação diferencial ordinária ao longo da trajetória do raio, usando as coordenadas do mesmo, expressa por (Červený, 2001):

$$
\frac{2}{\mathrm{v}^{2}} \frac{\mathrm{dA}}{\mathrm{d} \tau}+\frac{\mathrm{A}}{\mathrm{vJ}} \frac{\mathrm{d}}{\mathrm{d} \tau}\left(\frac{\mathrm{J}}{\mathrm{v}}\right)=0
$$

O parâmetro J (Jacobiano do raio) tem como regra operacional, fazer a mudança das coordenadas do raio $\tau, \gamma_{1}, \gamma_{2}$ para as coordenadas cartesianas $\mathrm{x}, \mathrm{y}, \mathrm{z}$, além de ser igual a zero quando a curvatura da frente de onda tende para o infinito, caracterizando assim, os chamados pontos cáusticos ou singulares, os quais acarretam problemas para a propriedade dinâmica da onda, visto que, $\mathrm{A}(\mathrm{x})$ não tem sentido nessas circunstâncias (ver Figura 2.3). Em uma interpretação geométrica, $\mathrm{J}$ representa a densidade do campo do raio, o qual pode ser expressado como um funcional determinante, ou seja:

$$
\mathrm{J}=\frac{1}{\mathrm{v}}\left|\frac{\mathrm{d}(\mathrm{x}, \mathrm{y}, \mathrm{z})}{\mathrm{d}\left(\tau, \gamma_{1}, \gamma_{2}\right)}\right| .
$$

O parâmetro $\tau$ é o eikonal da equação (2.17) e os parâmetros de partida $\gamma_{1}$ e $\gamma_{2}$ descrevem um raio especial, onde, $\tau$ indica uma posição de um ponto neste raio. (ver Figura 2.1). 


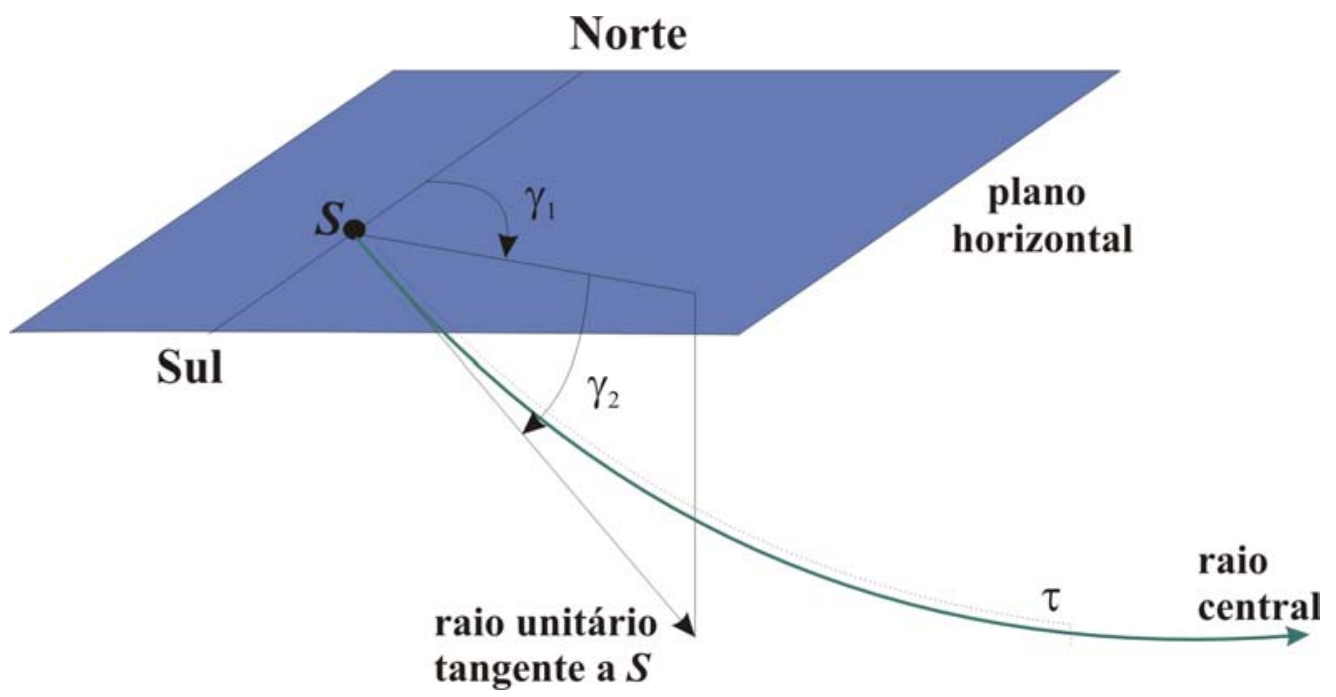

Figura 2.1 - Sistema de coordenadas do raio para um ponto fonte S em 3D. Os ângulos $\gamma_{1}, \gamma_{2}$ determinam as coordenadas do raio e o eikonal $\tau$ especifica a posição de um ponto no mesmo.

A equação (2.26) pode ser resolvida facilmente por separação de varáveis, tendo como implicação a obtenção do termo principal para amplitude, isto é:

$$
A=\frac{\sum\left(\gamma_{1}, \gamma_{2}\right)}{\sqrt{\frac{\mathrm{J}}{\mathrm{v}}}},
$$

onde, $\Sigma$ é a constante de integração dependente apenas dos parâmetros de partida $\gamma_{1}, \gamma_{2}$.

Até agora, a solução da equação de transporte foi reduzida ao cálculo do Jacobiano do raio, com o intuito de procurar os dados iniciais do mesmo, i.e. a constante de integração. Sendo assim, devido ao fato das frentes de ondas serem conhecidas, a avaliação de J pode ser resolvida numericamente (Popov, 1996).

\section{6-TEORIA PARAXIAL DO RAIO E TRAÇAMENTO DINÂMICO DO RAIO}

A amplitude do raio não pode ser calculada sem a avaliação do jacobiano J . A avaliação do mesmo e de algumas outras características geométricas da frente de onda na vizinhança de um raio central conhecido, pode ser feita durante um procedimento denominado traçamento dinâmico do raio. O sistema de traçamento dinâmico do raio pode ser expresso em diversas formas e em vários sistemas de coordenadas, no entanto, a simples forma é obtida em coordenadas centrada no 
raio $\mathrm{q}_{1}, \mathrm{q}_{2}$ e $\mathrm{q}_{3}$. O sistema de coordenadas centradas no raio é um sistema ortogonal curvilinear introduzido de tal forma, que o próprio raio representa o terceiro eixo do sistema, os outros são formados por duas linhas perpendiculares entre si, intersectando o raio num plano perpendicular (ver Figura 2.2). Os vetores unitários do sistema podem ser construídos a partir dos raios unitários tangente, normal e do binormal. Maiores detalhes podem ser encontrados no capítulo 3 desta dissertação ou em Červený (2001).

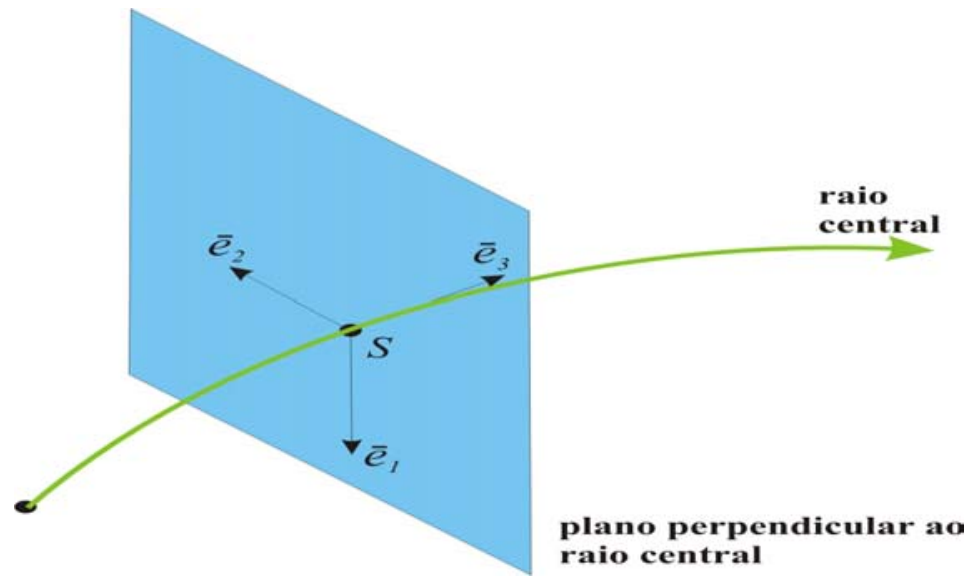

Figura 2.2 - Sistema de coordenadas centradas no raio. O vetor $\overrightarrow{\mathrm{e}}_{3}$ é o raio unitário tangente em $\mathrm{S}$ enquanto que os vetores $\overrightarrow{\mathrm{e}}_{1}, \overrightarrow{\mathrm{e}}_{2}$ formam um sistema cartesiano de coordenadas em um plano perpendicular ao raio, tendo origem no ponto de interseção do referido plano com o raio central. As coordenadas atuais são determinadas por $\mathrm{q}_{1}, \mathrm{q}_{2}$ e $\mathrm{q}_{3}$.

No sistema de coordenadas centradas no raio, a equação eikonal pode ser usada para derivar um simples sistema de equações diferencias ordinárias lineares de primeira ordem para raios situados na vizinhança de um raio central. Estes raios são denominados raios paraxiais, tendo como sistema relevante o sistema de traçamento do raio paraxial, onde o volume coberto por tais raios, denomina-se tubo de raio (ver Figura 2.3). A partir do traçamento do sistema de raios paraxiais, obtém-se imediatamente o sistema de traçamento dinâmico do raio, o qual compõe-se de quatro equações diferencias ordinárias lineares de primeira ordem. Na verdade, os dois sistemas são bastante conectados, possuindo um significado físico diferente nas quantidades calculadas. 


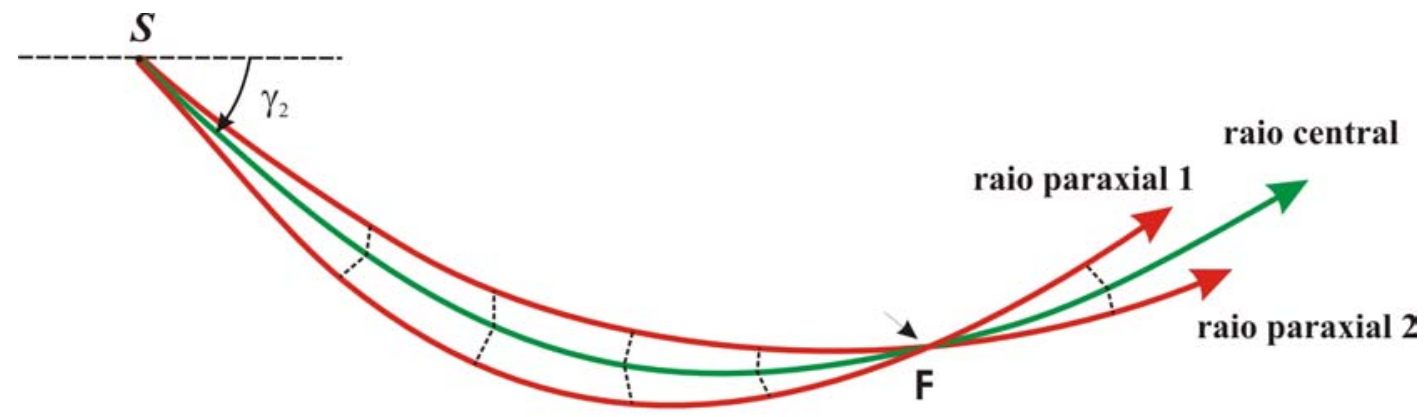

Figura 2.3 - Esboço de um tubo de raios em $2 \mathrm{D} ; \gamma_{2}$ é o ângulo de partida do raio central, tendo em vista que os ângulos de partida dos raios paraxiais diferem de $\gamma_{2}$ por um incremento de ângulo $d \gamma_{2}$. $O$ ponto $\mathrm{F}$ é chamado foco ou ponto cáustico de segunda ordem.

Usando as coordenadas centradas no raio, $\mathrm{q}_{1}, \mathrm{q}_{2}$ e $\mathrm{q}_{3}$, as coordenadas $\tau, \gamma_{1}, \gamma_{2}$ e a relação

$$
\left.J\left|\gamma_{\gamma_{1}=\gamma_{10}, \gamma_{2}=\gamma_{20}}=\right| \frac{\mathrm{d}(\mathrm{x}, \mathrm{y}, \mathrm{z})}{\mathrm{d}\left(\tau, \gamma_{1}, \gamma_{2}\right)}\right|_{\gamma_{1}=\gamma_{10}, \gamma_{2}=\gamma_{20}}=\mathrm{v}_{0}\left|\frac{\mathrm{d}\left(\mathrm{q}_{1}, \mathrm{q}_{2}\right)}{\mathrm{d}\left(\gamma_{1}, \gamma_{2}\right)}\right|_{\gamma_{1}=\gamma_{10}, \gamma_{2}=\gamma_{20}},
$$

onde, o índice 0 denota os parâmetros do raio central, pode-se reescrever a equação (2.28) na seguinte forma:

$$
A=\left.\frac{\sum\left(\gamma_{1}, \gamma_{2}\right)}{\sqrt{\frac{1}{\mathrm{v}}\left|\frac{\mathrm{d}\left(\mathrm{q}_{1}, \mathrm{q}_{2}\right)}{\mathrm{d}\left(\gamma_{1}, \gamma_{2}\right)}\right|}}\right|_{\gamma_{1}=\gamma_{10}, \gamma_{2}=\gamma_{20}}
$$

Desta forma, introduzindo a notação adicional:

$$
\begin{array}{ll}
\mathrm{Q}_{1,1}=\left.\frac{\partial \mathrm{q}_{1}}{\partial \gamma_{1}}\right|_{\gamma_{1}=\gamma_{10}, \gamma_{2}=\gamma_{20}} & \mathrm{Q}_{1,2}=\left.\frac{\partial \mathrm{q}_{1}}{\partial \gamma_{2}}\right|_{\gamma_{1}=\gamma_{10}, \gamma_{2}=\gamma_{20}}, \\
\mathrm{Q}_{2,1}=\left.\frac{\partial \mathrm{q}_{2}}{\partial \gamma_{1}}\right|_{\gamma_{1}=\gamma_{10}, \gamma_{2}=\gamma_{20}} & \mathrm{Q}_{2,2}=\left.\frac{\partial \mathrm{q}_{2}}{\partial \gamma_{2}}\right|_{\gamma_{1}=\gamma_{10}, \gamma_{2}=\gamma_{20}},
\end{array}
$$

e definido:

$$
\mathrm{Q}=\left(\begin{array}{ll}
\mathrm{Q}_{1,1} & \mathrm{Q}_{1,2} \\
\mathrm{Q}_{2,1} & \mathrm{Q}_{2,2}
\end{array}\right)
$$


obtém-se a seguinte expressão:

$$
\mathrm{A}=\frac{\sum_{0}\left(\gamma_{1}, \gamma_{2}\right)}{\sqrt{\frac{1}{\mathrm{v}_{0}}|\operatorname{det} \mathrm{Q}|}} .
$$

Esta é a expressão para amplitude avaliada num raio central de um tubo de raios (Popov, 1996). Note que as condições $\gamma_{1}=\gamma_{10}, \gamma_{2}=\gamma_{20}$, poderiam também ter sido expressas por $\mathrm{q}_{1}=\mathrm{q}_{2}=0$.

Vamos introduzir agora a transformação da matriz $\mathrm{P}$ de coordenadas do raio para componentes centradas no raio do vetor vagarosidade $\mathrm{p}$, ou seja:

$$
\mathbf{P}=\left(\begin{array}{ll}
\mathrm{P}_{1,1} & \mathrm{P}_{1,2} \\
\mathrm{P}_{2,1} & \mathrm{P}_{2,2}
\end{array}\right),
$$

com as componentes:

$$
\begin{array}{ll}
\mathrm{P}_{1,1}=\left.\frac{\partial \mathrm{p}_{1}}{\partial \gamma_{1}}\right|_{\gamma_{1}=\gamma_{10}, \gamma_{2}=\gamma_{20}} & \mathrm{P}_{1,2}=\left.\frac{\partial \mathrm{p}_{1}}{\partial \gamma_{2}}\right|_{\gamma_{1}=\gamma_{10}, \gamma_{2}=\gamma_{20}} . \\
\mathrm{P}_{2,1}=\left.\frac{\partial \mathrm{q}_{2}}{\partial \gamma_{1}}\right|_{\gamma_{1}=\gamma_{10}, \gamma_{2}=\gamma_{20}} & \mathrm{P}_{2,2}=\left.\frac{\partial \mathrm{q}_{2}}{\partial \gamma_{2}}\right|_{\gamma_{1}=\gamma_{10}, \gamma_{2}=\gamma_{20}}
\end{array}
$$

Usando a matriz $\mathrm{V}$, que contém as segundas derivadas da velocidade $\mathrm{v}$ em relação a $\mathrm{q}$ ao longo do raio central, obtemos:

$$
\mathrm{V}_{\mathrm{ik}}=\left.\frac{\partial^{2} \mathrm{v}}{\partial \mathrm{q}_{\mathrm{i}} \partial \mathrm{q}_{\mathrm{k}}}\right|_{\mathrm{q}_{1}=\mathrm{q}_{2}=0} \mathrm{i}, \mathrm{k}=1,2,
$$

podendo assim, escrever o sistema de traçamento dinâmico do raio na seguinte forma:

$$
\frac{\mathrm{dQ}}{\mathrm{ds}}=\mathrm{v}_{0} \mathrm{P} ; \frac{\mathrm{dP}}{\mathrm{ds}}=-\frac{1}{\mathrm{v}_{0}^{2}} \mathrm{VQ},
$$

onde, s é o comprimento do arco ao longo do raio central (Červený, 2001). O caso bidimensional será estudado no capítulo 3. Observe que podemos usar qualquer outra variável monotônica ao longo do raio central, tendo como exemplo o tempo de trânsito substituindo o comprimento do arco.

A matriz propagadora centrada no raio $4 \times 4 \prod$ de um raio conectado a um ponto inicial $\mathrm{S}$ (ponto fonte) e a um ponto final $\mathrm{G}$ (ponto receptor) pode ser expressa por: 


$$
\Pi(\mathrm{S}, \mathrm{G})=\left(\begin{array}{ll}
\mathrm{Q}_{1} & \mathrm{Q}_{2} \\
\mathrm{P}_{1} & \mathrm{P}_{2}
\end{array}\right) .
$$

As matrizes $2 \times 2 \mathrm{Q}_{1}, \mathrm{Q}_{2}, \mathrm{P}_{1}, \mathrm{P}_{2}$ podem ser obtidas pela solução do sistema de traçamento dinâmico do raio (2.37) para as condições iniciais $\mathrm{Q}(\mathrm{S})=\mathrm{I}, \mathrm{P}(\mathrm{S})=0$ (solução da onda plana) $\mathrm{Q}(\mathrm{S})=0, \mathrm{P}(\mathrm{S})=\mathrm{I}$ (solução do ponto fonte),respectivamente, sendo que no caso $2 \mathrm{D}$ a matriz $\Pi$ assume a forma $2 \times 2$, onde, $\mathrm{Q}_{1}, \mathrm{Q}_{2}, \mathrm{P}_{1}, \mathrm{P}_{2}$ são escalares como será visto no capítulo 3 . A matriz I é a matriz identidade, e a matriz 0 é a matriz nula (Červený, 2001). A matriz fundamental П é denominada matriz propagadora do sistema de traçamento dinâmico do raio ou simplesmente matriz propagadora do raio. A teoria do raio paraxial nos fornece a informação de que os parâmetros dinâmicos de um ponto de um raio paraxial são linearmente dependentes (LD) daqueles a um certo ponto $S$ do raio central. A matrix $\Pi$ transforma-se na matriz identidade no ponto $\mathrm{S}$ do raio central. Uma vez que a matriz propagadora do raio a partir de $\mathrm{S}$ tenha sido encontrada ao longo do raio, a solução do sistema de traçamento dinâmico do raio para qualquer condição inicial em S é obtida pela simples multiplicação da matriz propagadora pela matriz das condições iniciais (Červený, 2001). Além disso, é possível obter o fator de espalhamento geométrico e outros parâmetros dinâmicos a partir da matriz propagadora do raio.

Agora, estamos aptos para obter o fator de espalhamento geométrico $£$, o qual descreve a divergência geométrica de uma onda emitida a partir de um ponto fonte $\mathrm{S}$ pela expressão:

$$
£=\sqrt{\mathrm{J}}=\sqrt{\operatorname{det} \mathrm{Q}_{2}} .
$$

O fator de espalhamento geométrico normalizado é dado por:

$$
|£|=\frac{1}{\sqrt{\mathrm{v}_{\mathrm{S}} \mathrm{v}_{\mathrm{G}}}} \sqrt{\left|\operatorname{det} \mathrm{Q}_{2}\right|},
$$

onde, $\mathrm{v}_{\mathrm{S}} \mathrm{e} \mathrm{v}_{\mathrm{G}}$ são as velocidades de propagação da onda no ponto fonte $\mathrm{S}$ e no ponto receptor $G$,respectivamente. (Popov, 1996).

Contudo, uma outra matriz propagadora $\mathrm{T}$ de superfície para superfície é utilizada, sendo que, a mesma foi introduzida por Bortfeld (1989), tendo como submatriz mais importante, a matriz superior direita $2 \times 2 \mathrm{~B}$, que corresponde a matriz $\mathrm{Q}_{2}$ da matriz propagadora $\Pi$ centrada no raio. A matriz B descreve o fator de espalhamento geométrico de uma onda emitida de um ponto fonte $\mathrm{S}$. A relação completa entre a matriz propagadora $\mathrm{T}$ e a matriz propagadora $\Pi$ pode 
ser encontrada no capítulo 4 desta dissertação e com maiores detalhes em Červený (2001). Dessa forma, usando a nova notação, o fator de espalhamento geométrico normalizado pode ser reescrito na seguinte forma (Schleicher, 1993):

$$
|£|=\frac{\sqrt{\cos \alpha_{\mathrm{S}} \cos \alpha_{\mathrm{G}}}}{\sqrt{\mathrm{v}_{\mathrm{S}} \mathrm{v}_{\mathrm{G}}}} \sqrt{|\operatorname{det} \mathrm{B}|},
$$

onde, $\alpha_{\mathrm{S}}$ é o ângulo inicial do raio central em $\mathrm{S}$ e $\alpha_{\mathrm{G}}$ é o ângulo de emergência do raio central em $\mathrm{G}$. Os parâmetros $\mathrm{v}_{\mathrm{S}}$ e $\mathrm{v}_{\mathrm{G}}$ são novamente as velocidades de propagação da onda no ponto fonte $\mathrm{S}$ e no ponto receptor $\mathrm{G}$, respectivamente. Para estimar a fase correta, podemos reescrever a raiz quadrada do jacobiano J como (Červený, 2001):

$$
\sqrt{\mathrm{J}}=\sqrt{|\mathrm{J}|} \cdot \mathrm{e}^{-\mathrm{i} \frac{\pi}{2} \mathrm{k}}
$$

onde, $\mathrm{k}$ é o conhecido KMAH, índice que calcula o número de cáusticas ao longo do raio. 


\section{3- TEMPOS DE TRÂNSITO DE RAIOS PARAXIAIS PARA UMA LINHA DE MEDIÇÃO COM TOPOGRAFIA RUGOSA}

Neste capítulo, são apresentados diferentes sistemas de coordenadas utilizadas no estudo da propagação do campo de ondas tanto ao longo de um raio, previamente definido, bem como em sua vizinhança. Estes sistemas de coordenadas são aqui tratados no caso mais geral tridimensional, entretanto como é especial interesse desta dissertação o problema da propagação em um modelo bidimensional, o segundo eixo de coordenada será sempre tomado perpendicular ao plano do modelo, o qual coincide com o plano definido pelos outros dois eixos, além de apresentar às aproximações dos tempos de trânsito parabólico e hiperbólico de raios paraxiais em um sistema cartesiano local de coordenadas, dando ênfase à fórmula de aproximação hiperbólica dos tempos de trânsito refletidos associados a um raio central (normal) para uma linha de medição com topografia rugosa. Esta aproximação é usada para o empilhamento de eventos no método SRC.

\section{1- SISTEMA DE COORDENADAS DO RAIO}

O sistema de raios no espaço tridimensional é definido através de um sistema arbitrário de coordenadas representado por $\left(\eta_{1}, \eta_{2}, \eta_{3}\right)$, que em geral, forma um sistema não-ortogonal de coordenadas. Cada raio neste sistema é especificado através das coordenadas $\left(\eta_{1}, \eta_{2}\right)$, assim denominados parâmetros do raio. A terceira coordenada $\eta_{3}$ pode ser qualquer parâmetro variável ao longo do raio definido pelos outros dois parâmetros. Desde modo, tem-se que a equação paramétrica do sistema de raios é dada, em geral, pela expressão:

$$
r=r\left(\eta_{1}, \eta_{2}, \eta_{3}\right)
$$

O parâmetro representado por $\eta_{3}$, freqüentemente, corresponde ao comprimento de arco $s$ do raio selecionado. Contudo, este parâmetro pode ser representado por outras quantidades ao longo do raio, como por exemplo o tempo de trânsito $\tau$. Neste último caso a equação paramétrica do raio é dada como:

$$
r=r\left(\eta_{1}, \eta_{2}, \tau\right)
$$


caso o valor de $\tau$ seja constante, esta equação corresponde a superfície da frente de onda, caso $\left(\eta_{1}, \eta_{2}\right)$ seja fixado e $\tau$ variável tem-se a equação paramétrica do raio.

No caso do modelo bidimensional, o raio pode ser então representado da seguinte forma,

$$
\eta_{1}=\gamma ; \eta_{2}=0 ; \eta_{3}=\tau,
$$

onde $\gamma$ e $\tau$ correspondem ao ângulo de partida do raio, medido em relação a uma superfície inicial, e ao tempo de transito ao longo do raio, respectivamente. Isto significa em particular, que o raio possui componente nula ao longo da segunda coordenada.

\section{2- SISTEMA DE COORDNADAS CENTRADO NO RAIO}

O sistema de coordenadas centrado no raio é definido como segue: " Para qualquer raio $\Omega$, pode ser introduzido o sistema de coordenadas centrado no raio $\left(\mathrm{q}_{1}, \mathrm{q}_{2}, \mathrm{q}_{3}\right)$ conectado com o mesmo do seguinte modo, a coordenada $\mathrm{q}_{3}=\mathrm{s}$ corresponde ao comprimento de arco ao longo do raio, medido a partir de um ponto de referência conhecido a priori. As coordenadas $\left(\mathrm{q}_{1}, \mathrm{q}_{2}\right)$ formam um sistema de coordenadas Cartesianas bidimensional no plano perpendicular a $\Omega$ no ponto determinado por $\mathrm{q}_{3}=\mathrm{s}$, com a origem situada neste ponto", (Červený, 2001).

Como observado por Hubral (1979), a introdução deste sistema de coordenadas constitui um passo fundamental para o desenvolvimento da teoria destinada ao estudo da propagação do campo de ondas segundo a trajetória de raios e frentes de ondas.

O sistema de coordenadas centrado no raio possui uma base dada pelos vetores unitários

$$
\begin{gathered}
\mathrm{e}_{1}(\mathrm{~s})=\left(\mathrm{e}_{1}(\mathrm{~s}), 0,0\right)^{\mathrm{T}}, \mathrm{e}_{2}(\mathrm{~s})=\left(0, \mathrm{e}_{2}(\mathrm{~s}), 0\right)^{\mathrm{T}} \mathrm{e}_{3}(\mathrm{~s})=\left(0,0, \mathrm{e}_{3}(\mathrm{~s})\right)^{\mathrm{T}}, \mathrm{com} \\
\mathrm{e}_{1}(\mathrm{~s})=\mathrm{n} \cos \varphi-\mathrm{b} \operatorname{sen} \varphi, \\
\mathrm{e}_{1}(\mathrm{~s})=\mathrm{nsen} \varphi+\mathrm{b} \cos \varphi, \\
\mathrm{e}_{3}(\mathrm{~s})=\frac{\mathrm{p}}{|\mathrm{p}|}=\mathrm{t},
\end{gathered}
$$

onde $\mathrm{t}$ é o vetor unitário tangente a trajetória de $\Omega$ no ponto $\mathrm{O}_{\mathrm{s}}$, enquanto que $\mathrm{n}$ e $\mathrm{b}$ representam os vetores unitários normal e binormal relativos ao vetor $\mathrm{t}$ no mesmo ponto (Figura 3.1). Finalmente, $\varphi$ é o ângulo formado entre os vetores $e_{1} e n$. 
É importante ressaltar que este sistema especial de coordenadas depende do ponto selecionado no raio $\Omega$. Deste modo, o vetor posição $r$ de um ponto qualquer na vizinhança do raio $\Omega$, contido no plano do modelo, pode ser escrito na forma (Figura 3.2)

$$
\mathrm{r}=\mathrm{r}_{0}(0,0, \mathrm{~s})+\mathrm{q}_{1}(\mathrm{~s}) \mathrm{e}_{1}(\mathrm{~s})+\mathrm{q}_{2}(\mathrm{~s}) \mathrm{e}_{2}(\mathrm{~s}),
$$

onde $\mathrm{r}_{0}=\mathrm{r}_{0}(0,0, \mathrm{~s})$ representa o ponto do raio $\Omega$ determinado pela interseção do plano que passa pelo ponto especificado pelo vetor posição $\mathrm{r}$ e o raio $\Omega$, sendo perpendicular ao mesmo raio. Desde modo, no caso bidimensional que é de interesse deste trabalho, o plano do modelo é descrito pela condição $\mathrm{q}_{2}(\mathrm{~s})=0$.

As chamadas fórmulas de Frenet obtidas a partir da geometria diferencial (Carmo, 1992) estabelecem que,

$$
\begin{aligned}
& \frac{\mathrm{dn}}{\mathrm{ds}}=\mathrm{Tb}-\mathrm{Kt}, \\
& \frac{\mathrm{db}}{\mathrm{ds}}=-\mathrm{Tn}, \\
& \frac{\mathrm{dt}}{\mathrm{ds}}=\mathrm{Kn},
\end{aligned}
$$

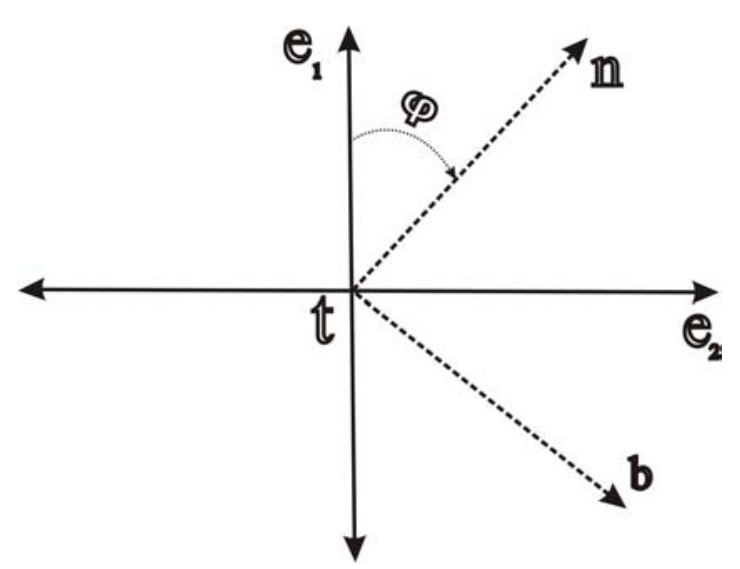

Figura 3.1- Representação da tripla de vetores unitários t, $\mathrm{n}$ e b 


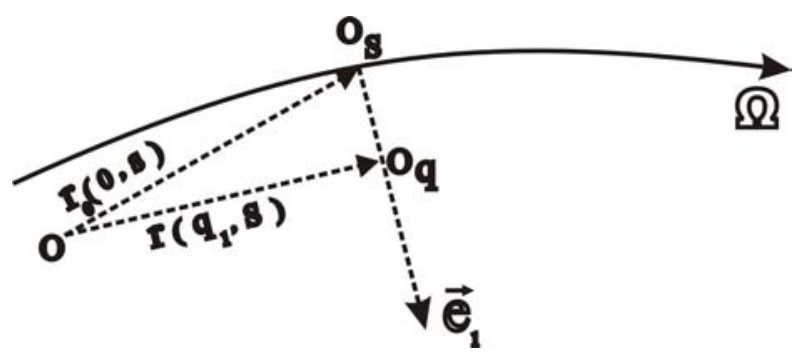

Figura 3.2 - Representação do vetor posição $\mathrm{r}$ de um ponto na vizinhança do raio $\Omega$

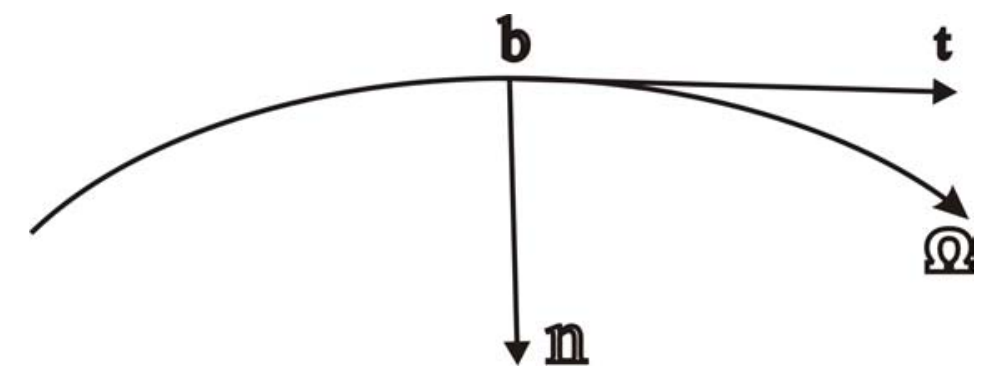

Figura 3.3 - Representação de um raio que se propaga ao longo de um único plano. Neste caso, tem-se que $\varphi$ é constante e não existe torsão ao longo do raio, $\mathrm{T}=0$

onde $\mathrm{T}$ e $\mathrm{K}$ são a torsão e a curvatura do raio, respectivamente. Usando-se a relação $\frac{\mathrm{d} \varphi}{\mathrm{ds}}=\mathrm{T}$ e as equações (3.8), (3.9) e (3.10), as derivadas de $\left(\mathrm{e}_{1}, \mathrm{e}_{2}, \mathrm{t}\right)$ são dadas por,

$$
\begin{aligned}
\frac{\mathrm{de}_{1}}{\mathrm{ds}} & =-\mathrm{K} \cos \varphi \mathrm{t}, \\
\frac{\mathrm{de}_{2}}{\mathrm{ds}} & =-\mathrm{K} \operatorname{sen} \varphi \mathrm{t}, \\
\frac{\mathrm{dt}}{\mathrm{ds}} & =\mathrm{K}\left(\mathrm{e}_{1} \cos \varphi+\mathrm{e}_{2} \operatorname{sen} \varphi\right) .
\end{aligned}
$$

Sob a hipótese de uma fonte linear, perpendicular ao plano do modelo e paralela ao eixo definido pelo vetor $\mathrm{e}_{2}$, a Figura 3.3 apresenta o caso particular em que o raio se propaga no plano formado pelos vetores $\mathrm{n}$ e $\mathrm{t}$, de modo que o vetor binormal $\mathrm{b}$ permanece normal ao plano de propagação. Neste casa, tem-se que $\mathrm{e}_{1}=\mathrm{n}, \mathrm{e}_{2}=\mathrm{b}$ e $\mathrm{e}_{3}=\mathrm{t}$, e considera-se que a energia elástica se propaga como se a mesma estivesse toda contida em um único plano.

Assim, far-se-á uso de uma importante equação que é parte do sistema de equações do raio qual será apresentado posteriormente, dada como: 


$$
\frac{\mathrm{dp}}{\mathrm{ds}}=\nabla\left(\frac{1}{\mathrm{v}}\right)
$$

ao longo do raio $\Omega$. Com isto tem-se que a variação do vetor unitário $t$ tangente ao raio, ao longo do mesmo, pode ser expresso por

$$
\frac{\mathrm{dt}}{\mathrm{ds}}=\frac{\mathrm{d}(\mathrm{vp})}{\mathrm{ds}}=\frac{\mathrm{dv}}{\mathrm{dt}} \mathrm{v}^{-1} \mathrm{t}-\mathrm{v}^{-1}\left(\frac{\mathrm{dv}}{\mathrm{ds}} \mathrm{t}+\frac{\partial \mathrm{v}}{\partial \mathrm{q}_{1}} \mathrm{e}_{1}+\frac{\partial \mathrm{v}}{\partial \mathrm{q}_{2}} \mathrm{e}_{2}\right)=-\mathrm{v}^{-1} \frac{\partial \mathrm{v}}{\partial \mathrm{q}_{1}}-\mathrm{v}^{-1} \frac{\partial \mathrm{v}}{\partial \mathrm{q}_{2}} \mathrm{e}_{2} .
$$

Pode-se verificar a ortogonalidade do sistema de coordenadas centrado no raio, estudando-se o chamado tensor métrico, $\mathrm{Z}_{\mathrm{ik}}$, definido por

$$
(\mathrm{dl})^{2}=\mathrm{Z}_{\mathrm{ik}} \mathrm{d} \varsigma_{\mathrm{i}} \mathrm{d} \varsigma_{\mathrm{k}}
$$

onde dlé um elemento de comprimento. Se este tensor é diagonal em qualquer ponto, então o sistema de coordenada é ortogonal (Červený, 2001). Pode-se facilmente verificar que

$$
\mathrm{drdr}=\mathrm{dq}_{1}^{2}+\mathrm{dq}_{2}^{2}+\mathrm{h}^{2} \mathrm{ds}^{2},
$$

onde

$$
\mathrm{h}=1-\mathrm{q}_{1} \mathrm{~K} \cos \varphi-\mathrm{q}_{2} \mathrm{~K} \operatorname{sen} \varphi,
$$

e K é a curvatura do raio $\Omega$. Combinando-se as equações (3.14), (3.15) e (3.18) pode-se reescrever esta última equação como

$$
\mathrm{h}=1+\left.\left(\mathrm{v}^{-1} \frac{\partial \mathrm{v}}{\partial \mathrm{q}_{1}}\right)\right|_{\left(\mathrm{q}_{1}=\mathrm{q}_{2}=0\right)} \mathrm{q}_{1}+\left.\left(\mathrm{v}^{-1} \frac{\partial \mathrm{v}}{\partial \mathrm{q}_{2}}\right)\right|_{\left(\mathrm{q}_{1}=\mathrm{q}_{2}=0\right)} \mathrm{q}_{2} .
$$

A partir desse resultado tem-se que

$$
\mathrm{Z}_{11}=\mathrm{Z}_{22}=1, \mathrm{Z}_{33}=\mathrm{h}^{2}, Z_{i k}=0 \text { para } \mathrm{i} \neq \mathrm{k} .
$$

O que mostra que o sistema de coordenadas centradas no raio é ortogonal. Pode-se escrever ainda

$$
(\mathrm{dl})^{2}=\mathrm{h}_{1}^{2} \mathrm{dq}_{1}^{2}+\mathrm{h}_{2}^{2} \mathrm{dq}_{2}^{2}+\mathrm{h}_{3}^{2} \mathrm{dq}_{3}^{2}
$$

onde $\mathrm{h}_{1}=\mathrm{h}_{2}=1$ e $\mathrm{h}_{3}=\mathrm{h}$ são denominados os fatores escalas do sistema de coordenadas.

Resumindo, têm-se as seguintes propriedades para este sistema de coordenadas:

- Os vetores unitários $\mathrm{e}_{1}, \mathrm{e}_{2}$ e $\mathrm{e}_{3}$ formam a base ortogonal do sistema de coordenadas centrado no raio $\Omega$.

- Este sistema de coordenadas depende do ponto em relação ao qual é definido ao longo do raio $\Omega$. 
- O par de vetores unitários $\mathrm{e}_{1} \mathrm{e}_{2}$ forma um sistema Cartesiano de coordenadas no plano perpendicular ao raio, tendo origem no ponto de interseção do referido plano com o raio $\Omega$. Por sua vez, $\mathrm{e}_{3}$ é tangente a trajetória do raio no ponto $\mathrm{O}_{\mathrm{s}}$.

- O sistema de coordenadas é móvel e seguira a trajetória do raio, permanecendo como destro, ou seja, $\mathrm{e}_{1} \times \mathrm{e}_{2}=\mathrm{e}_{3}$.

- Este sistema é determinado a partir das condições iniciais dadas em $\mathrm{s}=\mathrm{s}_{0}$, e das propriedades do raio $\Omega$ no ponto $\mathrm{O}_{\mathrm{s}}$.

- Variações de $\mathrm{e}_{1}$ e $\mathrm{e}_{2}$ ao longo do raio possuem projeções diferentes de zero apenas na direção dada pelo vetor $t$.

\section{3- SISTEMA CARTESIANO LOCAL DE COORDENADAS}

Nesta seção é definido um sistema Cartesiano de coordenadas de base dada pelos vetores $\mathrm{j}_{1}, \mathrm{j}_{2}$ e $\mathrm{j}_{3}$, com

$$
\mathrm{j}_{1}=\mathrm{e}_{1}\left(\mathrm{O}_{\mathrm{s}}\right), \mathrm{j}_{2}=\mathrm{e}_{2}\left(\mathrm{O}_{\mathrm{s}}\right), \mathrm{j}_{3}=\mathrm{e}_{3}\left(\mathrm{O}_{\mathrm{s}}\right)=\mathrm{t}\left(\mathrm{O}_{\mathrm{s}}\right)
$$

onde $\mathrm{O}_{\mathrm{s}}$ é um ponto fixo do raio $\Omega$. Estes vetores constituem, então, a base do sistema Cartesiano local de coordenadas, a qual coincide com a base do sistema centrado no raio no ponto $\mathrm{O}_{\mathrm{s}}$. Fora do ponto $\mathrm{O}_{\mathrm{s}}$ estes dois sistemas não coincidem: o sistema centrado no raio é móvel, enquanto o sistema Cartesiano local é fixo. Portanto, é interessante notar que o sistema Cartesiano local de coordenadas depende do ponto $\mathrm{O}_{\mathrm{s}}$ no raio $\Omega$, ao contrário do sistema Cartesiano geral que possui origem e base fixas, definida como $\left(i_{1}, i_{2}, i_{3}\right)$.

\section{4- APROXIMAÇÃO PARAXIAL DO RAIO}

Considere-se um raio $\Omega$ fixo, bem como um sistema de coordenadas centradas no raio associado $\left(\mathrm{q}_{1}, \mathrm{q}_{2}, \mathrm{q}_{3}=\mathrm{s}\right)$. A vizinhança paraxial do raio é definida como a região em torno de $\Omega$ para qual se tem pequenos valores de coordenadas centradas $\mathrm{q}_{1}, \mathrm{q}_{2}$ (Červený, 2001).

A fim de avaliar os diversos raios, tempos de trânsito e a frente de onda na vizinhança paraxial do raio $\Omega$, é utilizado a aproximação dada pela série de Taylor. Deste modo, uma 
medida da vizinhança paraxial é obtida pela diferença destas quantidades, dadas através da série de Taylor truncada (por exemplo, até segunda ordem) e pelo cálculo exato das mesmas quantidades através do sistema de traçamento do raio. Na vizinhança paraxial esta diferença não deve exceder a uma pequena quantidade.

È importante notar que as quantidades obtidas na vizinhança paraxial através da série de Taylor serão exatas apenas ao longo do raio $\Omega$, sendo apenas aproximadas em qualquer ponto na proximidade do referido raio. Isto implica que as equações derivadas considerando-se a aproximação paraxial terão sua precisão limitada ao termo de truncamento da série de Taylor, o qual, geralmente, corresponde ao termo de segunda ordem.

\subsection{1- Sistema Dinâmico da Trajetória do Raio}

A aproximação paraxial da equação eikonal para um modelo bidimensional definido pelas direções $\left(\mathrm{e}_{1}, \mathrm{e}_{3}\right)$ em coordenadas centradas no raio $\left(\mathrm{q}_{1}=\mathrm{q}, \mathrm{q}_{2}=0, \mathrm{q}_{3}=\mathrm{s}\right)$, com $\tau=\tau(\mathrm{q}, \mathrm{s})$, é dada com base em (Červený,2001), por

$$
\left(\frac{\partial \tau}{\partial q}\right)^{2}+\left(\frac{\partial \tau}{\partial s}\right)^{2}=\frac{1}{v^{2}}-\left.\frac{1}{v^{3}}\left(\frac{\partial^{2} v}{\partial q^{2}}\right)\right|_{q=0} q^{2},
$$

onde $\mathrm{v}=\mathrm{v}(0, \mathrm{~s})=\mathrm{v}\left(\mathrm{O}_{\mathrm{s}}\right)$ é a velocidade no ponto $\mathrm{O}_{\mathrm{s}}$ sobre o raio $\Omega$. Deve-se observar que esta equação é um caso particular do caso mais geral em três dimensões, e que na forma aqui apresentada corresponde a considerar apenas a propagação do raio no plano de incidência, coincidente com o plano do modelo, quando $\mathrm{q}_{2}=0$.

Além disto, consideremos o desenvolvimento da série de Taylor para o tempo de trânsito paraxial $\tau(\mathrm{q}, \mathrm{s})$, até a segunda ordem em $\mathrm{q}$ na vizinhança de $\mathrm{q}=0$, ou seja

$$
\tau(\mathrm{q}, \mathrm{s}) \approx \tau(0, \mathrm{~s})+\frac{1}{2} \mathrm{M}\left(\mathrm{O}_{\mathrm{s}}\right) \mathrm{q}^{2},
$$

onde $\mathrm{M}$ é dado por

$$
\mathrm{M}\left(\mathrm{O}_{\mathrm{s}}\right)=\left(\frac{\partial^{2} \tau}{\partial \mathrm{q}^{2}}\right)_{\mathrm{q}=0}
$$


Através da substituição da aproximação para o tempo de trânsito dado pela equação (3.24), na equação (3.23), e levando-se em consideração que $\left.\left(\frac{\partial \tau(\mathrm{q}, \mathrm{s})}{\partial \mathrm{s}}\right)\right|_{\mathrm{q}=0} \approx\left(\frac{1}{\mathrm{v}}\right)$ (Červený, 2001), tem-se que

$$
\frac{\mathrm{dM}}{\mathrm{ds}}+\mathrm{vM}^{2}+\mathrm{v}^{-2} \mathrm{~V}=0
$$

onde $\mathrm{V}=\mathrm{V}(\mathrm{s})$ é dado por

$$
\mathrm{V}=\left.\left(\frac{\partial^{2} \mathrm{v}(\mathrm{q}, \mathrm{s})}{\partial \mathrm{q}^{2}}\right)\right|_{\mathrm{q}=0}
$$

A equação diferencial ordinária não-linear de primeira ordem (3.26), referente ao modelo bidimensional em questão é denominada equação do tipo Ricatti, aqui descrita para o caso do modelo bidimensional. Resolvendo-se esta equação é possível avaliar $M$ ao longo da trajetória do raio $\Omega$. Esta equação é também denominado sistema dinâmico de raios (Červený, 2001).

Escrevendo-se agora conectados com $\mathrm{M}$, tal que

$$
\mathrm{M}=\mathrm{PQ}^{-1},
$$

onde $\mathrm{P}=\mathrm{P}(\mathrm{s})$ e $\mathrm{Q}=\mathrm{Q}(\mathrm{s})$ são funções a determinar e substituindo-se na equação de Ricatti (3.26), obtemos

$$
\mathrm{Q}\left(\frac{\mathrm{dP}}{\mathrm{ds}}+\frac{1}{\mathrm{v}^{2}} \mathrm{VP}\right)-\mathrm{P}\left(\frac{\mathrm{dQ}}{\mathrm{ds}}-\mathrm{vP}\right)=0
$$

Desta maneira, pode-se obter uma solução para equação de Ricatti se tomarmos $\mathrm{P}$ e Q satisfazendo ao chamado sistema dinâmico de raios (Červený, 2001),

$$
\left\{\begin{array}{c}
\frac{d Q}{d s}=v P \\
\frac{d P}{d s}=-\frac{1}{v^{2}} V Q
\end{array} .\right.
$$

Este sistema pode ainda ser escrito em uma forma mais instrutiva dada como

$$
\frac{\mathrm{dw}}{\mathrm{ds}}=\mathrm{Sw},
$$

onde, 


$$
\mathrm{W}=\left(\begin{array}{l}
\mathrm{Q} \\
\mathrm{P}
\end{array}\right)
$$

e

$$
S=\left(\begin{array}{cc}
0 & v \\
-v^{2} V & 0
\end{array}\right)
$$

O sistema dado pela equação (3.31) pode ser resolvido apenas se forem especificados adequadas condições iniciais para $\mathrm{P}$ e $\mathrm{Q}$ em algum ponto inicial $\mathrm{s}_{0}$ do raio $\Omega$. Uma discussão sobre os critérios utilizados na escolha das condições iniciais para o sistema dinâmico do raio pode ser encontrada em (Červený, 2001).

Introduzindo-se aqui a matriz de propagação do raio, $\left(\mathrm{s}, \mathrm{s}_{0}\right)$, a partir de um ponto inicial $\mathrm{s}_{0}$, como a matriz integral do sistema dado em (3.31), tem-se a notação

$$
\frac{\mathrm{d}}{\mathrm{ds}} \Pi=\mathrm{S} \Pi
$$

Esta matriz deve satisfazer como condição inicial em $\mathrm{s}=\mathrm{s}_{0}$ que

$$
\prod\left(\mathrm{s}_{0}, \mathrm{~s}_{0}\right)=\mathrm{I}
$$

onde I é a matriz identidade. A matriz de propagação do raio pode ser também reescrita segundo a seguinte notação (Červený, 2001)

$$
\Pi\left(\mathrm{s}_{\mathrm{s}} \mathrm{s}_{0}\right)=\left(\begin{array}{ll}
\mathrm{Q}_{1}\left(\mathrm{~s}, \mathrm{~s}_{0}\right) & \mathrm{Q}_{2}\left(\mathrm{~s}, \mathrm{~s}_{0}\right) \\
\mathrm{P}_{1}\left(\mathrm{~s}, \mathrm{~s}_{0}\right) & \mathrm{P}_{2}\left(\mathrm{~s}, \mathrm{~s}_{0}\right)
\end{array}\right) .
$$

Sendo assim, tem-se que as quantidades escalares $Q_{1}$ e $P_{1}$ são soluções do sistema dinâmico do raios quando admite-se as condições inicias $\mathrm{Q}\left(\mathrm{s}_{0}\right)=1$ e $\mathrm{P}\left(\mathrm{s}_{0}\right)=0$. Neste caso, tem-se no plano do modelo o correspondente a uma "onda plana" como condição inicial, e o valor de $\mathrm{M}\left(\mathrm{s}_{0}\right)=\mathrm{P}\left(\mathrm{s}_{0}\right) \mathrm{Q}\left(\mathrm{s}_{0}\right)^{-1}$ é zero no ponto inicial $\mathrm{s}_{0}$ do raio $\Omega$. E os escalares $\mathrm{Q}_{2}$ e $\mathrm{P}_{2}$ são também soluções do sistema dinâmico dos raios quando admite-se as condições iniciais $\mathrm{Q}\left(\mathrm{s}_{0}\right)=0$ e $\mathrm{P}\left(\mathrm{s}_{0}\right)=1$. Neste caso, tem-se no plano do modelo o correspondente a uma "fonte pontual" como condição inicial, e o valor de $\mathrm{M}\left(\mathrm{s}_{0}\right)=\mathrm{P}\left(\mathrm{s}_{0}\right) \mathrm{Q}\left(\mathrm{s}_{0}\right)^{-1}$ é infinito no ponto inicial $\mathrm{s}_{0}$ do raio $\Omega$. 
Considerando-se como conhecida a matriz de propagação $\Pi$, que no caso bidimensional assume a forma $(2 \times 2)$, pode-se determinar analiticamente os valores dos escalares $Q(s)$ e P(s) (Červený, 2001), a saber

$$
\begin{aligned}
& \mathrm{Q}(\mathrm{s})=\mathrm{Q}_{1}\left(\mathrm{~s}, \mathrm{~s}_{0}\right) \mathrm{Q}\left(\mathrm{s}_{0}\right)+\mathrm{Q}_{2}\left(\mathrm{~s}, \mathrm{~s}_{0}\right) \mathrm{P}\left(\mathrm{s}_{0}\right) \\
& \mathrm{P}(\mathrm{s})=\mathrm{P}_{1}\left(\mathrm{~s}, \mathrm{~s}_{0}\right) \mathrm{Q}\left(\mathrm{s}_{0}\right)+\mathrm{P}_{2}\left(\mathrm{~s}, \mathrm{~s}_{0}\right) \mathrm{P}\left(\mathrm{s}_{0}\right)
\end{aligned},
$$

Conseqüentemente, o vetor $\mathrm{w}$ em qualquer ponto do raio $\Omega$ pode ser expresso como

$$
\mathrm{w}(\mathrm{s})=\prod\left(\mathrm{s}, \mathrm{s}_{0}\right) \mathrm{w}\left(\mathrm{s}_{0}\right) \text {. }
$$

\subsection{2- Tempo de Trânsito Paraxial}

Considera-se conhecido um ponto $\mathrm{O}_{\mathrm{s}}$ de coordenadas $(0,0, \mathrm{~s})$, contido no plano do modelo, sobre o raio $\Omega$, juntamente com as quantidades $\mathrm{M}\left(\mathrm{O}_{\mathrm{s}}\right)$ e $\tau\left(\mathrm{O}_{\mathrm{s}}\right)$. Deste modo,o tempo da trajetória $\tau$ em um ponto $\mathrm{O}_{\mathrm{q}}$ de coordenada centrada no raio $\left(\mathrm{q}_{1}=\mathrm{q}, \mathrm{q}_{2}=0, \mathrm{q}_{3}=\mathrm{s}\right)$ localizado na reta perpendicular ao raio $\Omega$ no ponto $\mathrm{O}_{\mathrm{s}}$, pode ser calculado através da série de Taylor, truncando no termo de segunda ordem, como

$$
\tau\left(\mathrm{O}_{\mathrm{q}}\right)=\tau\left(\mathrm{O}_{\mathrm{s}}\right)+\frac{1}{2} \mathrm{M}\left(\mathrm{O}_{\mathrm{s}}\right) \mathrm{q}^{2} \text {. }
$$

Usando a aproximação da série de Taylor para o tempo de trânsito $\tau$ dado através da equação (3.24), e lembrando que $\mathrm{p}_{\mathrm{i}}^{(\mathrm{q})}=\frac{\partial \tau}{\partial \mathrm{q}_{\mathrm{i}}}$, tem-se que uma aproximação para o vetor vagarosidade nas aproximações do raio $\Omega$, em um ponto $\mathrm{O}_{\mathrm{s}}$, no plano do modelo, pode ser através de suas componentes como

$$
\begin{aligned}
& \mathrm{p}^{(\mathrm{q})}\left(\mathrm{O}_{\mathrm{q}}\right) \approx \mathrm{M}\left(\mathrm{O}_{\mathrm{s}}\right) \mathrm{q}, \\
& \mathrm{p}^{(\mathrm{s})}\left(\mathrm{O}_{\mathrm{q}}\right)=\mathrm{p}^{(\mathrm{s})}\left(\mathrm{O}_{\mathrm{s}}\right) .
\end{aligned}
$$

Nesta aproximação $\mathrm{p}^{(\mathrm{q})}\left(\mathrm{O}_{\mathrm{q}}\right)$ representa a componente do vetor vagarosidade perpendicular raio $\Omega$, enquanto $\mathrm{p}^{(\mathrm{s})}\left(\mathrm{O}_{\mathrm{q}}\right)$ representa a componente na direção do raio $\Omega$.

Observemos que o ponto $\mathrm{O}_{\mathrm{q}}^{\prime}$ na vizinhança de $\mathrm{O}_{\mathrm{s}}$, agora tem coordenadas centradas no raio $\left(\mathrm{q}, \mathrm{s}^{\prime}\right)$. Isto significa que o ponto $\mathrm{O}_{\mathrm{q}}^{\prime}$ encontra-se sobre uma reta que intercepta 
perpendicularmente o raio $\Omega$ em um ponto $\mathrm{O}_{\mathrm{s}}^{\prime}$ deslocado de $\mathrm{O}_{\mathrm{s}}$, tal que $\overline{\mathrm{O}_{\mathrm{s}} \mathrm{O}_{\mathrm{s}}^{\prime}}=\left|\mathrm{s}-\mathrm{s}^{\prime}\right| . \mathrm{O}$ tempo da trajetória é obtido introduzindo o sistema Cartesiano local de coordenadas $\mathrm{y}_{\mathrm{j}}(\mathrm{j}=1,3)$, de modo que esta aproximação é dada como (Červený, 2001)

$$
\tau\left(\mathrm{O}_{\mathrm{q}}^{\prime}\right)=\tau\left(\mathrm{O}_{\mathrm{S}}\right)+\mathrm{y}^{\mathrm{T}} \mathrm{p}^{(\mathrm{y})}\left(\mathrm{O}_{\mathrm{s}}\right)+\frac{1}{2} \mathrm{y}^{\mathrm{T}} \mathrm{M}\left(\mathrm{O}_{\mathrm{s}}\right) \mathrm{y},
$$

para a qual tem-se

$$
\begin{aligned}
\mathrm{M}\left(\mathrm{O}_{\mathrm{s}}\right) & =\left(\begin{array}{cc}
\mathrm{M} & -\frac{\partial \mathrm{v}}{\mathrm{v}^{2} \partial \mathrm{y}_{1}} \\
-\frac{\partial \mathrm{v}}{\mathrm{v}^{2} \partial \mathrm{y}_{1}} & -\frac{\partial \mathrm{v}}{\mathrm{v}^{2} \partial \mathrm{y}_{3}}
\end{array}\right), \\
\mathrm{y} & =\left(\begin{array}{c}
\mathrm{y}_{1} \\
\mathrm{y}_{3}
\end{array}\right) \mathrm{e}^{(\mathrm{y})}\left(\mathrm{O}_{\mathrm{s}}\right)=\left(\begin{array}{l}
0 \\
\frac{1}{\mathrm{v}}
\end{array}\right) .
\end{aligned}
$$

Nesta última equação $\mathrm{v}$ representa o valor da velocidade da onda no ponto $\mathrm{O}_{\mathrm{s}}$ do raio $\Omega$.

Dessa forma, considerando dois pontos $\mathrm{S}$ e $\mathrm{G}$ situados ao longo de um raio central $\Omega$ e dois pontos $\overline{\mathrm{S}}$ e $\overline{\mathrm{G}}$ na vizinhança de $\mathrm{S}$ e $\mathrm{G}$, respectivamente, onde o tempo de trânsito e a matriz propagadora do raio no sistema de coordenada centrado no raio para $\mathrm{S}$ e $\mathrm{G}$ ao longo do mesmo são conhecidos, podemos expressar a aproximação do tempo de trânsito parabólico de raios paraxiais em um sistema cartesiano local de coordenadas partindo da equação abaixo:

$$
\Delta \tau=\Delta \tau(\overline{\mathrm{G}}, \mathrm{G})-\Delta \tau(\overline{\mathrm{S}}, \mathrm{S}) .
$$

Assim, usando (3.38), (3.40), (3.41) e (3.42) em (3.44) com uma notação diferente, obtemos:

$$
\begin{aligned}
& \Delta \tau=\mathrm{y}^{\mathrm{T}}(\overline{\mathrm{G}}) \mathrm{p}^{(\mathrm{y})}(\mathrm{G})-\mathrm{y}^{\mathrm{T}}(\overline{\mathrm{S}}) \mathrm{p}^{(\mathrm{y})}(\mathrm{S})+\frac{1}{2} \mathrm{y}^{\mathrm{T}}(\overline{\mathrm{G}}) \underline{\mathrm{M}}(\mathrm{G}, \mathrm{S}) \mathrm{y}(\overline{\mathrm{G}})+\frac{1}{2} \mathrm{y}^{\mathrm{T}}(\overline{\mathrm{S}}) \underline{\mathrm{M}}(\mathrm{S}, \mathrm{G}) \mathrm{y}(\overline{\mathrm{S}}) \\
& -\mathrm{y}^{\mathrm{T}}(\overline{\mathrm{S}}) \underline{\mathrm{G}}(\mathrm{G}, \mathrm{S}) \mathrm{y}(\overline{\mathrm{G}})
\end{aligned}
$$

Agora, usando a transformação de coordenadas de um ponto fonte $\mathrm{S}$ e um receptor $\mathrm{G}$ em (3.45), ou seja:

$$
\left(\begin{array}{l}
\mathrm{y}_{1}(\overline{\mathrm{S}}) \\
\mathrm{y}_{3}(\overline{\mathrm{S}})
\end{array}\right)=\underline{\mathrm{D}}(\mathrm{S})\left(\begin{array}{l}
\mathrm{x}_{1}(\overline{\mathrm{S}}) \\
\mathrm{x}_{3}(\overline{\mathrm{S}})
\end{array}\right),\left(\begin{array}{l}
\mathrm{y}_{1}(\overline{\mathrm{G}}) \\
\mathrm{y}_{3}(\overline{\mathrm{G}})
\end{array}\right)=\underline{\mathrm{D}}(\mathrm{G})\left(\begin{array}{l}
\mathrm{x}_{1}(\overline{\mathrm{G}}) \\
\mathrm{x}_{3}(\overline{\mathrm{G}})
\end{array}\right),
$$

temos finalmente a aproximação do tempo de trânsito parabólico de raios paraxiais em um sistema cartesiano local expresso por (Modificado Červený, 2001): 


$$
\begin{aligned}
& \tau(\overline{\mathrm{G}}, \overline{\mathrm{S}})=\tau(\mathrm{G}, \mathrm{S})+\mathrm{x}^{\mathrm{T}}(\overline{\mathrm{G}}) \underline{\mathrm{D}}^{\mathrm{T}}(\mathrm{G}) \mathrm{p}^{(\mathrm{y})}(\mathrm{G})-\mathrm{x}^{\mathrm{T}}(\overline{\mathrm{S}}) \underline{\mathrm{D}}^{\mathrm{T}}(\mathrm{S}) \mathrm{p}^{(\mathrm{y})}(\mathrm{S}) \\
& +\frac{1}{2} \mathrm{x}^{\mathrm{T}}(\overline{\mathrm{G}}) \underline{\mathrm{D}}^{\mathrm{T}}(\mathrm{G}) \underline{\mathrm{M}}(\mathrm{G}, \mathrm{S}) \underline{\mathrm{D}}(\mathrm{G}) \mathrm{x}(\overline{\mathrm{G}}) \\
& +\frac{1}{2} \mathrm{x}^{\mathrm{T}}(\overline{\mathrm{S}}) \underline{\mathrm{D}}^{\mathrm{T}}(\mathrm{S}) \underline{\mathrm{M}}(\mathrm{S}, \mathrm{G}) \underline{\mathrm{D}}(\mathrm{S}) \mathrm{x}(\overline{\mathrm{S}}) \\
& -\mathrm{x}^{\mathrm{T}}(\overline{\mathrm{S}}) \underline{\mathrm{D}}^{\mathrm{T}}(\mathrm{S}) \underline{\mathrm{G}}(\mathrm{G}, \mathrm{S}) \underline{\mathrm{D}}(\mathrm{G}) \mathrm{x}(\overline{\mathrm{G}})
\end{aligned}
$$

onde

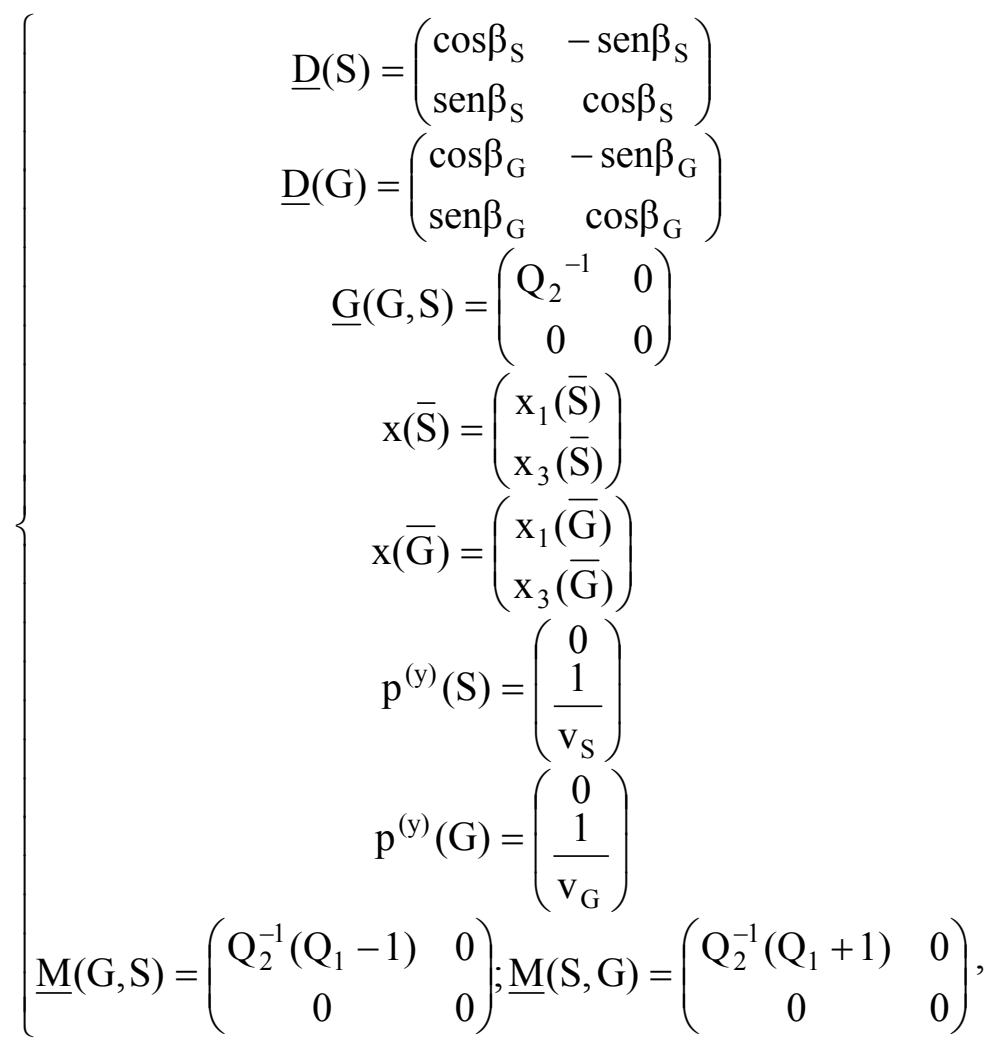

sendo $\beta_{\mathrm{S}}$ o ângulo de incidência do raio central em $\mathrm{S}$ e $\beta_{\mathrm{G}}$ o ângulo de emergência do raio central em G, bem como $\mathrm{x}(\overline{\mathrm{S}})$ e $\mathrm{x}(\overline{\mathrm{G}})$ o deslocamento do ponto $\bar{S}$ em relação a $\mathrm{S}$ e do ponto $\overline{\mathrm{G}}$ em relação $\mathrm{G}$, respectivamente, na equação (3.47). Ursin (1982) mostrou que os tempos de trânsito das reflexões se ajustam melhor por funções de tempo hiperbólicas do que parabólicas. Sendo assim, considerando o quadrado dos tempos de trânsito da equação (3.47) e negligenciando os termos superiores de segunda ordem, obtemos a aproximação hiperbólica de raios paraxiais em um sistema cartesiano local de coordenadas expressa por: 


$$
\begin{aligned}
& \tau^{2}(\overline{\mathrm{G}}, \overline{\mathrm{S}})=\left[\tau(\mathrm{G}, \mathrm{S})+\mathrm{x}^{\mathrm{T}}(\overline{\mathrm{G}}) \mathrm{p}^{(\mathrm{x})}(\mathrm{G})-\mathrm{x}^{\mathrm{T}}(\overline{\mathrm{S}}) \mathrm{p}^{(\mathrm{x})}(\mathrm{S})\right]^{2} \\
& +\tau(\mathrm{G}, \mathrm{S}) \mathrm{x}^{\mathrm{T}}(\overline{\mathrm{G}}) \underline{\mathrm{M}}^{(\mathrm{x})}(\mathrm{G}, \mathrm{S}) \mathrm{x}(\overline{\mathrm{G}}) \\
& +\tau(\mathrm{G}, \mathrm{S}) \mathrm{x}^{\mathrm{T}}(\overline{\mathrm{S}}) \underline{\mathrm{M}}^{(\mathrm{x})}(\mathrm{S}, \mathrm{G}) \mathrm{x}(\overline{\mathrm{S}}) \\
& -2 \tau(\mathrm{G}, \mathrm{S}) \mathrm{x}^{\mathrm{T}}(\overline{\mathrm{S}}) \mathrm{G}^{(\mathrm{x})}(\mathrm{G}, \mathrm{S}) \mathrm{x}(\overline{\mathrm{G}})
\end{aligned}
$$

onde

$$
p^{(x)}(S)=D^{T}(S) p^{(y)}(S), p^{(x)}(G)=D^{T}(G) p^{(y)}(G)
$$

e

$$
\begin{aligned}
& \mathrm{M}^{(\mathrm{x})}(\mathrm{G}, \mathrm{S})=\underline{\mathrm{D}}^{\mathrm{T}}(\mathrm{G}) \underline{\mathrm{M}}(\mathrm{G}, \mathrm{S}) \underline{\mathrm{D}}(\mathrm{G}), \\
& \mathrm{M}^{(\mathrm{x})}(\mathrm{S}, \mathrm{G})=\underline{\mathrm{D}}^{\mathrm{T}}(\mathrm{S}) \underline{\mathrm{M}}(\mathrm{S}, \mathrm{G}) \underline{\mathrm{D}}(\mathrm{S}), \\
& \mathrm{G}^{(\mathrm{x})}(\mathrm{G}, \mathrm{S})=\underline{\mathrm{D}}^{\mathrm{T}}(\mathrm{S}) \underline{\mathrm{G}}(\mathrm{G}, \mathrm{S}) \underline{\mathrm{D}}(\mathrm{G}) .
\end{aligned}
$$

\section{5- FORMALISMO PARA O MÉTODO DE EMPILHAMENTO SRC BIDIMENCIONAL COM AFASTAMENTO-NULO PARA UMA LINHA DE MEDIÇÃO COM TOPOGRAFIA RUGOSA}

A fórmula do tempo de trânsito de raios paraxiais, a um raio central com afastamentonulo (AN), pode ser derivada diretamente da equação (3.49) considerando:

- $\quad \mathrm{D}(\mathrm{G})=\mathrm{D}(\mathrm{S})$ e $\mathrm{p}^{(\mathrm{x})}(\mathrm{G})=-\mathrm{p}^{(\mathrm{x})}(\mathrm{S})$, já que o segmento de reflexão do raio normal para o caso de afastamento- nulo tem direção oposta com relação o seguimento de incidência do mesmo,

- A matriz propagadora do raio ao longo do raio normal com afastamento-nulo como (Hubral, 1983)

$$
\Pi_{\mathrm{AN}}(\mathrm{G}, \mathrm{S})=\frac{1}{\mathrm{~K}_{\mathrm{PIN}}-\mathrm{K}_{\mathrm{N}}}\left(\begin{array}{cc}
\mathrm{K}_{\mathrm{PIN}}+\mathrm{K}_{\mathrm{N}} & 2 \mathrm{v}_{\mathrm{S}} \\
\frac{2 \mathrm{~K}_{\mathrm{PIN}} \mathrm{K}_{\mathrm{N}}}{\mathrm{v}_{\mathrm{S}}} & \mathrm{K}_{\mathrm{PIN}}+\mathrm{K}_{\mathrm{N}}
\end{array}\right) .
$$

$\mathrm{Na}$ equação (3.54), $\mathrm{K}_{\mathrm{PIN}}$ e $\mathrm{K}_{\mathrm{N}}$ são as curvaturas das frentes de ondas consideradas ao longo do mesmo raio normal, ou seja, fonte e receptor coincidentes. Estas ondas são as ondas hipotéticas PIN e onda normal N, introduzidas por Hubral (1983), explicadas no Apêndice 
C. Dessa forma, a fórmula do tempo de trânsito para o empilhamento SRC bidimensional para uma linha de medição com topografia rugosa com afastamento-nulo (AN) pode ser expressa por:

$$
\begin{aligned}
& \tau_{\text {rug }}^{2}(\overline{\mathrm{G}}, \overline{\mathrm{S}})=\left(\mathrm{t}_{0}-\frac{2}{\mathrm{v}_{\mathrm{S}}}\left[\Delta \mathrm{m}_{\mathrm{x}} \operatorname{sen} \beta_{\mathrm{S}}+\Delta \mathrm{m}_{\mathrm{z}} \cos \beta_{\mathrm{S}}\right]\right)^{2}+\frac{2 \mathrm{t}_{0} \mathrm{~K}_{\mathrm{N}}}{\mathrm{v}_{\mathrm{S}}}\left(\Delta \mathrm{m}_{\mathrm{x}} \cos \beta_{\mathrm{S}}-\Delta \mathrm{m}_{\mathrm{z}} \operatorname{sen} \beta_{\mathrm{S}}\right)^{2} . \\
& +\frac{2 \mathrm{t}_{0} \mathrm{~K}_{\mathrm{PIN}}}{\mathrm{v}_{\mathrm{S}}}\left(\Delta \mathrm{h}_{\mathrm{x}} \cos \beta_{\mathrm{S}}-\Delta \mathrm{h}_{\mathrm{z}} \operatorname{sen} \beta_{\mathrm{S}}\right)^{2}
\end{aligned}
$$

Na equação (3.55) $\Delta \mathrm{m}_{\mathrm{x}}, \Delta \mathrm{m}_{\mathrm{z}}, \Delta \mathrm{h}_{\mathrm{x}}$ e $\Delta \mathrm{h}_{\mathrm{z}}$ são os componentes dos vetores ponto-médio e meio-afastamento bidimensional, respectivamente, definidos por:

$$
\left(\begin{array}{c}
\Delta \mathrm{m}_{\mathrm{x}} \\
\Delta \mathrm{m}_{\mathrm{z}}
\end{array}\right)=\frac{1}{2}\left(\begin{array}{l}
\mathrm{x}_{1}(\overline{\mathrm{G}})+\mathrm{x}_{1}(\overline{\mathrm{S}}) \\
\mathrm{x}_{3}(\overline{\mathrm{G}})+\mathrm{x}_{3}(\overline{\mathrm{S}})
\end{array}\right)
$$

e

$$
\left(\begin{array}{c}
\Delta \mathrm{h}_{\mathrm{x}} \\
\Delta \mathrm{h}_{\mathrm{z}}
\end{array}\right)=\frac{1}{2}\left(\begin{array}{l}
\mathrm{x}_{1}(\overline{\mathrm{G}})-\mathrm{x}_{1}(\overline{\mathrm{S}}) \\
\mathrm{x}_{3}(\overline{\mathrm{G}})-\mathrm{x}_{3}(\overline{\mathrm{S}})
\end{array}\right),
$$

sendo $t_{0}$ o tempo trânsito duplo ao longo do raio central com afastamento-nulo (AN), $\mathrm{v}_{\mathrm{S}}=\mathrm{v}_{0}$ a velocidade próxima a superfície no ponto fonte $\mathrm{S}=\mathrm{G}$ (conhecida) e $\beta_{\mathrm{S}}=\beta_{0}$ o ângulo de emergência do raio central (Figura3.5).

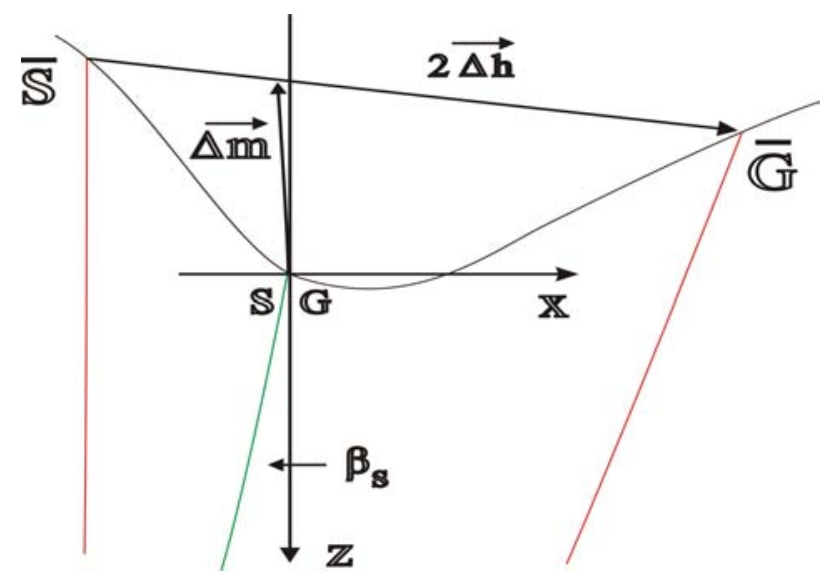

Figura 3.5- Modelo simples em profundidade com uma topografia de medição rugosa composto de uma raio central (cor verde) e um raio paraxial (cor vermelha), onde $\beta_{\mathrm{S}}=\beta_{0}$ é o ângulo de emergência do raio central (cor verde). $\Delta \overrightarrow{\mathrm{m}}, \Delta \overrightarrow{\mathrm{h}}$, são os vetores ponto-médio e meio-afastamento em sua forma bidimensional. A origem do sistema de coordenadas locais localiza-se no local do aparecimento do raio central (cor verde). 


\section{4- TEMPOS DE TRÂNSITO DE RAIOS PARAXIAIS PARA UMA SUPERFÍCIE DE MEDIÇÃO COM TOPOGRAFIA SUAVE}

Neste capítulo, será apresentado o desenvolvimento das equações dos tempos de trânsito parabólico e hiperbólico para raios paraxiais na vizinhança de um raio central refletido com afastamento fonte-receptor finito, sendo particularizado o tempo de trânsito hiperbólico para o caso do raio central com afastamento-nulo (AN). As derivações das aproximações dos tempos de trânsito são realizadas considerando uma linha de medição com topografia suave, com o objetivo de apresentar o operador SRC para a topografia suave, isto é, SRC-TS.

\section{1-TEORIA GEOMÉTRICA DO RAIO}

Nas seguintes considerações, suponhamos um meio isotrópico heterogêneo, 2-D, com interfaces suavemente encurvadas. Os raios que partem de uma superfície, onde estão localizadas as fontes, é denominado de superfície anterior e os que atingem uma superfície inferior a esta, onde estão localizados os receptores, é denominada superfície posterior, como mostra a Figura (4.1). O raio $S G$ que parte do ponto fonte $S$ atravessando o meio e emergindo no receptor $G$ é denominado raio central. Próximo ao raio central SG ou na vizinhança paraxial, o raio com

origem no ponto fonte $\overline{\mathrm{S}}$ e emergência no ponto receptor $\overline{\mathrm{G}}$ é denominado de raio paraxial $\overline{\mathrm{SG}}$.

Para descrever a trajetória desses raios, introduzimos dois sistemas de coordenadas localmente definidos (Figura 4.1). O primeiro sistema de coordenada cartesiana bidimensional é escolhido de tal maneira que o eixo $\mathrm{X}$ é tangente à superfície anterior passando pelo ponto fonte $\mathrm{S}$ e o eixo $\mathrm{Z}$ perpendicular ao eixo $\mathrm{X}$. O segundo sistema é escolhido de forma análoga, ou seja, o eixo $\mathrm{X}$ é tangente à superfície posterior passando pelo receptor G. As quantidades medidas no primeiro sistema de coordenada são denotadas pelo subscrito $\mathrm{S}$, enquanto que as quantidades medidas no segundo sistema de coordenadas são denotadas pelo subscrito G.

$\mathrm{O}$ raio central SG é definido pelo vetor posição e vetor vagarosidade no ponto fonte $\mathrm{S}$ e no receptor G. Da mesma maneira, o raio paraxial $\overline{\mathrm{SG}}$ é definido na superfície anterior em $\overline{\mathrm{S}}$ e na superfície posterior em $\overline{\mathrm{G}}$. Para o raio central é conhecido o vetor posição $\mathbf{x}_{\mathrm{S}}$ e o vetor 
vagarosidade $\mathbf{p}_{\mathbf{S}}$ em $\mathrm{S}$ e o vetor posição $\mathbf{x}_{\mathbf{G}}$ e o vetor vagarosidade $\mathbf{p}_{\mathbf{G}}$ em $\mathrm{G}$. De maneira análoga, o raio paraxial $\overline{\mathrm{SG}}$ em $\overline{\mathrm{S}}$ são descritos por $\overline{\mathbf{x}}_{\mathbf{S}}$ e $\overline{\mathbf{p}}_{\mathrm{S}}$, em $\overline{\mathrm{G}}$ por $\overline{\mathbf{x}}_{\mathbf{G}}$ e $\overline{\mathbf{p}}_{\mathrm{G}}$.

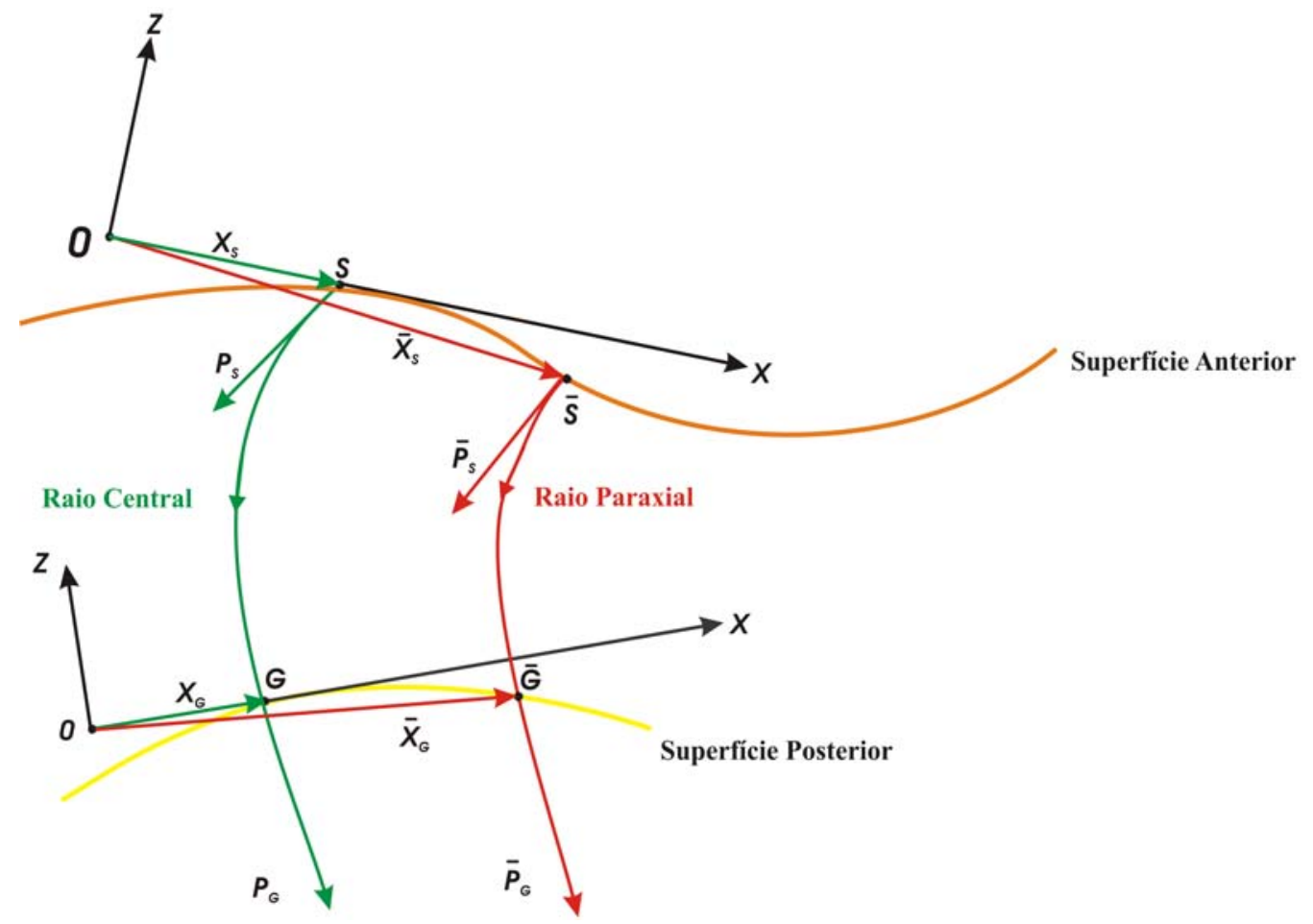

Figura 4.1 - Meio isotrópico heterogêneo 2-D, com interfaces encurvadas. O raio central (cor verde) passa através deste meio iniciando na superfície anterior no ponto $\mathrm{S}$ e emergindo no ponto $\mathrm{G}$. $\mathrm{O}$ raio paraxial (cor vermelha) está na vizinhança do raio central, iniciando no ponto $\overline{\mathrm{S}}$ e emergindo no ponto $\overline{\mathrm{G}}$.

Conhecendo as duas superfícies e as velocidades $\mathrm{v}_{\mathrm{S}}$ e $\mathrm{v}_{\mathrm{G}}$ próximas a elas, os vetores posição e vagarosidade podem ser reduzidos para seus valores escalares. Posteriormente, estes vetores poderão ser descritos a partir dos seus componentes escalares. Para o caso fonte-receptor localizados em $\mathbf{x}_{\mathrm{S}}, \overline{\mathbf{x}}_{\mathrm{S}}, \mathbf{x}_{\mathbf{G}}$ e $\overline{\mathbf{x}}_{\mathrm{G}}$, os vetores vagarosidade $\mathbf{p}_{\mathrm{S}}$ e $\mathbf{p}_{\mathrm{G}}$ do raio central tem suas componentes escalares obtidas através de uma simples projeção na direção do eixo $\mathrm{Z}$ sobre o eixo $\mathrm{X}$. Já no caso dos vetores vagarosidade $\overline{\mathbf{p}}_{\mathrm{s}} \mathrm{e} \overline{\mathbf{p}}_{\mathrm{G}}$ do raio paraxial, temos que executar uma projeção em cascata consistindo de duas etapas (Figura 4.2). Primeiro o vetor vagarosidade, por exemplo, $\overline{\mathbf{p}}_{\mathrm{s}}$ é projetado sobre a linha tangente à superfície anterior passando pelo ponto $\overline{\mathrm{S}}$. Posteriormente o vetor resultante $\overline{\mathbf{p}}_{\mathbf{S}, \mathbf{T}}$ é projetado sobre a linha tangente à superfície anterior 
passando pelo ponto $\mathrm{S}$ coincidindo com o eixo $\mathrm{X}$ do sistema de coordenadas cartesiana $(\mathrm{X}, \mathrm{Z})$ da superfície anterior, obtendo-se assim a componente $\overline{\mathrm{p}}_{\mathrm{S}}$. Analogamente o vetor vagarosidade $\overline{\mathbf{p}}_{\mathbf{G}}$ é projetado na linha tangente à superfície posterior passando por $\mathrm{G}$.

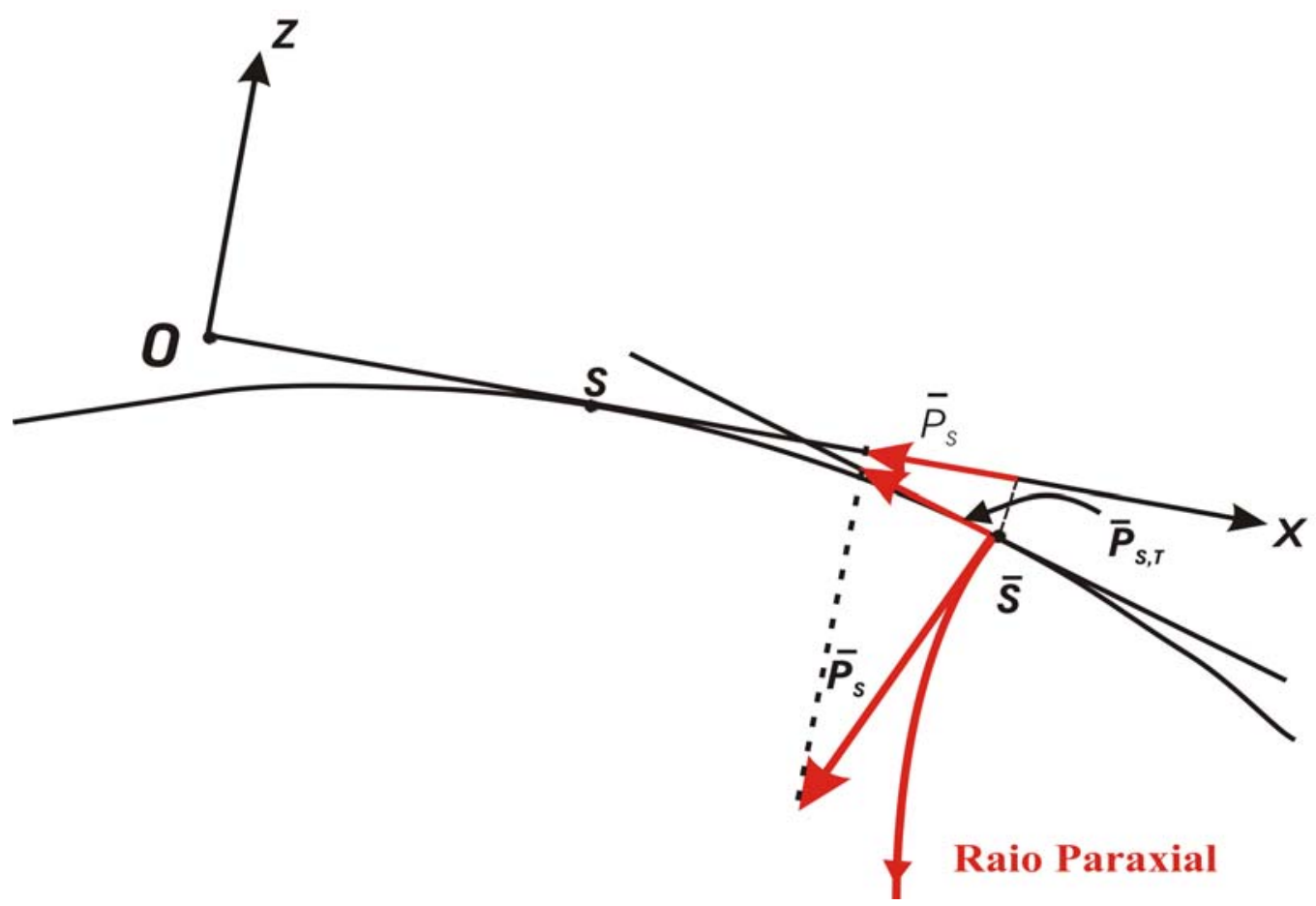

Figura 4.2- Construção das projeções do vetor vagarosidade $\overline{\mathbf{p}}_{\mathrm{s}}$ : O vetor vagarosidade $\overline{\mathbf{p}}_{\mathbf{s}}$ é primeiramente projetado na linha tangente à superfície anterior no ponto $\overline{\mathrm{S}}$. Em seguida, o vetor resultante $\overline{\mathbf{p}}_{\mathrm{S}, \mathbf{T}}$ é projetado na linha tangente à superfície que coincide com o eixo $\mathrm{X}$ do sistema de coordenadas $(\mathrm{X}, \mathrm{Z})$.

As quantidades que descrevem o raio central e o paraxial nas superfícies anterior e posterior estão resumidas na tabela abaixo. As quantidades em negrito correspondem aos vetores posição e vagarosidade do raio. As quantidades em parênteses correspondem aos vetores projeção representados apenas por seus componentes no eixo $\mathrm{X}$ visto que os mesmos não tem componentes na direção do eixo $\mathrm{Z}$. 


\begin{tabular}{l|l|l}
\hline & Raio central & Raio paraxial \\
\hline Superfície anterior & $\mathbf{x}_{\mathrm{S}}, \mathbf{p}_{\mathrm{S}},\left(\mathrm{x}_{\mathrm{S}}, \mathrm{p}_{\mathrm{S}}\right)$ & $\overline{\mathbf{x}}_{\mathrm{S}}, \overline{\mathbf{p}}_{\mathrm{s}},\left(\overline{\mathrm{x}}_{\mathrm{S}}, \overline{\mathrm{p}}_{\mathrm{S}}\right)$ \\
\hline Superfície posterior & $\mathbf{x}_{\mathrm{G}}, \mathbf{p}_{\mathrm{G}},\left(\mathrm{x}_{\mathrm{G}}, \mathrm{p}_{\mathrm{G}}\right)$ & $\overline{\mathbf{x}}_{\mathrm{G}}, \overline{\mathbf{p}}_{\mathrm{G}},\left(\overline{\mathrm{x}}_{\mathrm{G}}, \overline{\mathrm{p}}_{\mathrm{G}}\right)$ \\
\hline
\end{tabular}

\section{2- MATRIZ PROPAGADORA DO RAIO}

Partindo do pressuposto que o raio central SG seja conhecido, onde o mesmo é formado por um raio transmitido desde a fonte $S$ na superfície anterior até o ponto de emergência $G$ na superfície posterior. Neste caso o raio paraxial $\overline{\mathrm{SG}}$ na vizinhança do raio central pode ser aproximadamente determinado pela teoria paraxial do raio. Segundo o formalismo de Bortfeld (1989) em 2D, o raio central pode ser descrito por meio de uma matriz propagadora do raio de ordem $2 \times 2$, determinada por:

$$
\underline{T}=\left(\begin{array}{ll}
A & B \\
C & D
\end{array}\right)
$$

onde, A, B,C,D são os elementos que caracterizam o raio central. A matriz propagadora $\underline{T}$ fixa uma relação linear entre os pares de vetores $\left(\Delta \mathrm{x}_{\mathrm{G}}, \Delta \mathrm{p}_{\mathrm{G}}\right)^{\mathrm{T}} \mathrm{e}\left(\Delta \mathrm{x}_{\mathrm{S}}, \Delta \mathrm{p}_{\mathrm{S}}\right)^{\mathrm{T}},($ Bortfeld ,1989 ). Esses pares de vetores descrevem completamente o raio paraxial no ponto inicial $\overline{\mathrm{S}}$ sobre a superfície anterior e no ponto final $\overline{\mathrm{G}}$ sobre a superfície posterior. A relação linear pode ser expressa da seguinte forma:

$$
\left(\begin{array}{c}
\Delta \mathrm{x}_{\mathrm{G}} \\
\Delta \mathrm{p}_{\mathrm{G}}
\end{array}\right)=\underline{\mathrm{T}}\left(\begin{array}{c}
\Delta \mathrm{x}_{\mathrm{S}} \\
\Delta \mathrm{p}_{\mathrm{S}}
\end{array}\right)
$$

ou ainda por:

$$
\begin{aligned}
& \Delta \mathrm{x}_{\mathrm{G}}=\mathrm{A} \Delta \mathrm{x}_{\mathrm{S}}+\mathrm{B} \Delta \mathrm{p}_{\mathrm{s}}, \\
& \Delta \mathrm{p}_{\mathrm{G}}=\mathrm{C} \Delta \mathrm{x}_{\mathrm{S}}+\mathrm{D} \Delta \mathrm{p}_{\mathrm{s}},
\end{aligned}
$$

em que,

$$
\begin{aligned}
& \Delta \mathrm{x}_{\mathrm{S}}=\overline{\mathrm{x}}_{\mathrm{S}}-\mathrm{x}_{\mathrm{S}} \\
& \Delta \mathrm{x}_{\mathrm{G}}=\overline{\mathrm{x}}_{\mathrm{G}}-\mathrm{x}_{\mathrm{G}},
\end{aligned}
$$


são os deslocamentos da fonte paraxial $\overline{\mathrm{S}}$ e do receptor paraxial $\overline{\mathrm{G}}$ ao longo do eixo $\mathrm{X}$ na superfície anterior e posterior com relação a fonte $S$ e o receptor $G$ do raio central, respectivamente, assim como

$$
\begin{aligned}
& \Delta \mathrm{p}_{\mathrm{s}}=\overline{\mathrm{p}}_{\mathrm{s}}-\mathrm{p}_{\mathrm{s}} \\
& \Delta \mathrm{p}_{\mathrm{G}}=\overline{\mathrm{p}}_{\mathrm{G}}-\mathrm{p}_{\mathrm{G}},
\end{aligned}
$$

são os desvios das componentes horizontais do vetor vagarosidade do raio paraxial com relação ao raio central.

Agora, substituindo a equação (4.5a) em (4.3a), obtém-se:

$$
\overline{\mathrm{p}}_{\mathrm{S}}=\mathrm{p}_{\mathrm{S}}+\mathrm{B}^{-1} \Delta \mathrm{x}_{\mathrm{G}}-\mathrm{B}^{-1} \mathrm{~A} \Delta \mathrm{x}_{\mathrm{S}} \text {. }
$$

Analogamente, se substituir (4.5b), (4.6a) em (4.3b), obtém-se:

$$
\overline{\mathrm{p}}_{\mathrm{G}}=\mathrm{p}_{\mathrm{G}}+\mathrm{C} \Delta \mathrm{x}_{\mathrm{S}}+\mathrm{DB}^{-1} \Delta \mathrm{x}_{\mathrm{G}}-\mathrm{DB}^{-1} \mathrm{~A} \Delta \mathrm{x}_{\mathrm{S}} .
$$

\subsection{1- Propriedade de simplecticidade da matriz $\underline{\mathrm{T}}$}

Esta propriedade é considerada uma propriedade global elementar do sistema sísmico (Bortfeld, 1989) e é aplicada na obtenção das aproximações dos tempos de trânsito de raios paraxiais (Bortfeld, 1989, Hubral et al., 1992), zona de Fresnel (Hubral et al., 1992, Hubral et al., 1993) e etc. Esta propriedade determina que o inverso da matriz propagadora $\underline{T}$ pode ser escrita como:

$$
\underline{\mathrm{T}}^{-1}=\left(\begin{array}{ll}
\mathrm{A} & \mathrm{B} \\
\mathrm{C} & \mathrm{D}
\end{array}\right)^{-1}=\left(\begin{array}{cc}
\mathrm{D} & -\mathrm{B} \\
-\mathrm{C} & \mathrm{A}
\end{array}\right),
$$

onde,

$$
\underline{\mathrm{TT}} \underline{-}^{-1}=\mathrm{I} \text { ou }\left(\begin{array}{ll}
\mathrm{A} & \mathrm{B} \\
\mathrm{C} & \mathrm{D}
\end{array}\right)\left(\begin{array}{cc}
\mathrm{D} & -\mathrm{B} \\
-\mathrm{C} & \mathrm{A}
\end{array}\right)=\left(\begin{array}{ll}
1 & 0 \\
0 & 1
\end{array}\right) .
$$

Assim, satisfazendo a relação (4.8) as matrizes propagadoras estabelecem propriedades de simplecticidade expressas pelas seguintes equações:

$$
\begin{aligned}
& \mathrm{CD}-\mathrm{DC}=0 \\
& \mathrm{BA}-\mathrm{AB}=0 \\
& \mathrm{AD}-\mathrm{BC}=1 \\
& \mathrm{DA}-\mathrm{CB}=1,
\end{aligned}
$$


implicando que $\underline{T}$ possui três elementos independentes (A, B e D), sendo que a relação (4.11) é usada para eliminar o elemento $\mathrm{C}$.

\subsection{2- Raio reverso}

Pelo teorema da reciprocidade estudado na teoria da elastodinâmica as posições das fontes e receptores podem ser invertidas sem qualquer alteração na trajetória do raio, ou seja, a onda sísmica que se propaga do ponto receptor ao ponto fonte segue a mesma trajetória do raio considerado, porém, com sentido oposto, definindo assim o chamado raio reverso.A matriz propagadora $\left(\underline{T}^{*}\right)$ deste raio reverso relaciona-se com a matriz propagadora do raio $(\underline{\mathrm{T}})$ através da seguinte expressão:

$$
\underline{\mathrm{T}}^{*}=\left(\begin{array}{ll}
\mathrm{A}^{*} & \mathrm{~B}^{*} \\
\mathrm{C}^{*} & \mathrm{D}^{*}
\end{array}\right)^{-1}=\left(\begin{array}{ll}
\mathrm{D} & \mathrm{B} \\
\mathrm{C} & \mathrm{A}
\end{array}\right) .
$$

Comparando as equações (4.13) e (4.7), nota-se que a matriz propagadora inversa $\underline{\mathrm{T}}^{-1}$ e a matriz propagadora do raio reverso $\underline{\mathrm{T}}^{*}$ não são as mesmas.

\subsection{3- Regra da cadeia}

Para a aplicação das matrizes propagadoras em problemas sísmicos de reflexão, é necessário definir uma propriedade fundamental denominada regra da cadeia, esta regra estabelece que para qualquer ponto $\mathrm{R}$ ao longo do raio central SG (Figura 4.3) a matriz propagadora $\underline{T}$ satisfaz a seguinte equação:

$$
\underline{\mathrm{T}}(\mathrm{G}, \mathrm{S})=\underline{\mathrm{T}}(\mathrm{G}, \mathrm{R}) \underline{\mathrm{T}}(\mathrm{R}, \mathrm{S}),
$$

onde, $\underline{T}(R, S)$ denota a matriz propagadora do primeiro ramo de raio $S R$ e $\underline{T}(G, R)$ do segundo ramo de raio $\mathrm{RG}$, as quais constrói o raio central SRG.

A equação (4.14) é válida para todos as posições do ponto $R$, não importando se o ponto $\mathrm{R}$ está localizado precisamente sobre uma interface refletora ou transmissora, ou até mesmo em uma interface fictícia introduzida arbitrariamente, podendo ou não coincidir com as interfaces refletora e transmissora. 


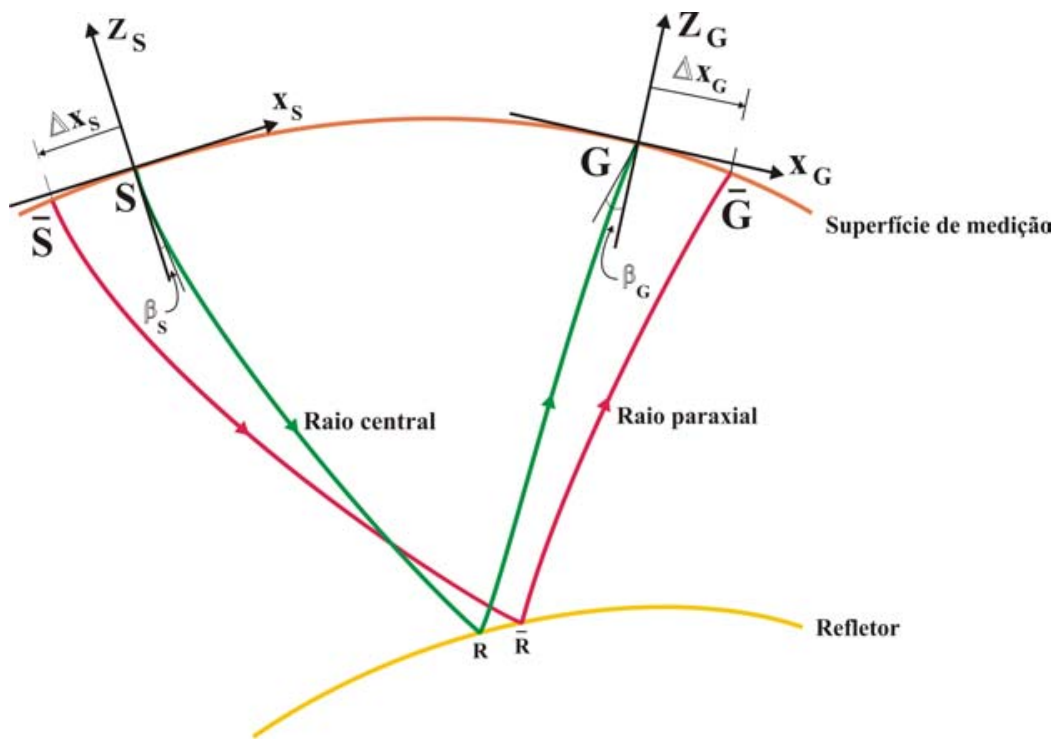

Figura 4.3- Modelo bidimensional para uma superfície de medição encurvada, contendo os raios central SRG e paraxial $\overline{\mathrm{S}} \overline{\mathrm{S}} \overline{\mathrm{S}}$, onde o ponto inicial $\mathrm{S}$ é a origem do eixo local $\mathrm{x}_{\mathrm{S}} \mathrm{e}$ o ponto final $G$ é a origem do eixo local $x_{G}$, sendo ambos tangentes a superfície de medição na fonte $\mathrm{S}$ e no receptor $\mathrm{G}$. (Modificado Chira et al., 2001)

\section{3- DERIVAÇÃO DO TEMPO DE TRÂNSITO PARAXIAL}

A matriz propagadora $\underline{T}$ é valida para raios arbitrários sem restrições no que diz respeito a trajetória de propagação dos raios, isto é, raios transmitidos ou refletidos. Assim, partindo deste pressuposto utilizaremos o formalismo da matriz propagadora $\underline{T}$ para derivar o tempo de trânsito do raio paraxial $\overline{\mathrm{S}} \overline{\mathrm{G}}$ refletido associado a um raio central SG também refletido (Figura 4.3). Esta derivação necessita de quantidades recorrentes do raio central SG definidas como sendo os ângulos que o raio central faz com as normais à superfície de medição nos pontos $\mathrm{S}$ e $\mathrm{G}$, e os três elementos independentes $\mathrm{A}, \mathrm{B}, \mathrm{D}$ da matriz $\underline{\mathrm{T}}$, além de escolhermos um sistema de coordenada local com origem no ponto inicial $S$ e um outro com origem no ponto final $G$ (Figura 4.3), sendo $\mathrm{x}_{\mathrm{S}}$ o eixo local tangente a superfície de medição no ponto inicial $\mathrm{S}$, analogamente, $x_{G}$ o eixo local tangente a superfície de medição no ponto final $G, \beta_{\mathrm{S}}$ e $\beta_{\mathrm{G}}$ são os ângulos que o raio central faz com as normais à superfície de medição nos pontos $\mathrm{S}$ e $\mathrm{G}$ com $\Delta \mathrm{x}_{\mathrm{S}}$ e $\Delta \mathrm{x}_{\mathrm{G}}$ sendo os deslocamentos da posição em relação a fonte $\mathrm{S}$ e o receptor $\mathrm{G}$. 
Portanto, com essas considerações e seguindo as linhas de Chira et al. (2001) será derivado o tempo de trânsito de raios paraxiais com afastamento-finito considerando uma linha de medição com topografia suave.

\subsection{1- Tempo de trânsito de um raio paraxial}

Nesta seção, será derivado o tempo de trânsito de um raio paraxial arbitrário associado a um raio central conhecido, assumindo a condição de que sempre possamos encontrar uma frente de onda que pertença a ambos os raios paraxial e central, referentes a uma mesma família de raios que satisfaçam a equação eikonal no que diz respeito a suas condições iniciais, com isso dando sentido a descrição de um raio paraxial associado a um raio central (Figura 4.4). De acordo com a (Figura 4.4) a diferença entre o tempo de trânsito de $S$ para $G, \tau(S, G)$, e o tempo de trânsito de $\overline{\mathrm{S}}$ para $\overline{\mathrm{G}}, \tau(\overline{\mathrm{S}}, \overline{\mathrm{G}})$ é expresso por:

$$
\mathrm{d} \tau=\tau(\overline{\mathrm{S}}, \overline{\mathrm{G}})-\tau(\mathrm{S}, \mathrm{G})=\mathrm{d} \tau_{\overline{\mathrm{G}}}-\mathrm{d} \tau_{\overline{\mathrm{S}}}
$$

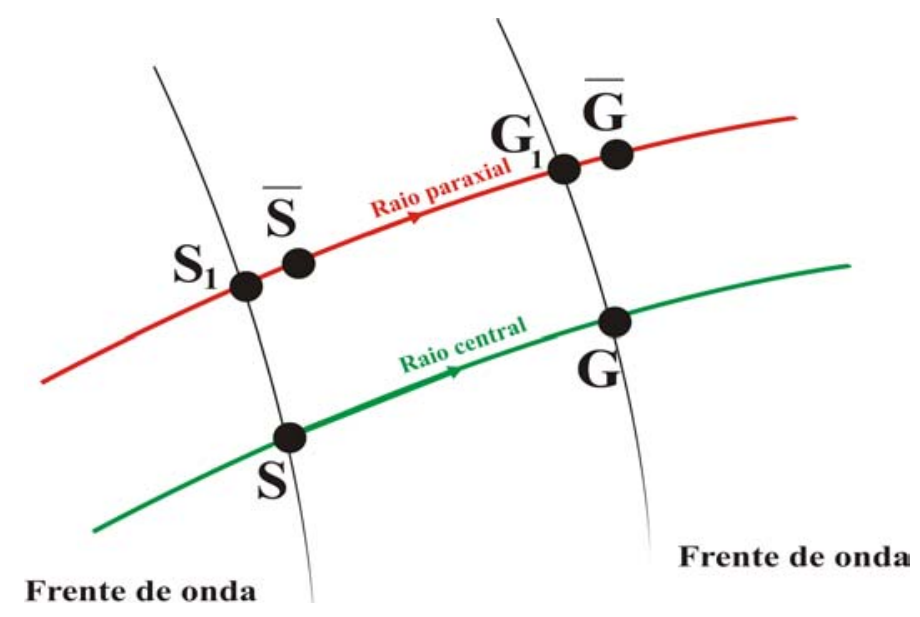

Figura 4.4- Raio paraxial $\overline{\mathrm{SG}}$ na vizinhança do raio central SG

onde $d \tau_{\overline{\mathrm{S}}}$ é o tempo de trânsito de $S_{1}$ para $\overline{\mathrm{S}}$ e $\mathrm{d} \tau_{\overline{\mathrm{G}}}$ o tempo de trânsito de $\mathrm{G}_{1}$ para $\overline{\mathrm{G}}$.

A mudança no tempo de trânsito paraxial devido uma perturbação infinitésima $\mathrm{d}\left(\overline{\mathbf{x}}_{\mathbf{S}}-\mathbf{x}_{\mathbf{S 1}}\right)$ no ponto fonte $\overline{\mathrm{S}}$ é determinado por:

$$
\mathrm{d} \tau_{\overline{\mathrm{s}}}=\overline{\mathbf{p}}_{\mathrm{s}} \cdot \mathrm{d}\left(\overline{\mathbf{x}}_{\mathrm{S}}-\mathbf{x}_{\mathrm{s} 1}\right)
$$


sob a condição de que $\overline{\mathbf{p}}_{\mathbf{s}}=\mathbf{p}_{\mathrm{s} 1}$. Por outro lado tem-se que:

$$
\mathrm{d} \tau_{\overline{\mathrm{s}}}=\overline{\mathbf{p}}_{\mathrm{s}} \cdot \mathrm{d}\left(\overline{\mathbf{x}}_{\mathrm{s}}-\mathbf{x}_{\mathrm{s}}\right),
$$

visto que $\overline{\mathbf{p}}_{\mathrm{S}}$ é paralelo a $\mathrm{d}\left(\overline{\mathbf{x}}_{\mathbf{S}}-\mathbf{x}_{\mathbf{S 1}}\right)$. Analogamente, as equação (4.16) e (4.17) são sugeridas para uma perturbação no ponto receptor $\overline{\mathrm{G}}$. Dessa forma, com base na relação (4.17) e levando em conta o formalismo de Bortfeld (1989) considerando as superfícies anterior e posterior nos pontos $\overline{\mathrm{S}}$ e $\overline{\mathrm{G}}$, a diferença do tempo de trânsito (4.15) pode ser rescrita na forma:

$$
\mathrm{d} \tau=\overline{\mathbf{p}}_{\mathrm{G}} \cdot \mathrm{d}\left(\overline{\mathbf{x}}_{\mathbf{G}}-\mathbf{x}_{\mathbf{G}}\right)-\overline{\mathbf{p}}_{\mathrm{S}} \cdot \mathrm{d}\left(\overline{\mathbf{x}}_{\mathrm{S}}-\mathbf{x}_{\mathrm{S}}\right) \text {. }
$$

A equação (4.18) é a equação de Hamilton para o traçamento de raio entre dois pontos com um formalismo matemático alternativo do princípio de Fermat, informando que a primeira derivada do tempo de trânsito na direção vertical do raio desaparece.

Portanto, como o objetivo é obter uma aproximação de segunda ordem do tempo de trânsito de um raio paraxial, faz-se necessário considerar somente termos lineares de $\Delta \mathrm{x}_{\mathrm{S}}$ e $\Delta \mathrm{x}_{\mathrm{G}}$ na equação (4.18), com o intuito de reduzir os vetores da mesma a seus valores escalares. Para tal feito vamos assumir as seguintes considerações dadas por Bortfeld (1989), ou seja:

(1) As superfícies anterior e posterior na vizinhança de $S$ e $G$, respectivamente, são descritas por $\mathrm{Z}=\mathrm{f}(\mathrm{x})$, sendo a qual, derivável até segunda ordem;

(2) Na superfície anterior os pontos que são infinitesimalmente próximos a fonte paraxial $\overline{\mathrm{S}}$ são descritos por $\left(\overline{\mathbf{x}}_{\mathbf{S}}-\mathbf{x}_{\mathbf{S}}\right)+\mathrm{d}\left(\overline{\mathbf{x}}_{\mathbf{S}}-\mathbf{x}_{\mathbf{S}}\right)$, sendo

$$
\mathrm{d}\left(\overline{\mathbf{x}}_{\mathrm{S}}-\mathbf{x}_{\mathrm{S}}\right)=\left(\Delta \mathrm{x}_{\mathrm{S}}, \mathrm{f}_{\mathrm{x}} \Delta \mathrm{x}_{\mathrm{S}}\right)^{\mathrm{T}}=\left(\begin{array}{c}
\mathrm{d}\left(\Delta \mathrm{x}_{\mathrm{S}}\right) \\
\mathrm{f}_{\mathrm{x}} \mathrm{d}\left(\Delta \mathrm{x}_{\mathrm{S}}\right)
\end{array}\right),
$$

onde $f_{x}$ é a primeira derivada de $f(x)$ para $x=\bar{x}_{S}$ e $\Delta x_{S}$ é a coordenada $x$ pertencente a $\mathrm{d}\left(\overline{\mathrm{x}}_{\mathrm{S}}-\mathrm{x}_{\mathrm{S}}\right)$, resultado da projeção de $\mathrm{d}\left(\overline{\mathbf{x}}_{\mathrm{S}}-\mathbf{x}_{\mathrm{S}}\right)$ sobre a tangente da superfície em $\mathrm{S}$, o qual caracteriza o eixo $\mathrm{X}$ do sistema de coordenada local da superfície anterior. Analogamente os pontos que são infinitesimalmente próximos ao receptor paraxial $\overline{\mathrm{G}}$ são descritos por $\mathrm{d}\left(\overline{\mathbf{x}}_{\mathbf{G}}-\mathbf{x}_{\mathbf{G}}\right)=\left(\mathrm{d}\left(\Delta \mathrm{x}_{\mathrm{G}}\right), \mathrm{f}_{\mathrm{x}} \mathrm{d}\left(\Delta \mathrm{x}_{\mathrm{G}}\right)\right)^{\mathrm{T}}=\left(\begin{array}{c}\mathrm{d}\left(\Delta \mathrm{x}_{\mathrm{G}}\right) \\ \mathrm{f}_{\mathrm{x}} \mathrm{d}\left(\Delta \mathrm{x}_{\mathrm{G}}\right)\end{array}\right),(4.19 .1)$ com $\mathrm{f}_{\mathrm{x}}$ sendo a primeira derivada de $\mathrm{f}(\mathrm{x})$ para $\mathrm{x}=\overline{\mathrm{x}}_{\mathrm{G}}$ e $\Delta \mathrm{x}_{\mathrm{G}}$ sendo a coordenada $\mathrm{x}$ pertencente a $\mathrm{d}\left(\overline{\mathbf{x}}_{\mathrm{G}}-\mathbf{x}_{\mathrm{G}}\right)$, resultado da projeção 
de $\mathrm{d}\left(\overline{\mathbf{x}}_{\mathbf{G}}-\mathbf{x}_{\mathbf{G}}\right)$ sobre a tangente da superfície em $\mathrm{G}$, caracterizando o eixo $\mathrm{X}$ do sistema de coordenada local da superfície posterior;

(3) A projeção do vetor vagarosidade $\overline{\mathbf{p}}_{\mathbf{S}}$ na tangente em $\overline{\mathrm{S}}$ da superfície anterior $\overline{\mathbf{p}}_{\mathbf{S}, \mathbf{T}}$ (Figura 4.2) é dado por :

$$
\overline{\mathbf{p}}_{\mathrm{s}, \mathbf{T}}=\left(\overline{\mathrm{p}}_{\mathrm{S}}, \mathrm{f}_{\mathrm{x}} \overline{\mathrm{p}}_{\mathrm{S}}\right)^{\mathrm{T}}=\left(\begin{array}{c}
\overline{\mathrm{p}}_{\mathrm{S}} \\
\mathrm{f}_{\mathrm{x}} \overline{\mathrm{p}}_{\mathrm{S}}
\end{array}\right)
$$

onde $\overline{\mathrm{p}}_{\mathrm{S}}$ é a coordenada $\mathrm{x}$ pertencente a $\overline{\mathbf{p}}_{\mathbf{s}, \mathbf{T}}$, resultado da projeção de $\overline{\mathbf{p}}_{\mathbf{s}, \mathbf{T}}$ sobre a superfície em S, de acordo com a Figura 4.2. Analogamente $\overline{\mathbf{p}}_{\mathbf{G}, \mathbf{T}}=\left(\overline{\mathrm{p}}_{\mathrm{G}}, \mathrm{f}_{\mathrm{x}} \overline{\mathrm{p}}_{\mathrm{G}}\right)^{\mathrm{T}}=\left(\begin{array}{c}\overline{\mathrm{p}}_{\mathrm{G}} \\ \mathrm{f}_{\mathrm{x}} \overline{\mathrm{p}}_{\mathrm{G}}\end{array}\right)(4.20 .1)$, na tangente em $\overline{\mathrm{G}}$ da superfície posterior, sendo $\overline{\mathrm{p}}_{\mathrm{G}}$ a coordenada $\mathrm{x}$ pertencente $\mathrm{a} \overline{\mathbf{p}}_{\mathbf{G}, \mathbf{T}}$, resultado da projeção de $\overline{\mathbf{p}}_{\mathbf{G}, \mathbf{T}}$ sobre a superfície em $\mathrm{G}$.

Agora, assumindo que os vetores deslocamento $\mathrm{d}\left(\overline{\mathbf{x}}_{\mathbf{S}}-\mathbf{x}_{\mathbf{S}}\right)$ e $\mathrm{d}\left(\overline{\mathbf{x}}_{\mathbf{G}}-\mathbf{x}_{\mathbf{G}}\right)$ são infinitésimos para pontos vizinhos de $\overline{\mathrm{S}}$ e $\overline{\mathrm{G}}$, respectivamente, sendo os mesmos tangentes à superfície anterior em $\overline{\mathrm{S}}$ e à superfície posterior em $\overline{\mathrm{G}}$ por uma aproximação linear, implicando que:

$$
\overline{\mathbf{p}}_{\mathbf{G}} \cdot \mathrm{d}\left(\overline{\mathbf{x}}_{\mathbf{G}}-\mathbf{x}_{\mathbf{G}}\right)=\overline{\mathbf{p}}_{\mathbf{G}, \mathbf{T}} \cdot \mathrm{d}\left(\overline{\mathbf{x}}_{\mathbf{G}}-\mathbf{x}_{\mathbf{G}}\right) \text { e } \overline{\mathbf{p}}_{\mathrm{S}} \cdot \mathrm{d}\left(\overline{\mathbf{x}}_{\mathbf{S}}-\mathbf{x}_{\mathbf{S}}\right)=\overline{\mathbf{p}}_{\mathbf{S}, \mathbf{T}} \cdot \mathrm{d}\left(\overline{\mathbf{x}}_{\mathbf{S}}-\mathbf{x}_{\mathbf{S}}\right) \text {. }
$$

Assim, inserindo as equações (4.21) em (4.18), obtém-se:

$$
\mathrm{d} \tau=\overline{\mathbf{p}}_{\mathbf{G}, \mathbf{T}} \cdot \mathrm{d}\left(\overline{\mathbf{x}}_{\mathbf{G}}-\mathbf{x}_{\mathbf{G}}\right)-\overline{\mathbf{p}}_{\mathbf{S}, \mathbf{T}} \cdot \mathrm{d}\left(\overline{\mathbf{x}}_{\mathbf{S}}-\mathbf{x}_{\mathbf{S}}\right) \text {. }
$$

Portanto, substituindo na equação (4.22) as considerações dadas por Bortfeld (1989), ou seja, termos lineares de $\Delta \mathrm{x}_{\mathrm{S}}$ e $\Delta \mathrm{x}_{\mathrm{G}}$ em que os produtos das segundas componentes dos vetores em (4.22) são de segunda ordem, sendo então negligenciadas, obtém-se, então equação escalar de Hamilton (Apêndice A):

$$
\mathrm{d} \tau=\overline{\mathrm{p}}_{\mathrm{G}} \mathrm{d}\left(\Delta \mathrm{x}_{\mathrm{G}}\right)-\overline{\mathrm{p}}_{\mathrm{S}} \mathrm{d}\left(\Delta \mathrm{x}_{\mathrm{S}}\right)
$$

Agora o próximo passo é substituir as equações (4.6) na equação (4.23), obtendo-se:

$$
\mathrm{d} \tau=\left[\mathrm{p}_{\mathrm{G}}+\Delta \mathrm{x}_{\mathrm{S}}\left(\mathrm{C}-\mathrm{DB}^{-1} \mathrm{~A}\right)+\mathrm{DB}^{-1} \Delta \mathrm{x}_{\mathrm{G}}\right] \mathrm{d}\left(\Delta \mathrm{x}_{\mathrm{G}}\right)-\left[\mathrm{p}_{\mathrm{S}}+\mathrm{B}^{-1} \Delta \mathrm{x}_{\mathrm{G}}-\mathrm{B}^{-1} \mathrm{~A} \Delta \mathrm{x}_{\mathrm{S}}\right] \mathrm{d}\left(\Delta \mathrm{x}_{\mathrm{S}}\right) .
$$


Com o uso da propriedade da simplecticidade $\mathrm{AD}-\mathrm{BC}=1$ e sabendo que $\mathrm{p}_{\mathrm{G}}, \mathrm{p}_{\mathrm{s}}, \mathrm{A}, \mathrm{B}$, C e D são escalares constantes e $\Delta \mathrm{x}_{\mathrm{S}}, \Delta \mathrm{x}_{\mathrm{G}}$ as variáveis de integração, podemos aplicar integrais em ambos os membros da equação (4.24) (Apêndice A), obtendo finalmente a equação do tempo de trânsito ao longo do raio paraxial $\overline{\mathrm{SG}}$ na vizinhança de um raio central SG com tempo de trânsito $\mathrm{t}_{\mathrm{SG}}$ :

$$
\tau\left(\Delta \mathrm{x}_{\mathrm{S}}, \Delta \mathrm{x}_{\mathrm{G}}\right)=\mathrm{t}_{\mathrm{SG}}+\mathrm{p}_{\mathrm{G}} \Delta \mathrm{x}_{\mathrm{G}}-\mathrm{p}_{\mathrm{S}} \Delta \mathrm{x}_{\mathrm{S}}-\Delta \mathrm{x}_{\mathrm{S}} \mathrm{B}^{-1} \Delta \mathrm{x}_{\mathrm{G}}+\frac{1}{2} \Delta \mathrm{x}_{\mathrm{S}} \mathrm{B}^{-1} \mathrm{~A} \Delta \mathrm{x}_{\mathrm{S}}+\frac{1}{2} \Delta \mathrm{x}_{\mathrm{G}} \mathrm{DB}^{-1} \Delta \mathrm{x}_{\mathrm{G}} .
$$

A expressão acima é a aproximação de segunda ordem em $\Delta \mathrm{x}_{\mathrm{S}}$ e $\Delta \mathrm{x}_{\mathrm{G}}$ do tempo de trânsito de raios paraxiais associados a um raio central arbitrário. Ursin (1982) mostrou que os tempos de trânsito das reflexões se ajustam melhor por funções de tempo hiperbólicas do que parabólicas. Portanto, considerando o quadrado dos tempos de trânsito da equação (4.25) e negligenciando os termos superiores de segunda ordem nos deslocamentos $\Delta \mathrm{x}_{\mathrm{S}}, \Delta \mathrm{x}_{\mathrm{G}}$, obtemos a aproximação hiperbólica de raios paraxiais expressa por:

$$
\tau^{2}\left(\Delta \mathrm{x}_{\mathrm{S}}, \Delta \mathrm{x}_{\mathrm{G}}\right)=\left[\mathrm{t}_{\mathrm{SG}}+\mathrm{p}_{\mathrm{G}} \Delta \mathrm{x}_{\mathrm{G}}-\mathrm{p}_{\mathrm{S}} \Delta \mathrm{x}_{S}\right]^{2}+2 \mathrm{t}_{\mathrm{SG}}\left[-\Delta \mathrm{x}_{S} \mathrm{~B}^{-1} \Delta \mathrm{x}_{G}+\frac{1}{2} \Delta \mathrm{x}_{S} \mathrm{~B}^{-1} \mathrm{~A} \Delta \mathrm{x}_{S}+\frac{1}{2} \Delta \mathrm{x}_{G} \mathrm{DB}^{-1} \Delta \mathrm{x}_{G}\right]
$$

\section{4- INFLUÊNCIA DA TOPOGRAFIA DE AQUISIÇÃO COM NÃO-HOMOGENEIDADE NO MODELO}

A matriz propagadora de superfície para superfície $\underline{T}$, que se refere a um raio central fixo, é uma conveniente formulação para descrever o tempo de trânsito de um raio paraxial em função de seus elementos. A matriz propagadora $\underline{T}$ é uma matriz $2 \times 2$ com três componentes independentes incorporando as propriedades globais de propagação do meio,ou seja, geometria de aquisição, características da superfície de medição e da velocidade do meio nos pontos inicial $\mathrm{S}$ e final $\mathrm{G}$ do raio central, (Figura 4.3). Em outras palavras a matriz propagadora de superfície para superfície será dependente da velocidade próxima à superfície e de seu gradiente, bem como da curvatura da superfície de medição nos pontos inicial e final do raio central. Seguindo (Červený, 2001), considera-se a superfície de medição nas proximidade de S e G do raio central, na forma quadrática (parabólica), como segue: 


$$
\mathrm{z}_{\mathrm{S}}=-\frac{1}{2} \mathrm{~K}_{\mathrm{S}} \mathrm{x}_{\mathrm{S}}^{2} \text { e } \mathrm{z}_{\mathrm{G}}=-\frac{1}{2} \mathrm{~K}_{\mathrm{G}} \mathrm{x}_{\mathrm{G}}^{2},
$$

onde $\mathrm{x}_{\mathrm{S}}, \mathrm{z}_{\mathrm{S}}$ são as direções das coordenadas horizontal (tangencial) e vertical (normal) no sistema de coordenada local com origem no ponto fonte $\mathrm{S}, \mathrm{K}_{\mathrm{S}}$ a curvatura da superfície de medição no ponto $\mathrm{S}$ (Figura 4.3). Uma definição similar é dada para $\mathrm{x}_{\mathrm{G}}, \mathrm{z}_{\mathrm{G}}$ e $\mathrm{K}_{\mathrm{G}}$ (Figura 4.3), onde a escolha do sinal negativo na equação (4.27) é arbitrária.

Portanto, para determinar a dependência dos elementos da matriz propagadora $\underline{T} \mathrm{em}$ função das propriedades da superfície de medição e das velocidades próximas à superfície em $\mathrm{S}$ e $\mathrm{G}$, é necessário relacionar esta matriz com uma matriz propagadora $\Pi$ centrada no raio referente ao mesmo raio central expressa de forma semelhante a matriz $\underline{\mathrm{T}}$, ou seja, (Červený, 2001):

$$
\Pi=\left(\begin{array}{ll}
\mathrm{Q}_{1} & \mathrm{Q}_{2} \\
\mathrm{P}_{1} & \mathrm{P}_{2}
\end{array}\right),
$$

onde seus elementos são escalares, relacionados através da propriedade de simplecticidade, $\mathrm{Q}_{1} \mathrm{P}_{2}-\mathrm{Q}_{2} \mathrm{P}_{1}=1$.

Quando a superfície de aquisição na vizinhança de S e G pode ser representada conforme (4.31), considerando somente variações de velocidade de primeira ordem na vizinhança de $\mathrm{S}$ e $\mathrm{G}$, a relação da matriz $\Pi$ com a matriz $\underline{T}$ é dada pela seguinte relação (Červený ,2001, equação (4.4.90) com uma notação diferente:

$$
\mathrm{T}(\mathrm{G}, \mathrm{S})=\mathrm{Y}(\mathrm{G}) \Pi(\mathrm{G}, \mathrm{S}) \mathrm{Y}^{-1}(\mathrm{~S}),
$$

onde (Červený, 2001, equação (4.13.21) com uma notação diferente), tem-se:

$$
\mathrm{Y}^{-1}(\mathrm{~S})=\epsilon_{\mathrm{S}}\left(\begin{array}{cc}
\cos \beta_{\mathrm{S}} & 0 \\
-\left(\frac{\mathrm{E}_{\mathrm{S}}}{\cos \beta_{\mathrm{S}}}-\epsilon_{\mathrm{S}} \frac{\mathrm{K}_{\mathrm{S}}}{\mathrm{v}_{\mathrm{S}}}\right) & \frac{1}{\cos \beta_{\mathrm{S}}}
\end{array}\right)
$$

$\mathrm{e}$

$$
Y(G)=\epsilon_{G}\left(\begin{array}{cc}
\frac{1}{\cos \beta_{G}} & 0 \\
\frac{E_{G}}{\cos \beta_{G}}-\epsilon_{G} \frac{K_{G}}{v_{G}} & \cos \beta_{G}
\end{array}\right),
$$


com $\mathrm{Y}(\mathrm{G})$ e $\mathrm{Y}^{-1}(\mathrm{~S})$, constituindo uma relação dependente apenas das propriedades da superfície de medição com a camada no topo na vizinhança de S e G, tendo:

$$
\operatorname{det}[\mathrm{Y}(\mathrm{G})]=\operatorname{det}\left[\mathrm{Y}^{-1}(\mathrm{~S})\right]=1 \text {. }
$$

$\mathrm{Na}$ equação (4.30), $\mathrm{v}_{\mathrm{S}}$ e $\mathrm{K}_{\mathrm{S}}$ definem a velocidade do meio e a curvatura da superfície de medição em $\mathrm{S}$, respectivamente, do mesmo modo na equação (4.31), $\mathrm{v}_{\mathrm{G}}$ e $\mathrm{K}_{\mathrm{G}}$ quantidades análogas no ponto $\mathrm{G}$. Os fatores $\epsilon_{\mathrm{S}} \mathrm{e} \in_{\mathrm{G}}$ são as funções indicadoras definidas como:

$$
\epsilon_{\mathrm{S}}=\operatorname{sgn}\left(\mathrm{p}_{\mathrm{S}} \cdot \mathrm{n}_{\mathrm{S}}\right) \text { e } \in_{\mathrm{G}}=\operatorname{sgn}\left(\mathrm{p}_{\mathrm{G}} \cdot \mathrm{n}_{\mathrm{G}}\right),
$$

onde

$$
\operatorname{sgn}(\mathrm{A})=\left\{\begin{array}{l}
-1, \mathrm{~A}<0 \\
+1, \mathrm{~A}>0
\end{array} .\right.
$$

$\mathrm{O}$ fator $\epsilon_{\mathrm{S}}$ (análogo para $\epsilon_{\mathrm{G}}$ ) indica a direção normal à superfície de medição, $\mathrm{n}_{\mathrm{S}}$ em $\mathrm{S}$ (análogo para $\mathrm{n}_{\mathrm{G}}$ em $\mathrm{G}$ ) com relação da vagarosidade $\mathrm{p}_{\mathrm{S}}$ em $\mathrm{S}$ (análogo para $\mathrm{p}_{\mathrm{G}}$ em $\mathrm{G}$ ), assim, assumindo o sentido da normal para fora da superfície em ambos os pontos $\mathrm{S}$ e $\mathrm{G}$ temos:

$$
\epsilon_{\mathrm{S}}=-1 \mathrm{e} \in_{\mathrm{G}}=1 \text {. }
$$

Os termos $E_{S}$ e $E_{G}$ das equações (4.30) e (4.31) são denominados fatores de nãohomogeneidade ou heterogeneidade, indicando as variações de primeira ordem da velocidade nas proximidades dos pontos inicial S e final $\mathrm{G}$, respectivamente. Eles são definidos por Červený (2001), equação (4.13.20):

$$
\mathrm{E}_{\mathrm{S}}=-\frac{\operatorname{sen} \beta_{\mathrm{S}}}{\mathrm{v}_{\mathrm{S}}^{2}}\left[\left(1+\cos ^{2} \beta_{\mathrm{S}}\right)\left(\partial_{1} \mathrm{v}\right)_{\mathrm{S}}+\epsilon_{\mathrm{S}} \cos \beta_{\mathrm{S}} \operatorname{sen} \beta_{\mathrm{S}}\left(\partial_{3} \mathrm{v}\right)_{\mathrm{S}}\right]
$$

e

$$
\mathrm{E}_{\mathrm{G}}=-\frac{\operatorname{sen} \beta_{\mathrm{G}}}{\mathrm{v}_{\mathrm{G}}^{2}}\left[\left(1+\cos ^{2} \beta_{\mathrm{G}}\right)\left(\partial_{1} \mathrm{v}\right)_{\mathrm{G}}-\in_{\mathrm{G}} \cos \beta_{\mathrm{G}} \operatorname{sen} \beta_{\mathrm{G}}\left(\partial_{3} \mathrm{v}\right)_{\mathrm{G}}\right]
$$

onde $\left(\partial_{1} \mathrm{v}\right)_{\mathrm{S}}$ e $\left(\partial_{3} \mathrm{v}\right)_{\mathrm{S}}$ definem as componentes do gradiente de velocidade do meio no ponto inicial $\mathrm{S}$, analogamente é definido no ponto final $\mathrm{G}$ as quantidades $\left(\partial_{1} \mathrm{v}\right)_{\mathrm{G}}$ e $\left(\partial_{3} \mathrm{v}\right)_{\mathrm{G}}$. Finalmente, substituindo as equações (4.30) e (4.31) na equação (4.29), obtém-se os elementos $\{A, B, C, D\}$ da matriz propagadora $\underline{T}$ em função dos elementos equivalentes $\left\{\mathrm{P}_{1}, \mathrm{Q}_{1}, \mathrm{P}_{2}, \mathrm{Q}_{2}\right\}$ da matriz propagadora centrada no raio $\Pi$, ou seja: 


$$
\left\{\begin{array}{c}
-\frac{1}{\mathrm{~B}}=\frac{\cos \beta_{\mathrm{S}} \cos \beta_{\mathrm{G}}}{\mathrm{Q}_{2}} \\
\frac{\mathrm{A}}{2 \mathrm{~B}}=\left(\frac{\mathrm{Q}_{1}}{\mathrm{Q}_{2}}\right) \cos ^{2} \beta_{\mathrm{S}}-\frac{\cos \beta_{\mathrm{S}}}{\mathrm{v}_{\mathrm{S}}} \mathrm{K}_{\mathrm{S}}-\mathrm{E}_{\mathrm{S}} \\
\frac{\mathrm{D}}{2 \mathrm{~B}}=\left(\frac{\mathrm{P}_{2}}{\mathrm{Q}_{2}}\right) \cos ^{2} \beta_{\mathrm{G}}-\frac{\cos \beta_{\mathrm{G}}}{\mathrm{v}_{\mathrm{G}}} \mathrm{K}_{\mathrm{G}}+\mathrm{E}_{\mathrm{G}}
\end{array}\right.
$$

\section{5- CASO DO RAIO CENTRAL COM AFASTAMNETO-NULO (AN)}

Considerando-se o caso em que a fonte e o receptor coincidem, ou seja, o raio central é um raio normal à equação (4.26) simplifica-se substancialmente, essas simplificações acontecem pelo fato de que num raio de reflexão normal as trajetórias que se propagam e emergem mudam suas direções tendo com isso duas conseqüências imediatas:

(1) As direções do raio de incidência nos pontos fonte-receptor coincidentes são opostas, tendo como implicação dois ângulos correspondentes simétricos, ou seja,

$$
\beta_{\mathrm{S}}=-\beta_{\mathrm{G}}=\beta_{0},
$$

(2) Pelo fato do raio de reflexão com afastamento-nulo (AN) coincidir com seu raio reverso, suas matrizes propagadoras superfície para superfície devem também coincidir.

A matriz propagadora de um raio de reflexão com afastamento-nulo (AN) é expressa por:

$$
\underline{T}_{A N}=\left(\begin{array}{ll}
A & B \\
C & D
\end{array}\right)=\left(\begin{array}{ll}
D & B \\
C & A
\end{array}\right)=\underline{T}_{A N}^{*}, \text { em que } A D-B C=1 \text { com a propriedade adicional } A=D \text {, }
$$

o qual implica que a matriz propagadora $\underline{I}_{\mathrm{AN}}$ tem dois valores independentes.

Definindo as coordenadas ponto-médio $\left(\mathrm{x}_{\mathrm{m}}\right)$ e meio-afastamento $(\mathrm{h})$ como sendo:

$$
\mathrm{x}_{\mathrm{m}}=\frac{\Delta \mathrm{x}_{\mathrm{S}}+\Delta \mathrm{x}_{\mathrm{G}}}{2}, \mathrm{~h}=\frac{\Delta \mathrm{x}_{\mathrm{G}}-\Delta \mathrm{x}_{\mathrm{S}}}{2},
$$

e introduzindo (4.39), (4.40) e (4.41) na fórmula tempo de trânsito em sua forma hiperbólica (4.26), obtém-se:

$$
\tau_{\mathrm{AN}}^{2}=\left(\mathrm{t}_{0}+2 \frac{\operatorname{sen} \beta_{0}}{\mathrm{v}_{0}} \mathrm{x}_{\mathrm{m}}\right)^{2}+2 \mathrm{t}_{0}\left(\left[\frac{\mathrm{A}-1}{\mathrm{~B}}\right] \mathrm{x}_{\mathrm{m}}^{2}+\left[\frac{\mathrm{A}+1}{\mathrm{~B}}\right] \mathrm{h}^{2}\right),
$$


onde, $p_{S}=-p_{G}=p_{0}=\frac{\operatorname{sen} \beta_{0}}{v_{0}}$.

De acordo com Bortfeld (1989) e Hubral (1983), a matriz propagadora centrada no raio $\prod_{\mathrm{AN}}$ em relação ao raio normal é expressa por:

$$
\Pi_{\mathrm{AN}}=\left(\begin{array}{ll}
\mathrm{Q}_{1} & \mathrm{Q}_{2} \\
\mathrm{P}_{1} & \mathrm{P}_{2}
\end{array}\right)
$$

onde os coeficientes de segunda ordem $\left[\frac{\mathrm{A}-1}{\mathrm{~B}}\right]$ e $\left[\frac{\mathrm{A}+1}{\mathrm{~B}}\right]$ podem ser expressos em termos dos elementos da matriz $\prod_{\mathrm{AN}}$, segundo Červený (2001), usando as equações (4.38), ou seja:

$$
\begin{aligned}
& \frac{\mathrm{A}-1}{\mathrm{~B}}=\left(\frac{\mathrm{Q}_{1}+1}{\mathrm{Q}_{2}}\right) \cos ^{2} \beta_{0}-\frac{\cos \beta_{0}}{\mathrm{~V}_{0}} \mathrm{~K}_{0}-\mathrm{E}_{0}, \\
& \frac{\mathrm{A}+1}{\mathrm{~B}}=\left(\frac{\mathrm{Q}_{1}-1}{\mathrm{Q}_{2}}\right) \cos ^{2} \beta_{0}-\frac{\cos \beta_{0}}{\mathrm{v}_{0}} \mathrm{~K}_{0}-\mathrm{E}_{0},
\end{aligned}
$$

onde,

$$
\mathrm{E}_{0}=\frac{-\operatorname{sen} \beta_{0}}{\mathrm{v}_{0}^{2}}\left[\left(1+\cos ^{2} \beta_{0}\right)\left(\partial_{1} \mathrm{v}\right)\left(\mathrm{S}_{0}\right)+\cos \beta_{0} \operatorname{sen} \beta_{0}\left(\partial_{3}\right)\left(\mathrm{S}_{0}\right)\right]
$$

sendo $\mathrm{E}_{0}$ o fator de heterogeneidade, $\left(\partial_{1}\right)\left(\mathrm{S}_{0}\right)$ e $\left(\partial_{3}\right)\left(\mathrm{S}_{0}\right)$ as componentes bidimensionais do gradiente de velocidade no meio $v$ na fonte-receptor coincidentes em $\mathrm{S}=\mathrm{G}=\mathrm{S}_{0}$.

Para o caso de uma situação com afastamento-nulo (AN) é possível expressar os elementos da matriz propagadora $\prod_{\mathrm{AN}}$ centrada no raio em função de duas curvaturas das frentes de ondas $\mathrm{K}_{\mathrm{PIN}}$ (ou raio de curvatura $\mathrm{R}_{\mathrm{PIN}}=\frac{1}{\mathrm{~K}_{\mathrm{PIN}}}$ ) da onda PIN e da $\mathrm{K}_{\mathrm{N}}$ (ou raio de curvatura $\mathrm{R}_{\mathrm{N}}=\frac{1}{\mathrm{~K}_{\mathrm{N}}}$ ) da onda $\mathrm{N}$, ambas medidas no ponto $\mathrm{X}_{0}$ (Apêndice C). Estas ondas são as ondas hipotéticas introduzidas inicialmente por Hubral (1983), sendo explicadas no Apêndice C, assim temos:

$$
\Pi_{\mathrm{AN}}=\frac{-1}{\mathrm{~K}_{\mathrm{PIN}}-\mathrm{K}_{\mathrm{N}}}\left(\begin{array}{cc}
\mathrm{K}_{\mathrm{PIN}}+\mathrm{K}_{\mathrm{N}} & 2 v_{0} \\
\left(2 \mathrm{~K}_{\mathrm{PIN}} \mathrm{K}_{\mathrm{N}}\right) / v_{0} & \mathrm{~K}_{\mathrm{PIN}}+\mathrm{K}_{\mathrm{N}}
\end{array}\right) .
$$

Agora, substituindo (4.47) em (4.44) e (4.45), obtém-se: 


$$
\begin{aligned}
& \frac{\mathrm{A}-1}{\mathrm{~B}}=\frac{\cos ^{2} \beta_{0}}{\mathrm{v}_{0}} \mathrm{~K}_{\mathrm{N}}-\frac{\cos \beta_{0}}{\mathrm{v}_{0}} \mathrm{~K}_{0}-\mathrm{E}_{0}, \\
& \frac{\mathrm{A}+1}{\mathrm{~B}}=\frac{\cos ^{2} \beta_{0}}{\mathrm{v}_{0}} \mathrm{~K}_{\mathrm{PIN}}-\frac{\cos \beta_{0}}{\mathrm{v}_{0}} \mathrm{~K}_{0}-\mathrm{E}_{0} .
\end{aligned}
$$

De maneira análoga a equação (4.27), assumiremos que na vizinhança de $\mathrm{X}_{0}$ a superfície de medição é representada pela parábola :

$$
\mathrm{z}=-\frac{1}{2} \mathrm{~K}_{0} \mathrm{x}^{2}
$$

onde, $\mathrm{K}_{0}$ é curvatura da superfície de medição no ponto $S=G$ (Figura B.1).

Finalmente, substituindo (4.48), (4.49) na equação (4.42), obtém-se a aproximação do tempo de trânsito SRC para uma linha de medição com topografia suave e gradiente de velocidade constante, ou seja:

$\tau^{2}\left(\mathrm{x}_{\mathrm{m}}, \mathrm{h}\right)=\left(\mathrm{t}_{0}+2 \frac{\operatorname{sen} \beta_{0}}{\mathrm{v}_{0}} \mathrm{x}_{\mathrm{m}}\right)^{2}+\frac{2 \mathrm{t}_{0}}{\mathrm{v}_{0}}\left(\mathrm{~K}_{\mathrm{N}} \cos ^{2} \beta_{0}-\cos \beta_{0} \mathrm{~K}_{0}-\mathrm{v}_{0} \mathrm{E}_{0}\right) \mathrm{x}_{\mathrm{m}}^{2}+\frac{2 \mathrm{t}_{0}}{\mathrm{v}_{0}}\left(\mathrm{~K}_{\mathrm{PIN}} \cos ^{2} \beta_{0}-\cos \beta_{0} \mathrm{~K}_{0}-\mathrm{v}_{0} \mathrm{E}_{0}\right) \mathrm{h}^{2}$

Uma equação particular da equação (4.51), previamente testada por Chira e Hubral (2001), faz-se $\mathrm{E}_{0}=0$ em (4.51), obtendo:

$$
\tau^{2}\left(\mathrm{x}_{\mathrm{m}}, \mathrm{h}\right)=\left(\mathrm{t}_{0}+2 \frac{\operatorname{sen} \beta_{0}}{\mathrm{v}_{0}} \mathrm{x}_{\mathrm{m}}\right)^{2}+\frac{2 \mathrm{t}_{0}}{\mathrm{v}_{0}}\left(\mathrm{~K}_{\mathrm{N}} \cos ^{2} \beta_{0}-\cos \beta_{0} \mathrm{~K}_{0}\right) \mathrm{x}_{\mathrm{m}}^{2}+\frac{2 \mathrm{t}_{0}}{\mathrm{v}_{0}}\left(\mathrm{~K}_{\mathrm{PIN}} \cos ^{2} \beta_{0}-\cos \beta_{0} \mathrm{~K}_{0}\right) \mathrm{h}^{2},
$$

o qual define o operador Superfície de Reflexão Comum com topografia suave (SRC-TS), usado nesta dissertação.

A equação (4.52) reduz-se ao caso de uma linha sísmica plano-horizontal considerando $\mathrm{K}_{0}=0$, ou seja:

$$
\tau^{2}\left(\mathrm{x}_{\mathrm{m}}, \mathrm{h}\right)=\left(\mathrm{t}_{0}+2 \frac{\operatorname{sen} \beta_{0}}{\mathrm{v}_{0}} \mathrm{x}_{\mathrm{m}}\right)^{2}+\frac{2 \mathrm{t}_{0}}{\mathrm{v}_{0}}\left(\mathrm{~K}_{\mathrm{N}} \cos ^{2} \beta_{0}\right) \mathrm{x}_{\mathrm{m}}^{2}+\frac{2 \mathrm{t}_{0}}{\mathrm{v}_{0}}\left(\mathrm{~K}_{\mathrm{PIN}} \cos ^{2} \beta_{0}\right) \mathrm{h}^{2} .
$$




\section{5- COMPARAÇÃO DOS TEMPOS DE TRÂNSITO PARAXIAIS COM TOPOGRAFIA SUAVE E RUGOSA}

Para a simulação de seções AN através do método de Empilhamento por Superfícies de Reflexão Comum (SRC), a fórmula de aproximação hiperbólica dos tempos de transito é usada para calcular as superfícies ou curvas de empilhamento. Para meios 2D o operador de empilhamento SRC depende de três atributos cinemáticos de frentes de onda ou parâmetros que são: o ângulo de emergência do raio central com afastamento fonte-receptor nulo $\left(\beta_{0}\right)$, a curvatura da onda ponto de incidência normal ( $\left.\mathrm{K}_{\mathrm{PIN}}\right)$ e a curvatura da onda normal $\left(\mathrm{K}_{\mathrm{N}}\right)$ (Apêndice $\mathrm{B}$ ). Estes três parâmetros, que estão associados a cada ponto de amostragem da seção AN, são determinados, a partir dos dados sísmicos de cobertura múltipla, por meio de processos de otimização e análise de coerência utilizando estratégias que envolvem processos de busca de um, dois ou três parâmetros. Após ter determinado o trio de parâmetros $\left(\beta_{0}, \mathrm{~K}_{\mathrm{PIN}}, \mathrm{K}_{\mathrm{N}}\right)$ que definem a superfície de empilhamento que melhor se ajusta aos eventos sísmicos, os mesmos são somados ou empilhados para simular o evento com afastamento-nulo (AN). A repetição deste processo para cada ponto de amostragem produz a seção AN simulada.

O método de empilhamento SRC usa aproximações de tempos de trânsito para definir as curvas ou superfícies de empilhamento. Portanto, neste capítulo, serão apresentadas duas aproximações hiperbólicas dos tempos de trânsito associado a um raio central com afastamentonulo (AN) refletido, considerando-se uma linha de medição com topografia suave e rugosa desenvolvidas nos dois capítulos anteriores, com o objetivo de mostrar graficamente tais aproximações. Por outro lado, é realizada uma particularização dessas aproximações para o caso de eventos de difração e para o caso de uma configuração afastamento-nulo (AN), também representadas graficamente.

\section{1- SUPERFÍCIE DE EMPILHAMENTO SRC PARA UMA LINHA DE MEDIÇÃO COM TOPOGRAFIA SUAVE}

Para o caso desta dissertação, será usada a equação (4.52), a qual assume um sistema de coordenada Cartesiano com origem em $\mathrm{X}_{0}$, onde, o eixo $\mathrm{x}_{1}$ é tangente á superfície de medição (Figura 5.1), com as coordenadas ponto-médio $\left(\mathrm{x}_{\mathrm{m}}\right)$ e meio-afastamento (h) definidas 
ao longo do eixo $\mathrm{x}_{1}$ (Figura 5.1). No entanto, é valido salientar que na prática essa equação apresenta um formalismo um tanto quanto inconveniente no que diz respeito ao seu uso, pois fazendo variar $\mathrm{X}_{0}$ com relação a sua posição, faz-se necessário novos sistemas de coordenadas locais para compensar tal deslocamento, problema este causado pela superfície de medição.

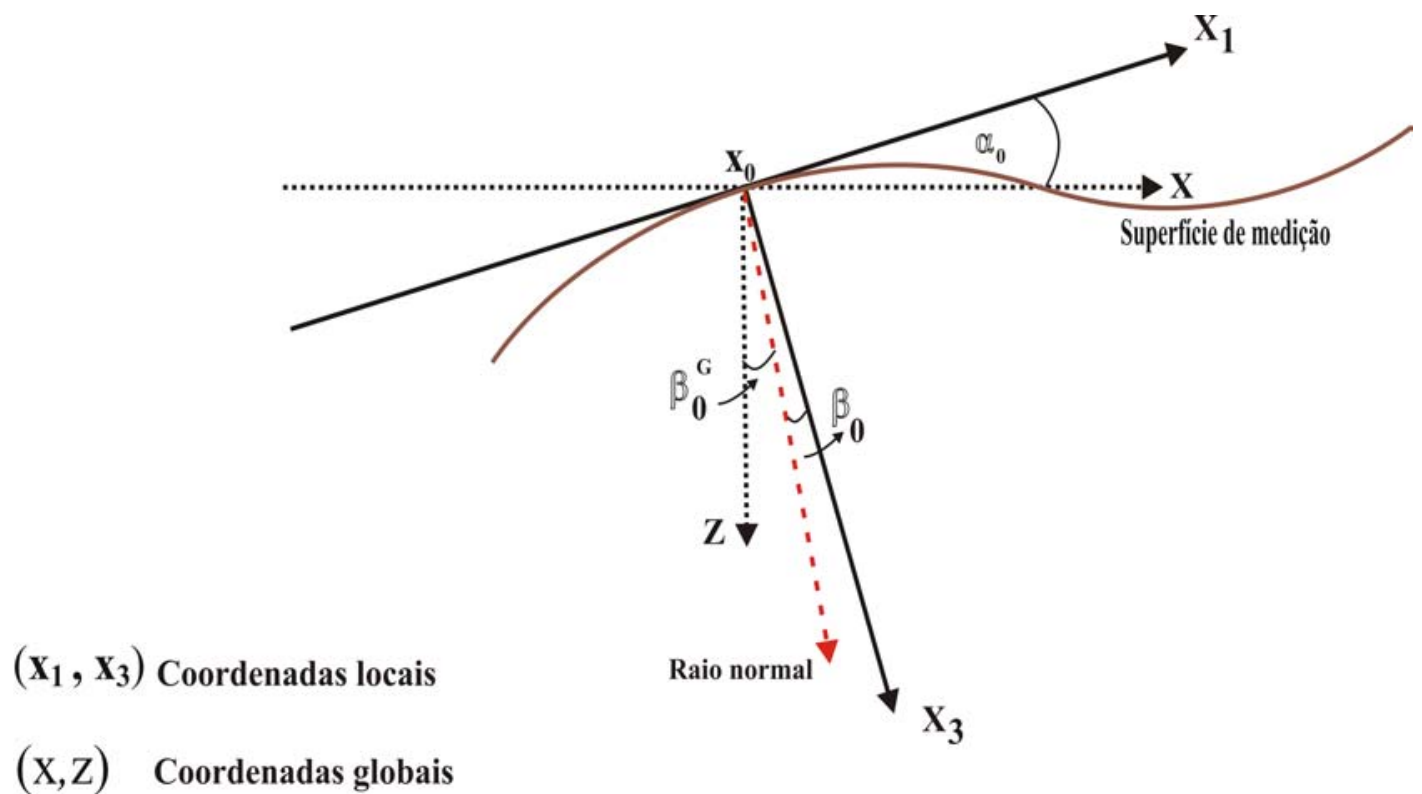

Figura 5.1- Relação entre os ângulos de emergência $\beta_{0}$ e $\beta_{0}^{\mathrm{G}}$ do raio normal na superfície curva no ponto central com o ângulo de mergulho $\alpha_{0}$ da superfície de medição. Note que os ângulos $\beta_{0}$ e $\beta_{0}^{\mathrm{G}}$ são mensurados nos sistemas de coordenada local e global, respectivamente. Nesta figura a origem do sistema de coordenada global coincide com a origem do sistema de coordenada local $\mathrm{X}_{0}$.

Para resolver este problema, será introduzido a seguir fórmulas de tempos de trânsito ligeiramente modificadas que recorrem ao sistema de coordenada global, onde as coordenadas das fontes e dos receptores são freqüentemente medidas (Figura 5.2). Em geral estas fórmulas são mais convenientes na sua implementação em virtude das coordenadas das fontes e dos receptores não necessitarem de transferências para sistemas de coordenadas locais diferentes.

Sendo assim, para o caso de um sistema de coordenada global com origem arbitrária (Figura 5.2), projetam-se às coordenadas locais neste sistema obtendo-se as seguintes relações:

$$
\mathrm{h}=\mathrm{h}^{\prime} \frac{1}{\cos \alpha_{0}} \text { e } \mathrm{x}_{\mathrm{m}}=\left(\mathrm{x}_{\mathrm{m}}^{\prime}-\mathrm{x}_{0}\right) \frac{1}{\cos \alpha_{0}}
$$


sendo $\mathrm{x}_{\mathrm{m}}^{\prime}-\mathrm{x}_{0}$ e $\mathrm{h}^{\prime}$ as coordenadas projetadas no sistema de coordenadas globais das coordenadas locais $\mathrm{x}_{\mathrm{m}} \mathrm{e} \mathrm{h}, \alpha_{0}$ o ângulo de mergulho da tangente à superfície de medição curva no ponto $\mathrm{X}_{0}$ (Figura 5.2).

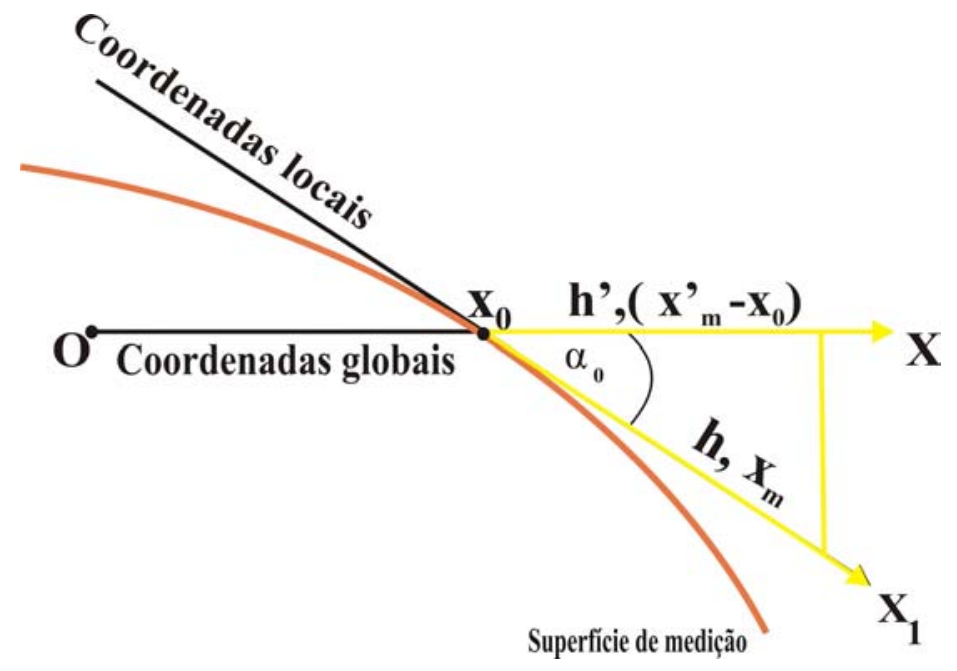

Figura 5.2- Transformação das coordenadas Cartesianas locais $\mathrm{x}_{\mathrm{m}} \mathrm{e} \mathrm{h}$ para suas respectivas coordenadas Cartesianas globais $\left(\mathrm{x}_{\mathrm{m}}^{\prime}-\mathrm{x}_{0}\right)$ e $\mathrm{h}^{\prime}, \alpha_{0}$ é o ângulo de mergulho local da tangente no ponto $\mathrm{X}_{0}\left(\right.$ eixo $\left.\mathrm{x}_{1}\right)$.

Dessa forma, introduzindo as relações (5.1) na equação (4.52) obtém-se:

$$
\begin{aligned}
& \tau^{2}\left(\mathrm{x}_{\mathrm{m}}^{\prime}, \mathrm{h}^{\prime}\right)=\left(\mathrm{t}_{0}+2 \frac{\operatorname{sen} \beta_{0}}{\mathrm{v}_{0} \cos \alpha_{0}}\left(\mathrm{x}_{\mathrm{m}}^{\prime}-\mathrm{x}_{0}\right)\right)^{2}+\frac{2 \mathrm{t}_{0}}{\mathrm{v}_{0} \cos ^{2} \alpha_{0}}\left(\mathrm{~K}_{\mathrm{N}} \cos ^{2} \beta_{0}-\cos \beta_{0} \mathrm{~K}_{0}\right)\left(\mathrm{x}_{\mathrm{m}}^{\prime}-\mathrm{x}_{0}\right)^{2} \\
& +\frac{2 \mathrm{t}_{0}}{\mathrm{v}_{0} \cos ^{2} \alpha_{0}}\left(\mathrm{~K}_{\mathrm{PIN}} \cos ^{2} \beta_{0}-\cos \beta_{0} \mathrm{~K}_{0}\right)\left(\mathrm{h}^{\prime}\right)^{2}
\end{aligned}
$$

Observe que a equação (5.2) está em função dos três parâmetros ou atributos de frentes de ondas $\left(\beta_{0}, K_{\mathrm{PIN}}\right.$ e $\left.\mathrm{K}_{\mathrm{N}}\right)$.

Para a ilustração gráfica de uma superfície de empilhamento definida pela equação (5.2), considera-se um modelo sintético (parte inferior da Figura 5.3) composta por três camadas homogêneas separadas por interfaces suaves e contínuas com velocidades $\mathrm{v}_{0}=2000 \mathrm{~m} / \mathrm{s}$, $\mathrm{v}_{1}=3000 \mathrm{~m} / \mathrm{s}$ e $\mathrm{v}_{2}=3500 \mathrm{~m} / \mathrm{s}$. Usando um algoritmo de traçamento de raios foram calculados os tempos de trânsito de reflexões primárias para diferentes afastamentos comuns entre fontes e 
receptores. Portanto, as curvas de cor azul representam os tempos de trânsito afastamento-comum (AC) de reflexões primárias associadas ao segundo refletor (parte superior da Figura 5.3). Estas curvas correspondem a afastamentos de 0 até 1000 metros, com intervalos de 40 metros. Para um raio central com afastamento-nulo (AN) que emerge na posição $\mathrm{X}_{0}=2000 \mathrm{~m}$ (linha de cor vermelha parte inferior da Figura 5.3) foram calculados por modelamento direto, usando um programa de traçamento de raios o trio de parâmetros $\left(\beta_{0}, \mathrm{~K}_{\mathrm{PIN}}, \mathrm{K}_{\mathrm{N}}\right)$, bem como os valores $\mathrm{K}_{0} \mathrm{e}$ $\alpha_{0}$ conforme mostra a Tabela 5.1. Então associado a esse raio central normal, as curvas de cor vermelha (na parte superior da Figura 5.3), representam a superfície de empilhamento SRC para uma linha de medição com topografia suave (SRC-TS), obtida pela equação (5.2), não apresentando um bom ajuste com os tempo de trânsito verdadeiros (curvas de cor azul azul).

Tabela 5.1- Valores dos parâmetros associados ao raio central (normal) $\mathrm{X}_{0} \mathrm{RX}_{0}$.

\begin{tabular}{c|c|c|c|c}
\hline$\beta_{0}\left[{ }^{0}\right]$ & $\alpha_{0}\left[{ }^{0}\right]$ & $\mathrm{K}_{\mathrm{PIN}}[1 / \mathrm{m}]$ & $\mathrm{K}_{\mathrm{N}}[1 / \mathrm{m}]$ & $\mathrm{K}_{0}[1 / \mathrm{m}]$ \\
\hline$-5,24680$ & $-18,569952$ & 857,4885 & 1160,7858 & $-177,8097$ \\
\hline
\end{tabular}

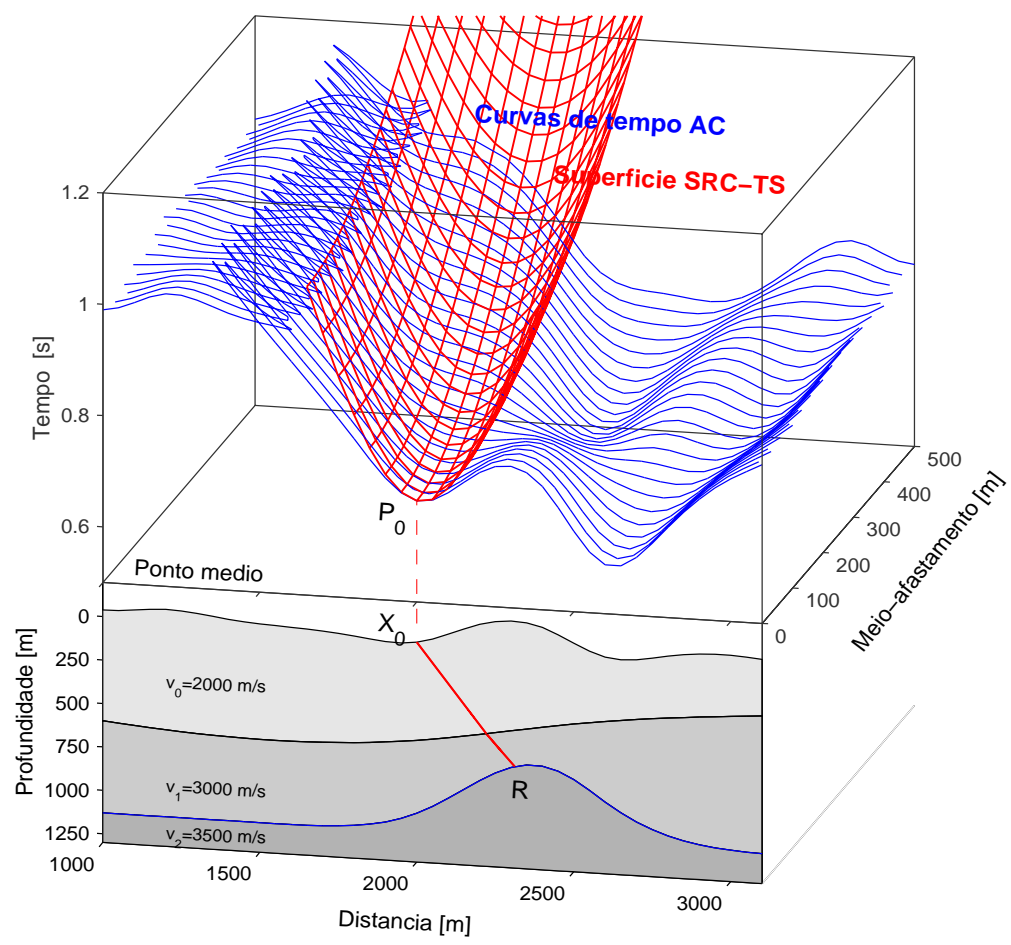

Figura 5.3- Parte inferior (frontal): meio 2D com três camadas homogêneas separadas por interfaces suaves e um raio central (linha de cor vermelha) com afastamento-nulo (AN). Parte superior: são mostradas as curvas de tempo de trânsito para diferentes afastamentos comuns (cor azul) referentes às reflexões primárias da segunda interface, tendo a aproximação SRCTS (cor vermelha) associada ao ponto $\mathrm{P}_{0}$. 
Denota-se por $\mathrm{P}_{0}=\left(\mathrm{x}_{0}, \mathrm{t}_{0}\right)$ a coordenada de um ponto amostragem (ou ponto imagem) na seção AN a ser simulada. Na Figura 5.3 para cada ponto $\mathrm{P}_{0}=\left(\mathrm{x}_{0}, \mathrm{t}_{0}\right)$ da seção de afastamentonulo (AN), haverá três parâmetros associados a ele e conseqüentemente uma superfície de empilhamento para cada ponto $\mathrm{P}_{0}$ seção $\mathrm{AN}$.

Recentemente, Garabito (2001) considerando a aproximação hiperbólica dos tempos de trânsito de raios paraxiais a um raio central $\mathrm{AN}$, definiu uma superfície de empilhamento considerando um ponto difrator em profundidade, denominado de superfície de difração comum (SDC). Desta forma, considerando o caso particular em que $\mathrm{K}_{\mathrm{N}}=\mathrm{K}_{\mathrm{PIN}}$, as duas curvaturas passam a definir a posição de um ponto difrator em subsuperfície, isto é, o elemento refletor colapsa num ponto difrator não proporcionando mais informação sobre a forma local do mesmo. Assim, aplicando esta condição na equação (5.2) obtém-se a aproximação Superfície de Difração Comum com Topografia Suave (SDC-TS) expressa por:

$$
\tau^{2}\left(\mathrm{x}_{\mathrm{m}}^{\prime}, \mathrm{h}^{\prime}\right)=\left(\mathrm{t}_{0}+2 \frac{\operatorname{sen} \beta_{0}}{\mathrm{v}_{0} \cos \alpha_{0}}\left(\mathrm{x}_{\mathrm{m}}^{\prime}-\mathrm{x}_{0}\right)\right)^{2}+\frac{2 \mathrm{t}_{0}}{\mathrm{v}_{0} \cos ^{2} \alpha_{0}}\left(\mathrm{~K}_{\mathrm{PIN}} \cos ^{2} \beta_{0}-\cos \beta_{0} \mathrm{~K}_{0}\right)\left(\left(\mathrm{x}_{\mathrm{m}}^{\prime}-\mathrm{x}_{0}\right)^{2}+\left(\mathrm{h}^{\prime}\right)^{2}\right) .(5
$$

Observe que a aproximação hiperbólica dos tempos de trânsito de raios paraxiais SDCTS depende agora de dois parâmetros de frentes de ondas ( $\beta_{0}$ e $\left.K_{\text {PIN }}\right)$.

Similarmente, ao caso das reflexões e considerando o mesmo modelo sintético (parte inferior da Figura 5.3), temos que, na parte superior da Figura 5.4 com linhas de cor verde é mostrada a superfície de empilhamento SDC-TS construída pela equação (5.3). No entanto, conforme observado na Figura 5.3, esta superfície também não apresenta um bom ajuste com os tempos de trânsito verdadeiros (cor azul). 


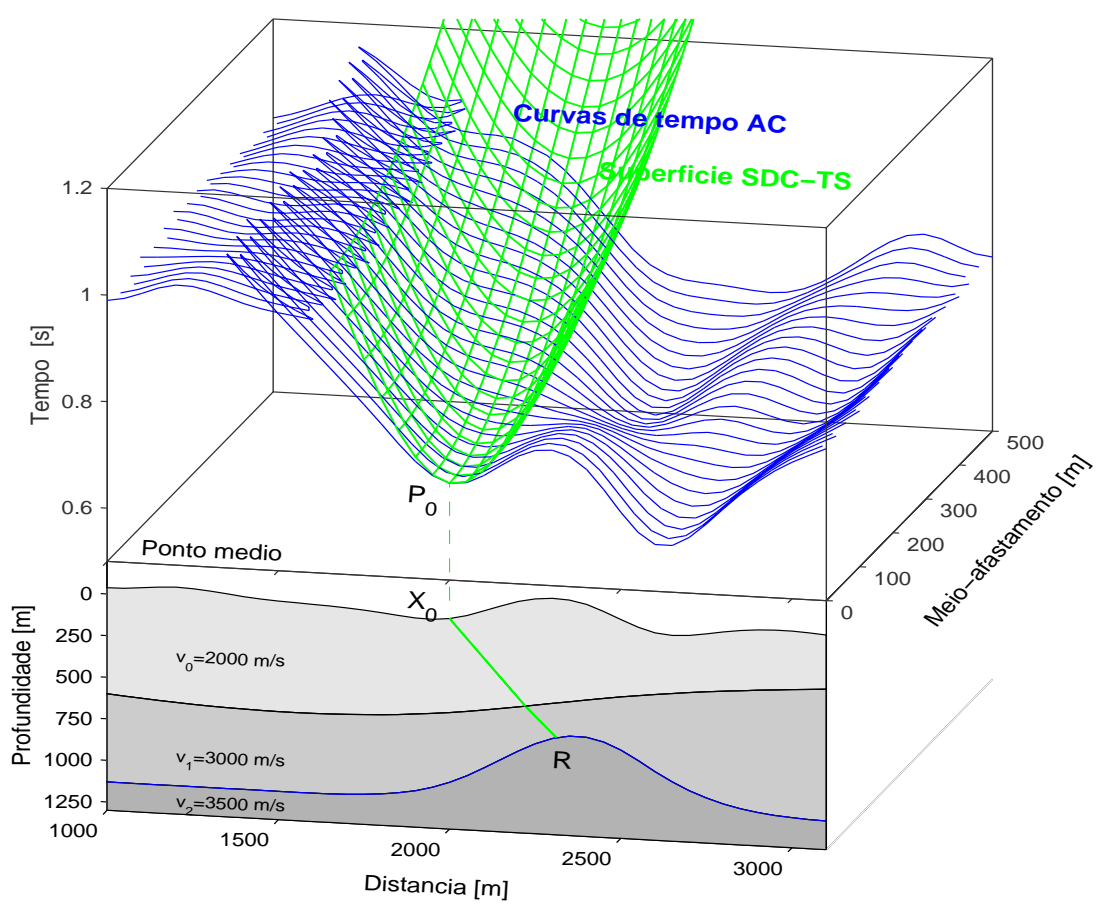

Figura 5.4- Parte inferior (frontal): meio 2D com três camadas homogêneas separadas por interfaces suaves e um raio central (linha de cor verde) com afastamento-nulo (AN). Parte superior: são mostradas as curvas de tempo de trânsito para diferentes afastamentos comuns (cor azul) referentes às reflexões primárias da segunda interface, tendo a aproximação SDCTS (cor verde) associada ao ponto $\mathrm{P}_{0}$.

Note que as superfícies de empilhamento das Figuras 5.3 e 5.4, apresentam uma considerável semelhança, este fato acontece em virtude dos valores das curvaturas $\mathrm{K}_{\text {PIN }}$ e $\mathrm{K}_{\mathrm{N}}$ estarem suficientemente próximos entre si (Tabela 5.1).

\subsection{1- Configuração Afastamento-Nulo (AN)}

Para o caso, $\mathrm{h}^{\prime}=0$, considerando os pares fonte-receptor coincidentes na superfície de medição e aproximando as reflexões AN na vizinhança de $X_{0}$, a equação (5.2) reduz-se a:

$$
\tau^{2}\left(\mathrm{x}_{\mathrm{m}}^{\prime}, \mathrm{h}^{\prime}\right)=\left(\mathrm{t}_{0}+2 \frac{\operatorname{sen} \beta_{0}}{\mathrm{v}_{0} \cos \alpha_{0}}\left(\mathrm{x}_{\mathrm{m}}^{\prime}-\mathrm{x}_{0}\right)\right)^{2}+\frac{2 \mathrm{t}_{0}}{\mathrm{v}_{0} \cos ^{2} \alpha_{0}}\left(\mathrm{~K}_{\mathrm{N}} \cos ^{2} \beta_{0}-\cos \beta_{0} \mathrm{~K}_{0}\right)\left(\mathrm{x}_{\mathrm{m}}^{\prime}-\mathrm{x}_{0}\right)^{2} .
$$

As curvas de empilhamento definidas pela equação (5.4), aproximam aos tempos de trânsito das reflexões normais com afastamento-nulo. A primeira curva de empilhamento de cor vermelha (parte superior da Figura 5.3), representa a curva de empilhamento que é obtida pela 
equação (5.4), situando-se no plano frontal da Figura associada ao ponto $\mathrm{P}_{0}$ que corresponde a reflexão primária.

\section{2- SUPERFÍCIE DE EMPILHAMENTO SRC PARA UMA LINHA DE MEDIÇÃO COM} TOPOGRAFIA RUGOSA

O tempo de trânsito hiperbólico para raios paraxiais na vizinhança de um raio central (normal) refletido, considerando uma superfície de medição com topografia rugosa dependente de três parâmetros ou atributos de frentes de onda, como visto no capítulo 3, é dado por:

$$
\begin{aligned}
& \tau_{\text {rug }}{ }^{2}(\overline{\mathrm{G}}, \overline{\mathrm{S}})=\left(\mathrm{t}_{0}-\frac{2}{\mathrm{v}_{0}}\left[\Delta \mathrm{m}_{\mathrm{x}} \operatorname{sen} \beta_{0}+\Delta \mathrm{m}_{\mathrm{z}} \cos \beta_{0}\right]\right)^{2}+\frac{2 \mathrm{t}_{0} \mathrm{~K}_{\mathrm{N}}}{\mathrm{v}_{0}}\left(\Delta \mathrm{m}_{\mathrm{x}} \cos \beta_{0}-\Delta \mathrm{m}_{\mathrm{z}} \operatorname{sen} \beta_{0}\right)^{2} \\
& +\frac{2 \mathrm{t}_{0} \mathrm{~K}_{\mathrm{PIN}}}{\mathrm{v}_{0}}\left(\Delta \mathrm{h}_{\mathrm{x}} \cos \beta_{0}-\Delta \mathrm{h}_{\mathrm{z}} \operatorname{sen} \beta_{0}\right)^{2}
\end{aligned}
$$

De maneira similar, ao caso das reflexões com topografia suave e considerando o mesmo modelo sintético (parte inferior da Figura 5.3), pode-se representar graficamente a equação (5.5), onde, a parte superior da Figura 5.5 com linhas de cor vermelha representa a superfície de empilhamento para uma linha de medição com topografia rugosa (SRC-TR) construída pela equação (5.5), observando-se um bom grau de ajuste com os tempos de trânsito verdadeiros (cor azul). 


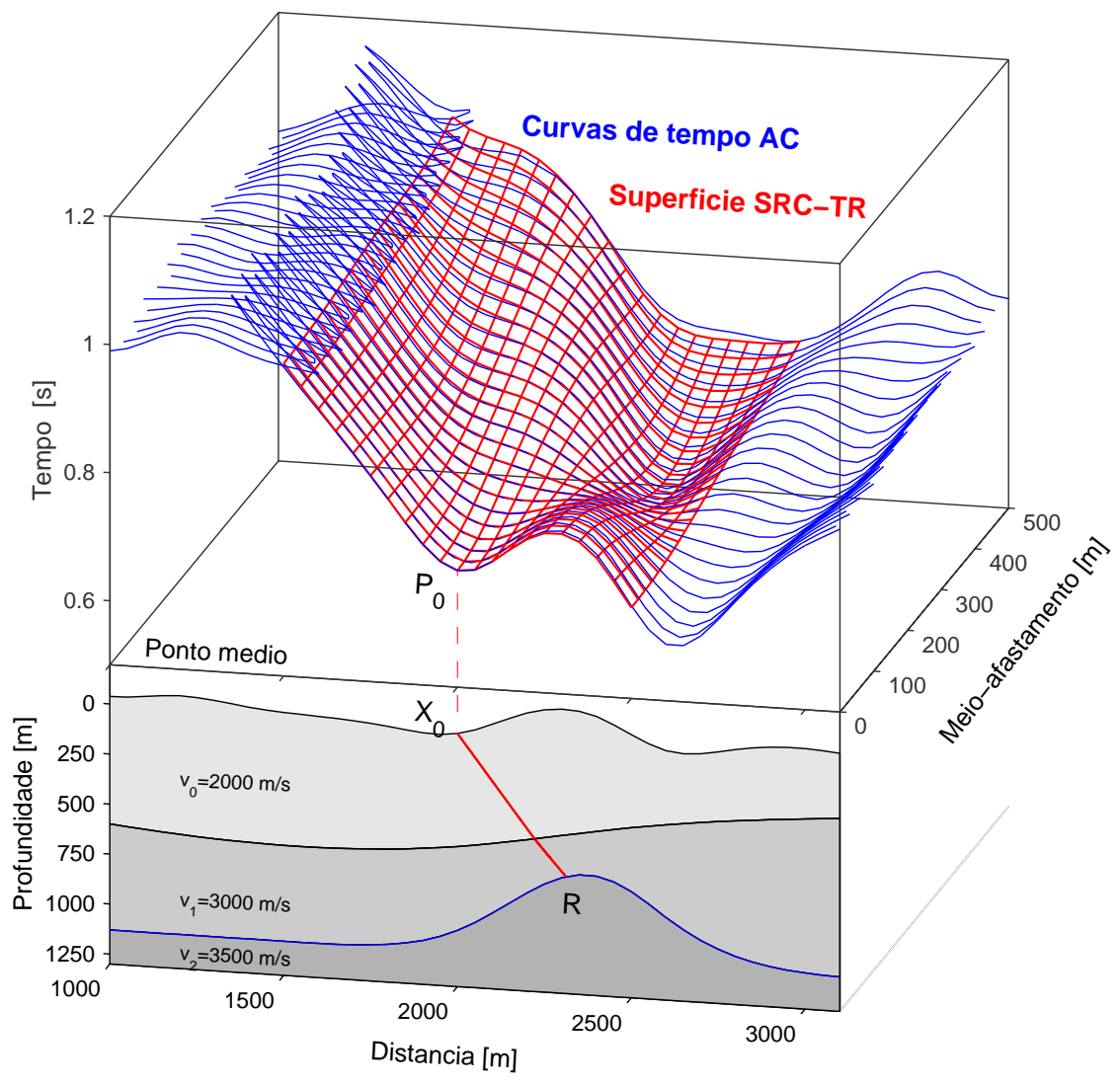

Figura 5.5- Parte inferior (frontal): meio 2D com três camadas homogêneas separadas por interfaces suaves e um raio central (linha de cor vermelha) com afastamento-nulo (AN). Parte superior: são mostradas as curvas de tempo de trânsito para diferentes afastamentos comuns (cor azul) referentes às reflexões primárias da segunda interface, tendo a aproximação SRCTR (cor vermelha) associada ao ponto $\mathrm{P}_{0}$.

Para o caso de um ponto difrator, considera-se a mesma condição explicada anteriormente para o caso da superfície de empilhamento SDC-TS, isto é, $\mathrm{K}_{\mathrm{N}}=\mathrm{K}_{\mathrm{PIN}}$. Assim, aplicando esta condição na equação (5.5) obtém-se:

$\tau_{\text {rug, dif }}{ }^{2}(\overline{\mathrm{G}}, \overline{\mathrm{S}})=\left(\mathrm{t}_{0}-\frac{2}{\mathrm{v}_{0}}\left[\Delta \mathrm{m}_{\mathrm{x}} \operatorname{sen} \beta_{0}+\Delta \mathrm{m}_{\mathrm{z}} \cos \beta_{0}\right]\right)^{2}+\frac{2 \mathrm{t}_{0} \mathrm{~K}_{\mathrm{PIN}}}{\mathrm{v}_{0}}\left[\left(\Delta \mathrm{m}_{\mathrm{x}} \cos \beta_{0}-\Delta \mathrm{m}_{\mathrm{z}} \operatorname{sen} \beta_{0}\right)^{2}+\left(\Delta \mathrm{h}_{\mathrm{x}} \cos \beta_{0}-\Delta \mathrm{h}_{\mathrm{z}} \operatorname{sen} \beta_{0}\right)^{2}\right]$

Similarmente, na Figura 5.6 apresentam-se as mesmas considerações descritas anteriormente, porém considerando uma superfície de empilhamento, denominada de superfície de difração comum com topografia rugosa (SDC-TR). Portanto, a parte superior da Figura 5.6 
com linha de cor verde representa a superfície de empilhamento SDC-TR construída pela equação 5.6. Devido ao fato desta superfície de empilhamento estar associada ao raio central (normal) difratado, a aproximação SDC-TR aproxima melhor os eventos de difração. No entanto, conforme observado na Figura 5.5, esta superfície também apresenta um bom grau de ajuste com os tempos de trânsito de reflexões primárias (cor azul).

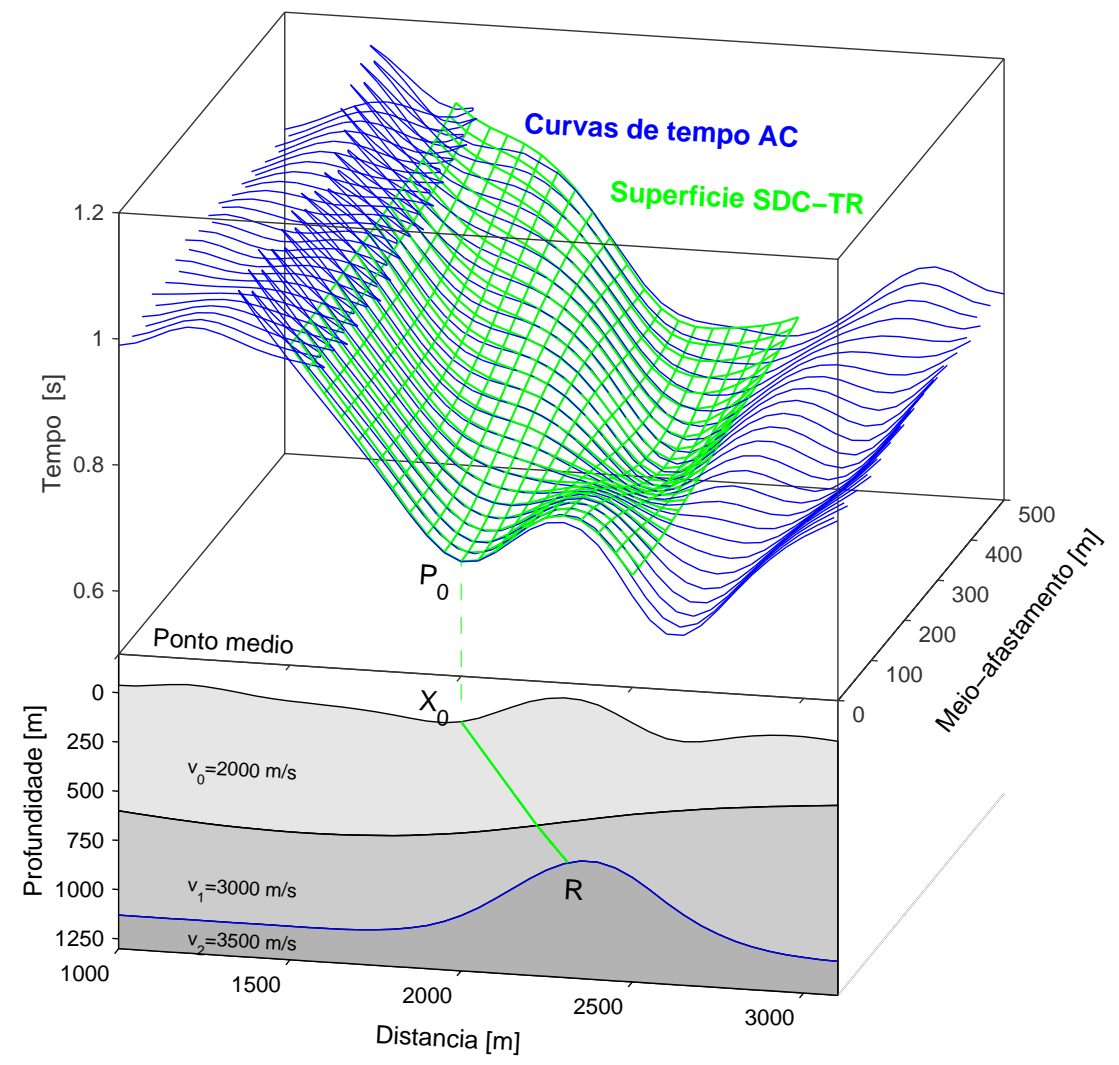

Figura 5.6- Parte inferior (frontal): meio 2D com três camadas homogêneas separadas por interfaces suaves e um raio central (linha de cor verde) com afastamento-nulo (AN). Parte superior: são mostradas as curvas de tempo de trânsito para diferentes afastamentos comuns (cor azul) referentes às reflexões primárias da segunda interface, tendo a aproximação SDCTR (cor verde) associada ao ponto $\mathrm{P}_{0}$. 
Nas superfícies de empilhamento das Figuras 5.3 e 5.4, é também observado um comportamento similar para as superfícies SRC-TR e SDC-TR ilustradas nas Figuras 5.5 e 5.6, pelas mesmas considerações ditas anteriormente, isto é, valores próximos das curvaturas das frentes de ondas $\mathrm{K}_{\mathrm{PIN}}$ e $\mathrm{K}_{\mathrm{N}}$.

\subsection{1- Configuração Afastamento-Nulo (AN)}

Para o caso, $\Delta \mathrm{h}_{\mathrm{x}}=\Delta \mathrm{h}_{\mathrm{z}}=0$, considerando os pares fonte-receptor coincidentes na superfície de medição e aproximando as reflexões $\mathrm{AN}$ na vizinhança de $\mathrm{X}_{0}$, a equação (5.5) reduz-se a:

$$
\tau_{\text {rug }, A N}^{2}(\bar{G}, \bar{S})=\left(\mathrm{t}_{0}-\frac{2}{\mathrm{v}_{0}}\left[\Delta \mathrm{m}_{\mathrm{x}} \operatorname{sen} \beta_{0}+\Delta \mathrm{m}_{\mathrm{z}} \cos \beta_{0}\right]\right)^{2}+\frac{2 \mathrm{t}_{0} \mathrm{~K}_{\mathrm{N}}}{\mathrm{v}_{0}}\left(\Delta \mathrm{m}_{\mathrm{x}} \cos \beta_{0}-\Delta \mathrm{m}_{\mathrm{z}} \operatorname{sen} \beta_{0}\right)^{2}
$$

As curvas de empilhamento definidas pela equação (5.7), também aproximam aos tempos de trânsito AN das reflexões normais. Tendo como representação gráfica na parte superior da Figura 5.5 a primeira curva de empilhamento de cor vermelha que pode ser obtida pela equação (5.7) para o ponto $\mathrm{P}_{0}$ correspondente à reflexão primária em $\mathrm{R}$, a qual esta situada no plano frontal da Figura.

Portanto, com base nas representações gráficas das Figuras 5.3, 5.4, 5.5 e 5.6, é observado que as aproximações SRC-TR e SDC-TR são mais apropriadas para linha de medição com topografia rugosa. Implicando que para a implementação de um algoritmo de simulação de seções AN para linha de medição com topografias mais complexas é mais conveniente o uso destas aproximações paraxiais. (ié, equações 5.5, 5.6 e 5.7). 


\section{6- ALGORITMO DE EMPILHAMENTO SRC-TR}

Neste capítulo, é apresentado um algoritmo de empilhamento Superfície de Reflexão comum com topografia rugosa (SRC-TR) para a simulação de seções AN a partir dos dados de cobertura múltipla. Para isso, o procedimento necessário é utilizar processos de otimização para

encontrar os melhores conjuntos $\left(\beta_{0}, \mathrm{~K}_{\mathrm{PIN}}, \mathrm{K}_{\mathrm{N}}\right)$. Em geral, isto requer muito tempo e esforço computacional para achar qual é a melhor combinação destes parâmetros. Para realizar a solução deste problema, podem ser usadas diferentes estratégias de busca, envolvendo a busca de combinações de parâmetros resultantes das simplificações das aproximações dos tempos de trânsito como apresentado no capítulo 5. Para definir a prioridade na busca dos parâmetros é necessário realizar uma análise de sensibilidade dos tempos de transito SRC-TR e SDC-TR, isto é, verificar quanto é sensível estes tempos de trânsito hiperbólicos para variações de cada parâmetro. A análise de sensibilidade realizada neste capítulo será através da perturbação de cada parâmetro visualizado na superfície de empilhamento e da primeira derivada dos tempos de trânsito SRC-TR e SDC-TR.

\section{1- ESTUDO DE SENSIBILIDADE DOS ATRIBUTOS DE FRENTES DE ONDAS}

\section{- Análise de sensibilidade nas superfícies de empilhamento SRC-TR e SDC-TR}

Primeiramente, foi aplicado uma análise de sensibilidade nas superfícies de empilhamento SRC-TR e SDC-TR, através da perturbação dos parâmetros $\beta_{0}, K_{P I N}$ e $K_{N}$. Isto permite observar o comportamento de cada parâmetro (mediante a perturbação do valor original) no resultado das superfícies de empilhamento ou aproximações dos tempos de trânsito.

Nesta análise de sensibilidade foram perturbados os valores dos parâmetros que definem as superfícies SRC-TR da Figura (5.5) e SDC-TR da Figura (5.6). Para efeito de comparação serão mostradas as superfícies SRC-TR e SDC-TR definidas com valores corretos e as superfícies que resultam depois da perturbação de um dado parâmetro.

Os resultados desta análise de sensibilidade podem ser observadas nas ilustrações das superfícies SRC-TR e SDC-TR, Figuras (6.1), (6.2), (6.3), (6.4) e (6.5). 
Nas Figuras (6.1), (6.2) e (6.3), as superfícies de cor vermelha corresponde aos valores corretos, a superfície de cor amarela foi obtida com a perturbação do parâmetro em $25 \%$ do seu valor original e a superfície azul foi obtida com a perturbação de $-25 \%$. De maneira similar, nas Figuras (6.4) e (6.5) as superfícies verdes correspondem aos valores corretos, as superfícies de cor amarela são obtidas perturbando o parâmetro em $25 \%$ do seu valor original e as superfícies de cor azul correspondem às perturbações em $-25 \%$ dos parâmetros.

Mediante a perturbação de $25 \%$ para mais e para menos dos valores verdadeiros dos parâmetros $\beta_{0}, K_{P I N}$ e $K_{N}$, conforme mostra a Tabela (6.1). Pelo grau de mudança ou variações apresentadas pelos gráficos da superfície SRC-TR observa-se que esta superfície é mais sensível à variação dos parâmetros $\beta_{0}$ e $K_{P I N}$, enquanto que a variação do parâmetro $K_{N}$ não causa grandes mudanças na superfície SRC-TR. Segundo estes resultados constata-se que o parâmetro $\mathrm{K}_{\mathrm{N}}$ é o parâmetro menos sensível. Portanto, pode-se inferir que o parâmetro $\mathrm{K}_{\mathrm{N}}$ será determinado com maior dificuldade e menor precisão através de processos de busca (otimização). Os parâmetros mais sensíveis $\beta_{0}$ e $K_{P I N}$ em geral serão determinados com maior facilidade e maior precisão.

Dos dois parâmetros que definem a superfície SDC-TR observa-se que o parâmetro menos sensível é $\mathrm{K}_{\mathrm{PIN}}$ (Figura 6.5). Sendo assim, como observado no caso da superfície SRC-TR, o parâmetro $\beta_{0}$ mostra grande sensibilidade, isto é, variação do mesmo causa deformação na superfície SDC-TR. Pode-se ainda observar, que tanto $\beta_{0}$ como $K_{\text {PIN }}$ apresentam comportamentos similares aos observados na superfície SRC-TR, fato este, definindo que ambos os parâmetros são sensíveis, podendo então serem determinados simultaneamente pelos processos de busca (otimização).

Tabela (6.1) - Perturbação de 25\% para mais e para menos dos valores verdadeiros dos parâmetros, $\beta_{0}$, $\mathrm{K}_{\mathrm{PIN}}$ e $\mathrm{K}_{\mathrm{N}}$.

\begin{tabular}{|c|c|c|c|}
\hline & $\beta_{0}\left[^{0}\right]$ & $K_{\text {PIN }}[1 / m]$ & $K_{N}[1 / m]$ \\
\hline$-25 \%$ & $-3,9351$ & 643,116375 & 870,58935 \\
\hline exatos & $-5,24680$ & 857,4885 & 1160,7858 \\
\hline$+25 \%$ & $-6,5585$ & 1071,860625 & 1450,98225 \\
\hline
\end{tabular}




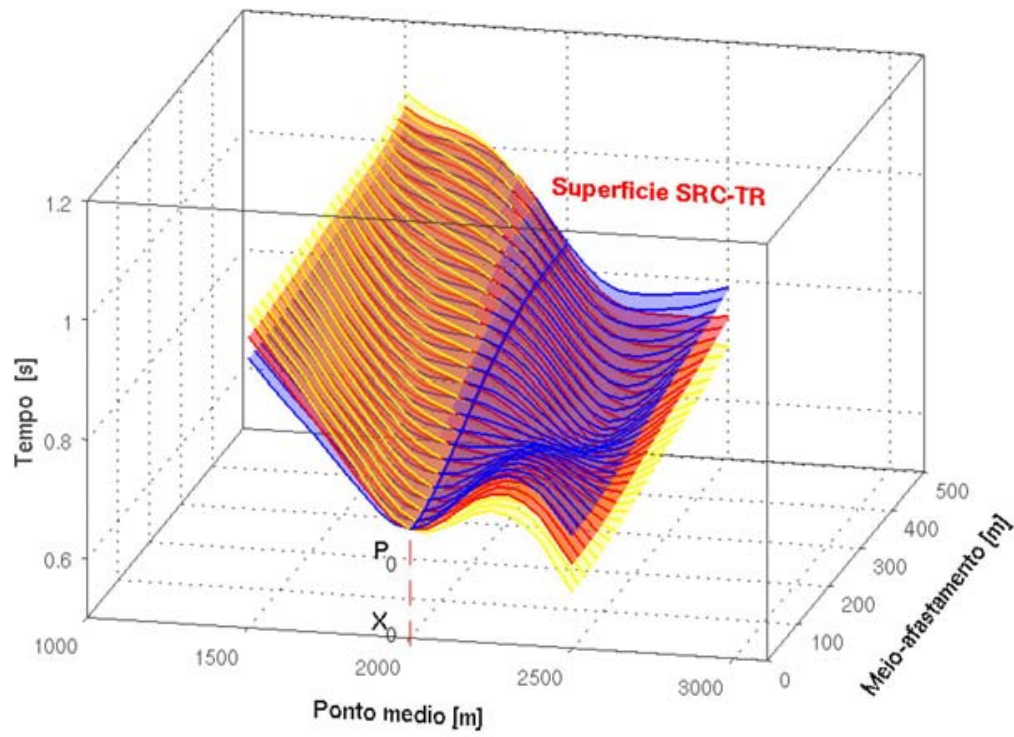

Figura 6.1 - Sensibilidade na superfície do empilhamento SRC-TR mediante a perturbação do parâmetro $\beta_{0}$. Perturbação do parâmetro $\beta_{0}$ correspondendo a $\pm 25 \%$ do valor original. As superfícies transparentes: de cor vermelha corresponde aos valores originais, a superfície de cor amarela $+25 \%$ e a superfície de cor azul - $25 \%$ do valor original.

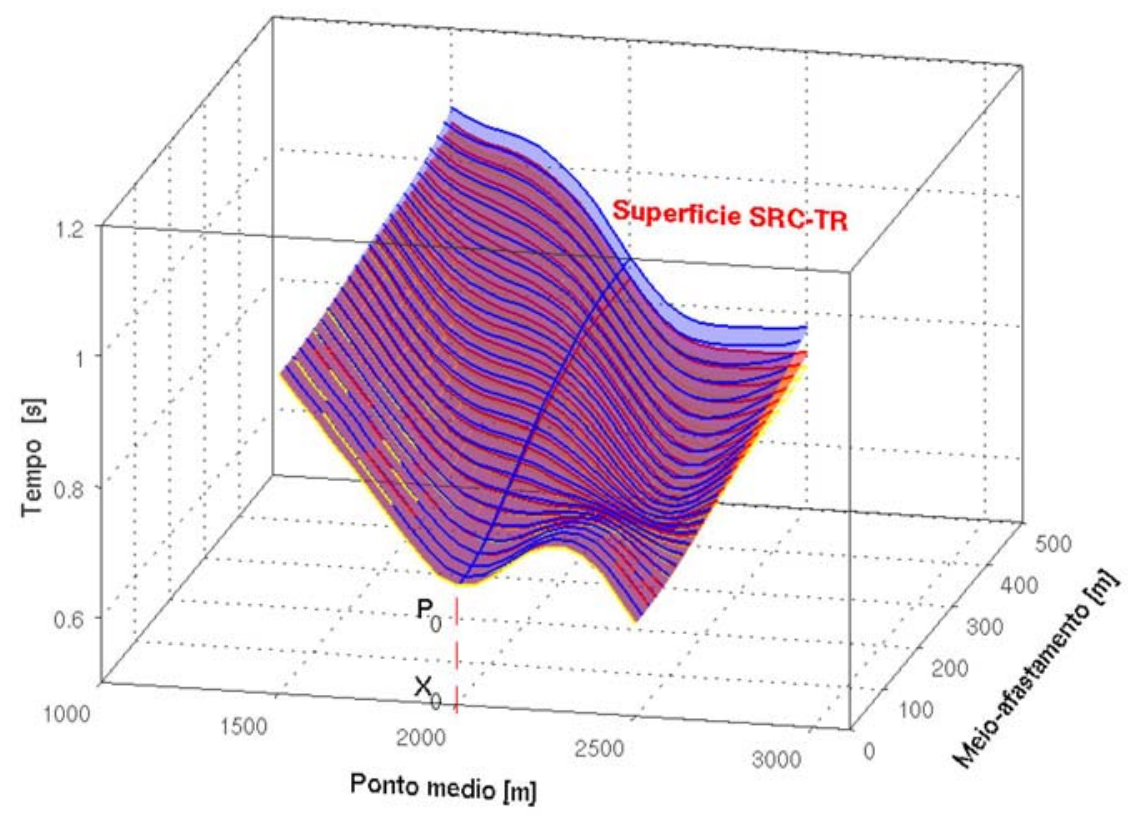

Figura 6.2 - Sensibilidade na superfície do empilhamento SRC-TR mediante a perturbação do parâmetro $K_{\mathrm{PIN}}$. Perturbação do parâmetro $\mathrm{K}_{\mathrm{PIN}}$ correspondendo a $\pm 25 \%$ do valor original. As superfícies transparentes: de cor vermelha corresponde aos valores originais, a superfície de cor amarela $+25 \%$ e a superfície de cor azul - $25 \%$ do valor original. 


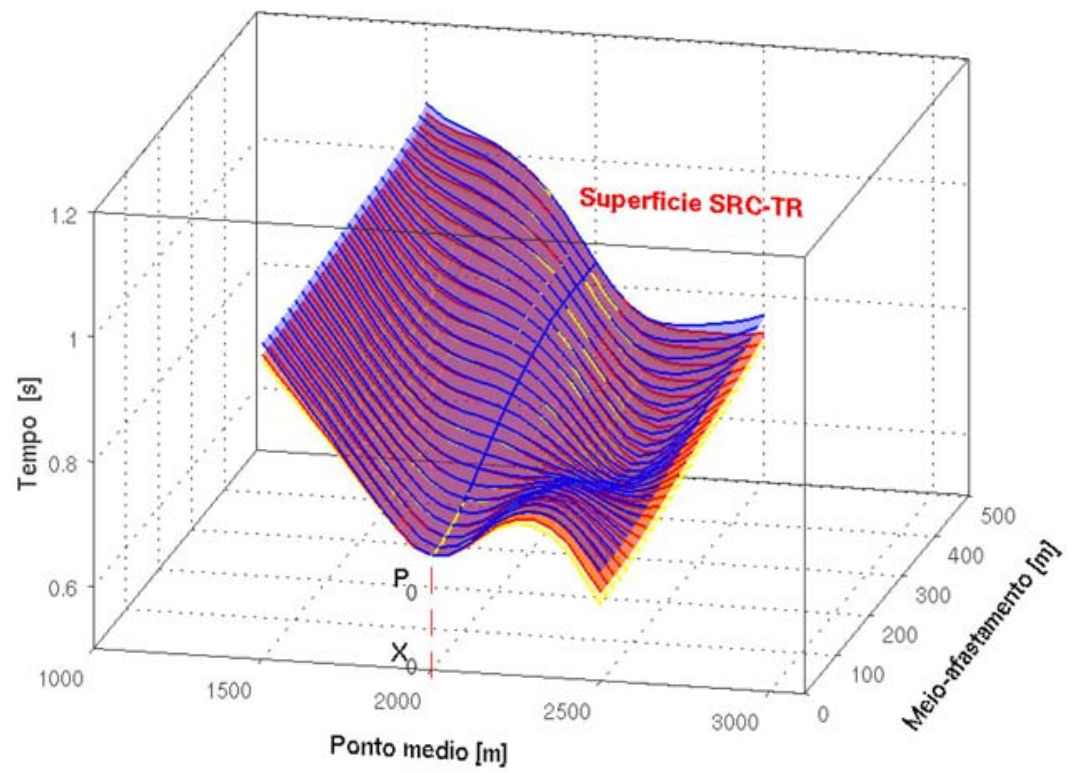

Figura 6.3 - Sensibilidade na superfície do empilhamento SRC-TR mediante a perturbação do parâmetro $K_{N}$. Perturbação do parâmetro $K_{N}$ correspondendo a $\pm 25 \%$ do valor original. As superfícies transparentes: de cor vermelha corresponde aos valores originais, a superfície de cor amarela $+25 \%$ e a superfície de cor azul - $25 \%$ do valor original. 


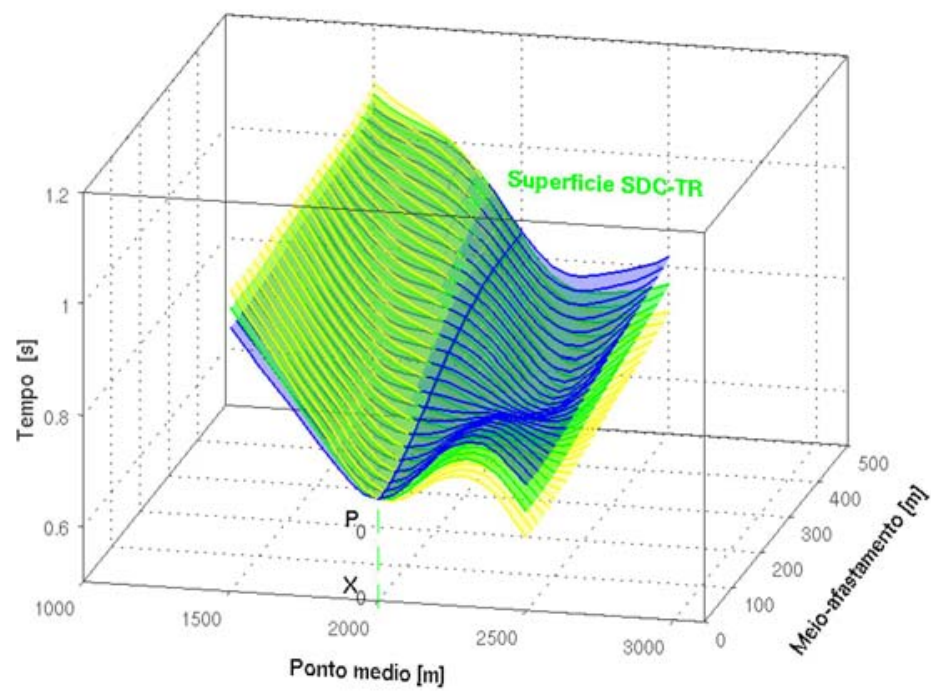

Figura 6.4 - Sensibilidade na superfície do empilhamento SDC-TR mediante a perturbação do parâmetro $\beta_{0}$. Perturbação do parâmetro $\beta_{0}$ correspondendo a $\pm 25 \%$ do valor original. As superfícies transparentes: de cor verde corresponde aos valores originais, a superfície de cor amarela $+25 \%$ e a superfície de cor azul - $25 \%$ do valor original.

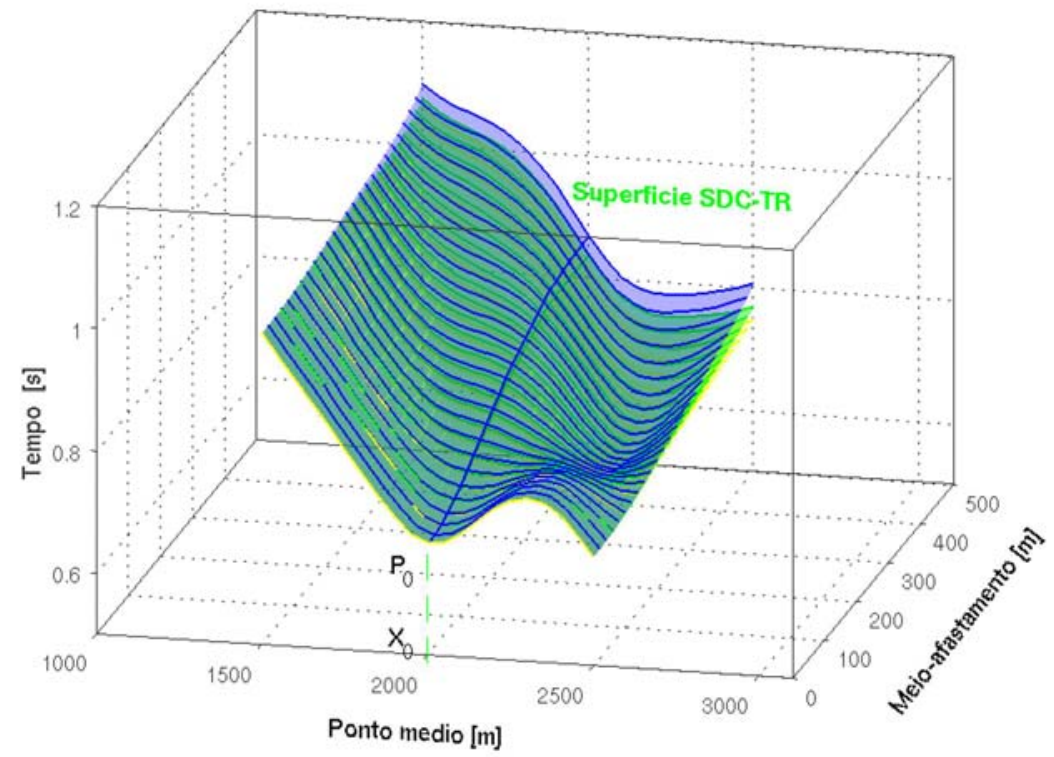

Figura 6.5 - Sensibilidade na superfície do empilhamento SDC-TR mediante a perturbação do parâmetro $K_{\mathrm{PIN}}$. Perturbação do parâmetro $\mathrm{K}_{\mathrm{PIN}}$ correspondendo a $\pm 25 \%$ do valor original. As superfícies transparentes: de cor verde corresponde aos valores originais, a superfície de cor amarela $+25 \%$ e a superfície de cor azul $-25 \%$ do valor original. 


\section{- Análise da primeira derivada do tempo de trânsito SRC-TR e SDC-TR}

Também foi aplicada uma análise de sensibilidade através da primeira derivada das aproximações hiperbólicas dos tempos de trânsito em função de seus parâmetros, permitindo analisar a sensibilidade destas aproximações. As derivadas foram realizadas utilizando os tempos de trânsito SRC-TR e SDC-TR em relação a cada parâmetro, isto é: $\left(\beta_{0}, \mathrm{~K}_{\mathrm{PIN}}, \mathrm{K}_{\mathrm{N}}\right)$. Dessa forma, usando o operador SRC-TR, equação (5.4), obtém-se as três derivadas:

- Derivada do tempo de trânsito em relação a $\beta_{0}\left(\frac{\partial \tau_{\text {rug }}}{\partial \beta_{0}}\right)$

$$
\begin{aligned}
& \frac{\partial \tau_{\text {rug }}}{\partial \beta_{0}}=\frac{1}{\tau_{\text {rug }}}\left(\mathrm{t}_{0}-\frac{2}{\mathrm{v}_{0}}\left(\Delta \mathrm{m}_{\mathrm{x}} \operatorname{sen} \beta_{0}+\Delta \mathrm{m}_{\mathrm{z}} \cos \beta_{0}\right)\right)\left(-\frac{2}{\mathrm{v}_{0}}\left(\Delta \mathrm{m}_{\mathrm{x}} \cos \beta_{0}-\Delta \mathrm{m}_{\mathrm{z}} \operatorname{sen} \beta_{0}\right)\right) \\
& +\frac{2 \mathrm{t}_{0} \mathrm{~K}_{\mathrm{N}}}{\mathrm{v}_{0} \tau_{\text {rug }}}\left(\Delta \mathrm{m}_{\mathrm{x}} \cos \beta_{0}-\Delta \mathrm{m}_{\mathrm{z}} \operatorname{sen} \beta_{0}\right)\left(-\Delta \mathrm{m}_{\mathrm{x}} \operatorname{sen} \beta_{0}-\Delta \mathrm{m}_{\mathrm{z}} \cos \beta_{0}\right) \\
& +\frac{2 \mathrm{t}_{0} \mathrm{~K}_{\mathrm{PIN}}}{\mathrm{v}_{0} \tau_{\text {rug }}}\left(\Delta \mathrm{h}_{\mathrm{x}} \cos \beta_{0}-\Delta \mathrm{h}_{\mathrm{z}} \operatorname{sen} \beta_{0}\right)\left(-\Delta \mathrm{h}_{\mathrm{x}} \operatorname{sen} \beta_{0}-\Delta \mathrm{h}_{\mathrm{z}} \cos \beta_{0}\right)
\end{aligned}
$$

- Derivada do tempo de trânsito em relação a $\mathrm{K}_{\mathrm{PIN}}\left(\frac{\partial \tau_{\mathrm{rug}}}{\partial \mathrm{K}_{\mathrm{PIN}}}\right)$

$$
\frac{\partial \tau_{\text {rug }}}{\partial \mathrm{K}_{\mathrm{PIN}}}=\frac{\mathrm{t}_{0}}{\mathrm{v}_{0} \tau_{\mathrm{rug}}}\left(\Delta \mathrm{h}_{\mathrm{x}} \cos \beta_{0}-\Delta \mathrm{h}_{\mathrm{z}} \operatorname{sen} \beta_{0}\right)^{2}
$$

- Derivada do tempo de trânsito em relação a $\mathrm{K}_{\mathrm{N}}\left(\frac{\partial \tau_{\text {rug }}}{\partial \mathrm{K}_{\mathrm{N}}}\right)$

$$
\frac{\partial \tau_{\text {rug }}}{\partial \mathrm{K}_{\mathrm{N}}}=\frac{\mathrm{t}_{0}}{\mathrm{v}_{0} \tau_{\mathrm{rug}}}\left(\Delta \mathrm{m}_{\mathrm{x}} \cos \beta_{0}-\Delta \mathrm{m}_{\mathrm{z}} \operatorname{sen} \beta_{0}\right)^{2}
$$

Usando o operador SDC-TR, equação (5.5), obtém-se as duas derivadas: 
- Derivada do tempo de trânsito em relação a $\beta_{0}\left(\frac{\partial \tau_{\text {rug,dif }}}{\partial \beta_{0}}\right)$

$$
\begin{aligned}
& \frac{\partial \tau_{\text {rug,dif }}}{\partial \beta_{0}}=\frac{1}{\tau_{\text {rug }}}\left(\mathrm{t}_{0}-\frac{2}{\mathrm{v}_{0}}\left(\Delta \mathrm{m}_{\mathrm{x}} \operatorname{sen} \beta_{0}+\Delta \mathrm{m}_{\mathrm{z}} \cos \beta_{0}\right)\right)\left(-\frac{2}{\mathrm{v}_{0}}\left(\Delta \mathrm{m}_{\mathrm{x}} \cos \beta_{0}-\Delta \mathrm{m}_{\mathrm{z}} \operatorname{sen} \beta_{0}\right)\right) \\
& +\frac{\mathrm{t}_{0} \mathrm{~K}_{\text {PIN }}}{\mathrm{v}_{0} \tau_{\text {rug,dif }}}\left(2\left[\Delta \mathrm{m}_{\mathrm{x}} \cos \beta_{0}-\Delta \mathrm{m}_{\mathrm{z}} \operatorname{sen} \beta_{0}\right]\left[-\Delta \mathrm{m}_{\mathrm{x}} \operatorname{sen} \beta_{0}-\Delta \mathrm{m}_{\mathrm{z}} \cos \beta_{0}\right]\right) \\
& +2\left[\Delta \mathrm{h}_{\mathrm{x}} \cos \beta_{0}-\Delta \mathrm{h}_{\mathrm{z}} \operatorname{sen} \beta_{0}\right] \cdot\left[-\Delta \mathrm{h}_{\mathrm{x}} \operatorname{sen} \beta_{0}-\Delta \mathrm{h}_{\mathrm{z}} \cos \beta_{0}\right]
\end{aligned}
$$

- Derivada do tempo de trânsito em relação a $\mathrm{K}_{\mathrm{PIN}}\left(\frac{\partial \tau_{\text {rug,dif }}}{\partial \mathrm{K}_{\mathrm{PIN}}}\right)$

$$
\frac{\partial \tau_{\text {rug,dif }}}{\partial \mathrm{K}_{\text {PIN }}}=\frac{\mathrm{t}_{0}}{\mathrm{v}_{0} \tau_{\text {rug,dif }}}\left[\left(\Delta \mathrm{m}_{\mathrm{x}} \cos \beta_{0}-\Delta \mathrm{m}_{\mathrm{z}}\right)^{2}+\left(\Delta \mathrm{h}_{\mathrm{x}} \cos \beta_{0}-\Delta \mathrm{h}_{\mathrm{z}} \operatorname{sen} \beta_{0}\right)^{2}\right]
$$

Cada uma dessas derivadas é mostrada graficamente nas Figuras (6.6) e (6.7) usando os seguintes meios afastamentos: $\mathrm{h}=0,0 \mathrm{Km} ; \mathrm{h}=0,1 \mathrm{Km} ; \mathrm{h}=0,2 \mathrm{Km} ; \mathrm{h}=0,3 ; \mathrm{h}=0,4 \mathrm{Km}$ e $\mathrm{h}=$ 0,5 $\mathrm{Km}$, onde o eixo horizontal corresponde a componente do ponto médio e eixo vertical ao valor da derivada de cada parâmetro. As curvas das derivadas dos parâmetros foram geradas com cores diferentes para cada um dos cinco meios afastamentos considerados, ou seja: cor azul para $\mathrm{h}=0,0 \mathrm{Km}$, magenta para $\mathrm{h}=0,1 \mathrm{Km}$, ciano para $\mathrm{h}=0,2 \mathrm{Km}$, cor amarela para $\mathrm{h}=0,3 \mathrm{Km}$, cor verde para $h=0,4 \mathrm{Km}$ e cor vermelha para $\mathrm{h}=0,5 \mathrm{Km}$.

$\mathrm{Na}$ Figura 6.6, observa-se na vizinhança do ponto central fixo $\mathrm{X}_{0}$ associado a um raio central considerado anteriormente, que as derivadas da aproximação hiperbólica do tempo de transito SRC-TR com relação aos parâmetros $\beta_{0}$ e $K_{\text {PIN }}$ (Figuras 6.6 a,b), são sensíveis as variações de $\Delta \mathrm{m}_{\mathrm{x}}$ e $\Delta \mathrm{h}_{\mathrm{x}}$, enquanto que o parâmetro $\mathrm{K}_{\mathrm{N}}$ apresenta uma menor sensibilidade às mudanças de $\Delta \mathrm{m}_{\mathrm{x}}$ e $\Delta \mathrm{h}_{\mathrm{x}}$ (Figuras $\left.6.6 \mathrm{c}\right)$.

Portanto, para o raio central com emergência no ponto $\mathrm{X}_{0} \mathrm{o}$ tempo de trânsito hiperbólico SRC-TR, apresenta um comportamento similar ao encontrado anteriormente pela perturbação de cada parâmetro visualizado na superfície de empilhamento SRC-TR, onde o ângulo $\beta_{0}$ também é muito sensível seguido do parâmetro $K_{P I N}$ e de $K_{N}$. Isto implica que os parâmetros $\beta_{0}$ e $K_{P I N}$ podem ser com maior facilidade determinados por processos de busca (otimização). O parâmetro $\mathrm{K}_{\mathrm{N}}$ apresentará maior grau de dificuldade na sua determinação. 
Na Figura 6.7, observa-se que para as variações ao longo das coordenadas de $\Delta \mathrm{m}_{\mathrm{x}} \mathrm{e} \Delta \mathrm{h}_{\mathrm{x}}$, na vizinhança do ponto central fixo $\mathrm{X}_{0}$, as derivadas da aproximação hiperbólica do tempo de trânsito SDC-TR é mais sensível ao parâmetro $\beta_{0}$ (Figura 6.7 a), enquanto que o parâmetro $K_{P I N}$ similar ao casa anterior também apresenta sensibilidade principalmente ao longo das coordenada $\Delta \mathrm{h}_{\mathrm{x}}($ Figura $6.7 \mathrm{~b})$.

Tanto para a aproximação hiperbólica SRC-TR quanto para SDC-TR, foram observados que os parâmetros $\beta_{0}$ e $K_{P I N}$ são sensíveis ao longo das coordenadas $\Delta \mathrm{m}_{\mathrm{x}} \mathrm{e} \quad \Delta \mathrm{h}_{\mathrm{x}}$. O comportamento desses parâmetros é similar nas aproximações SRC-TR e SDC-TR. Devido a este fato, pode-se estabelecer a busca dos parâmetros $\beta_{0}$ e $K_{\text {PIN }}$ utilizando a aproximação SDC-TR, não dependente do parâmetro $\mathrm{K}_{\mathrm{N}}$. Assim sendo, a busca do parâmetro $\mathrm{K}_{\mathrm{N}}$ menos sensível pode ser realizada usando os valores conhecidos de $\beta_{0}$ e $K_{\text {PIN }}$.

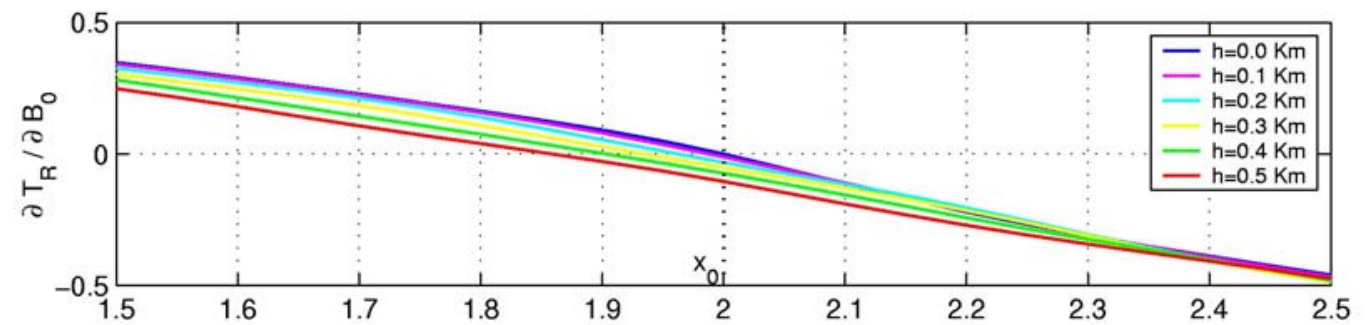

(a)

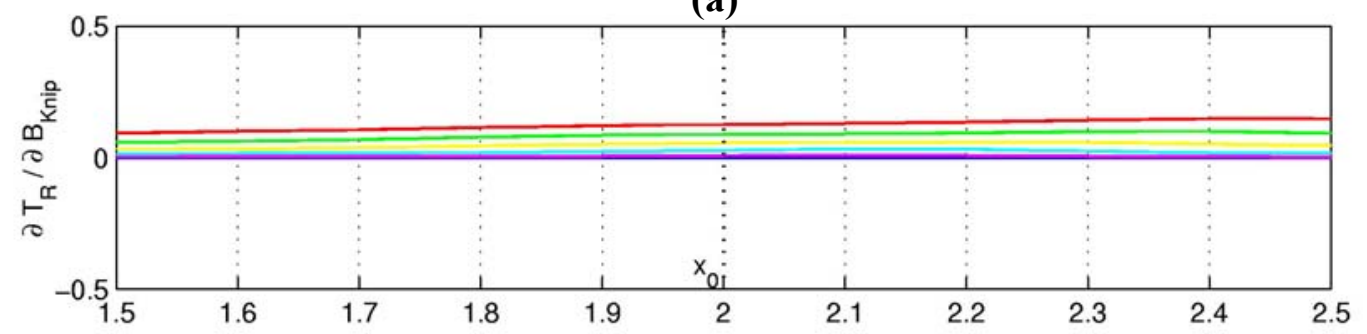

(b)

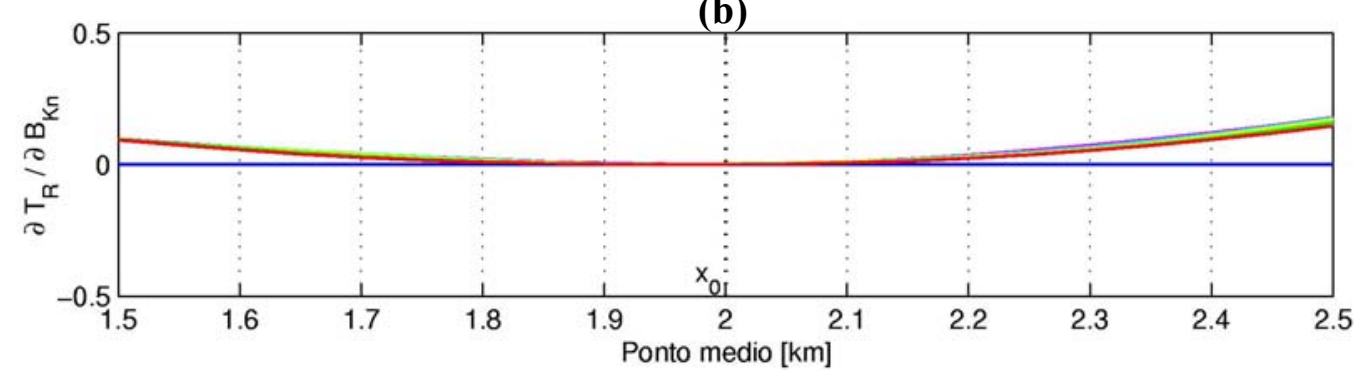

(c)

Figura 6.6 - Sensibilidade através da primeira derivada da aproximação hiperbólica do tempo de trânsito SRC-TR em relação: (a) ao ângulo $\beta_{0}$, (b) a curvatura $K_{P I N}$ e (c) a curvatura $K_{N}$. As curvas correspondem aos meios afastamentos de $\mathrm{h}=0,0 \mathrm{Km}$ (cor azul), $\mathrm{h}=0,1 \mathrm{Km}$ (cor magenta), $\mathrm{h}=0,2$ $\mathrm{Km}$ (cor ciano), $\mathrm{h}=0,3 \mathrm{Km}$ (cor amarela), $\mathrm{h}=0,4 \mathrm{Km}$ (cor verde) e $\mathrm{h}=0,5 \mathrm{Km}$ (cor vermelha). 


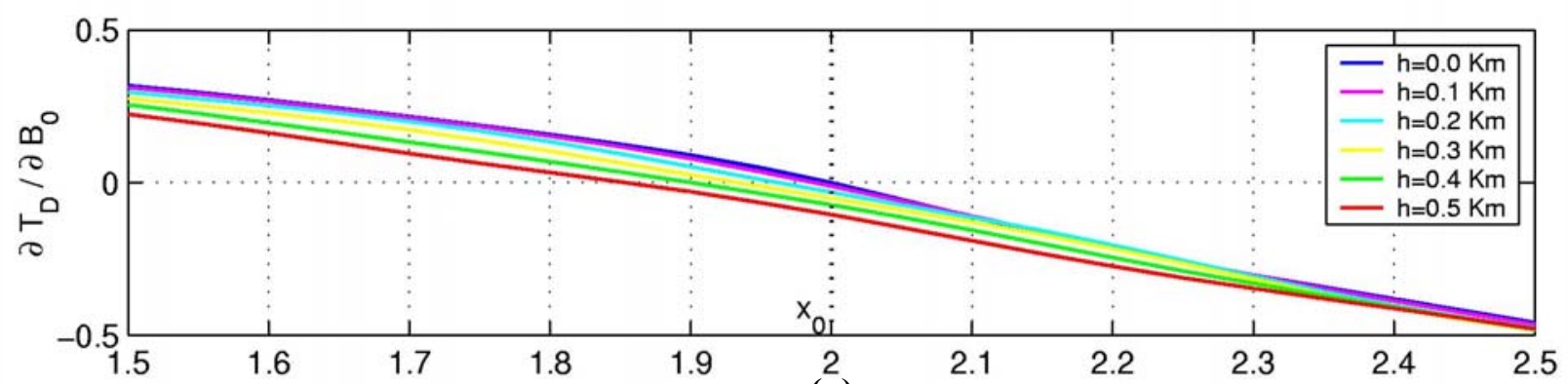

(a)

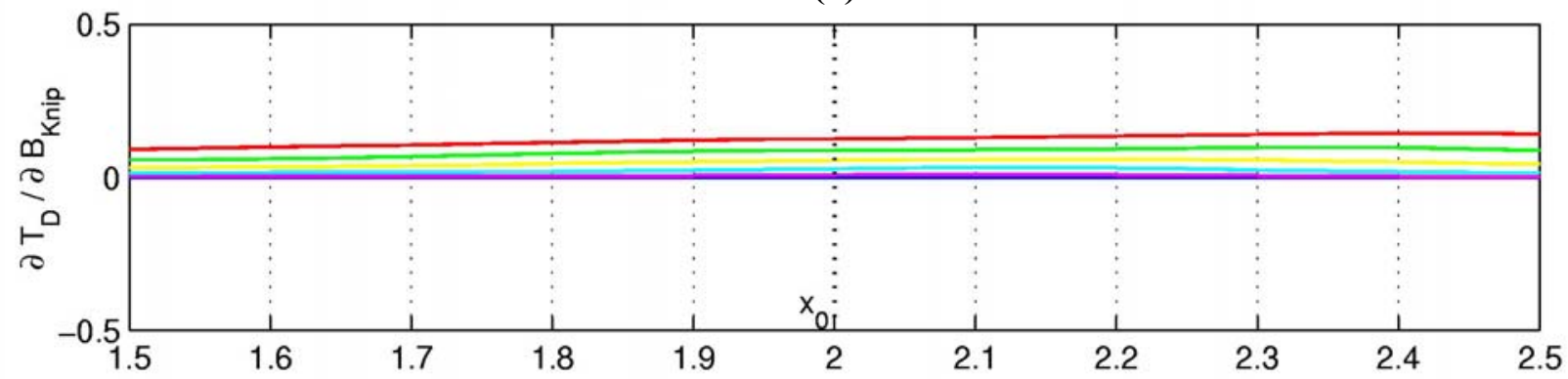

(b)

Figura 6.7 - Sensibilidade através da primeira derivada da aproximação hiperbólica do tempo de trânsito SDC-TR em relação: (a) ao ângulo $\beta_{0} \mathrm{e}(\mathrm{b})$ a curvatura $\mathrm{K}_{\mathrm{PIN}}$. As curvas correspondem aos meios afastamentos de $\mathrm{h}=0,0 \mathrm{Km}$ (cor azul), $\mathrm{h}=0,1 \mathrm{Km}$ (cor magenta), $\mathrm{h}=0,2 \mathrm{Km}$ (cor ciano), $\mathrm{h}=0,3 \mathrm{Km}$ (cor amarela), $\mathrm{h}=0,4 \mathrm{Km}$ (cor verde) e $\mathrm{h}=0,5 \mathrm{Km}$ (cor vermelha).

\section{2 - ALGORITMO DO EMPILHAMENTO SRC-TR}

Um dos principais problemas do método de empilhamento sísmico SRC para simular seções com afastamento-nulo (SRC-AN) é a determinação dos três parâmetros que definem o operador de empilhamento, definida pela fórmula hiperbólica dos tempos de trânsito. Como visto no Capitulo 5, para a simulação de seções com afastamento nulo pelo método de empilhamento SRC-TR, o operador de empilhamento é definido por uma aproximação hiperbólica dos tempos de trânsito que depende de três parâmetros ou atributos de frentes de ondas. Assim sendo, o operador SRC-TR associado a um certo ponto de amostragem $\mathrm{P}_{0}$ da seção $\mathrm{AN}$ requer da determinação a partir dos dados de cobertura múltipla dos parâmetros $\left(\beta_{0}, K_{P I N}\right.$ e $\left.K_{N}\right)$ que produzam o operador SRC-TR com melhor ajuste aos eventos sísmicos associados ao ponto $\mathrm{P}_{0}$. Portanto, a parte crucial deste procedimento é a determinação dos parâmetros SRC ou atributos 
de frentes de ondas, a partir de dados sísmicos, por meio de processos de otimização usando como função-objeto a função de coerência (semblance). Nesta dissertação, propõe-se a determinação desses parâmetros usando operadores ou superfícies de empilhamento definidas no domínio $\left(\Delta \mathrm{m}_{\mathrm{x}}, \Delta \mathrm{h}_{\mathrm{x}}\right)$, definidas por três parâmetros. O algoritmo SRC-TR proposto a seguir compreende em três etapas, que pode ser aplicado um algoritmo de otimização global para a determinação inicial dos parâmetros e, finalmente, para o refinamento desses parâmetros pode ser utilizado um algoritmo de otimização local.

Com a realização da análise de sensibilidade da aproximação hiperbólica dos tempos de trânsito, verificamos que o tempo de trânsito SDC-TR não mostra grande sensibilidade para amplo intervalo de variação do parâmetro $\mathrm{K}_{\mathrm{N}}$, tanto na perturbação dos parâmetros sobre superfície de empilhamento, quanto na primeira derivada, (Figura 6.3 e 6.6c). Segundo a condição de $K_{N}=K_{P I N}$, este parâmetro menos sensível $\left(K_{N}\right)$ pode ser negligenciado, resultando assim uma nova aproximação dependente de $\beta_{0}$ e $K_{\text {PIN }}$ (equação 5.6). Assim, no algoritmo descrito a seguir este parâmetro será o último estimado durante o processo de busca.

A estratégia para a determinação dos parâmetros SRC, que será aplicada para a implementação do algoritmo no caso de uma linha de medição com topografia rugosa, consiste em: primeiro, busca simultânea dos parâmetros $\beta_{0}$ e $K_{\text {PIN }}$ aplicando a aproximação SDC-TR; e segundo, busca do parâmetro $\mathrm{K}_{\mathrm{N}}$ aplicando a aproximação SRC-TR, usando os valores conhecidos de $\beta_{0}$ e $K_{\text {PIN. }}$

Portanto, o algoritmo proposto a seguir resulta das considerações teóricas do capitulo 5 e da análise de sensibilidade realizada no capitulo 6, consistindo das três etapas seguintes:

\section{Etapa 1 - Busca bidimensional dos parâmetros $\beta_{0}$ e K $K_{\text {IIN }}$.}

Nesta etapa, são determinados os parâmetros $\beta_{0}$ e $K_{P I N}$ para cada ponto imagem $P_{0}$ da seção sísmica AN a ser simulada, mediante uma busca bidimensional nos dados de cobertura múltipla aplicando um algoritmo de otimização global. A função objeto utilizada neste problema é o semblance que usa a equação (5.6) para calcular as superfícies de empilhamento testadas. 


\section{Etapa 2 - Busca unidimensional do parâmetro $K_{N}$.}

Nesta etapa, também, para cada ponto imagem $\mathrm{P}_{0}$ da seção sísmica $\mathrm{AN}$ a ser simulada, é determinado o terceiro parâmetro $K_{N}$ mediante uma busca unidimensional na seção AN resultante da primeira etapa. Os valores dos parâmetros estimados da Etapa I são usados para fixar $\beta_{0}$ na equação (5.5) utilizada nesta etapa. O problema de otimização é formulado para estimar o melhor $\mathrm{K}_{\mathrm{N}}$ como valor máximo do semblance medido ao longo das curvas de tempos de trânsito na seção AN, nesta etapa também se usa um algoritmo de otimização global.

\section{Etapa3- Refinamento dos três parâmetros $\beta_{0}, K_{P I N}$ e $K_{N}$.}

Os resultados das etapas anteriores são considerados como uma boa aproximação para os parâmetros de empilhamento, os mesmos serão usados como aproximações inicias nesta etapa. Sendo assim, para cada ponto $\mathrm{P}_{0}$ da seção $\mathrm{AN}$ a ser simulada, utilizando a equação 5.7, são estimados simultaneamente os três parâmetros ótimos a partir de dados de cobertura múltipla por meio de uma busca local.

O problema de otimização é formulado para estimar o melhor trio de parâmetros $\left(\beta_{0}\right.$, $\mathrm{K}_{\mathrm{PIN}}, \mathrm{K}_{\mathrm{N}}$ ) com o valor máximo do semblance, fazendo uso de um algoritmo de otimização local.

Como resultado final desta etapa será obtida a seção AN simulada pelo empilhamento SRC-TR dos dados de cobertura múltipla, uma seção de coerência e seções dos três parâmetros ou atributos de frentes de ondas.

Na Figura 6.8 é mostrado o diagrama de fluxo simplificado que resume as principais etapas do algoritmo proposto. 


\section{ENTRADA}

Dados de Cobertura Múltipla

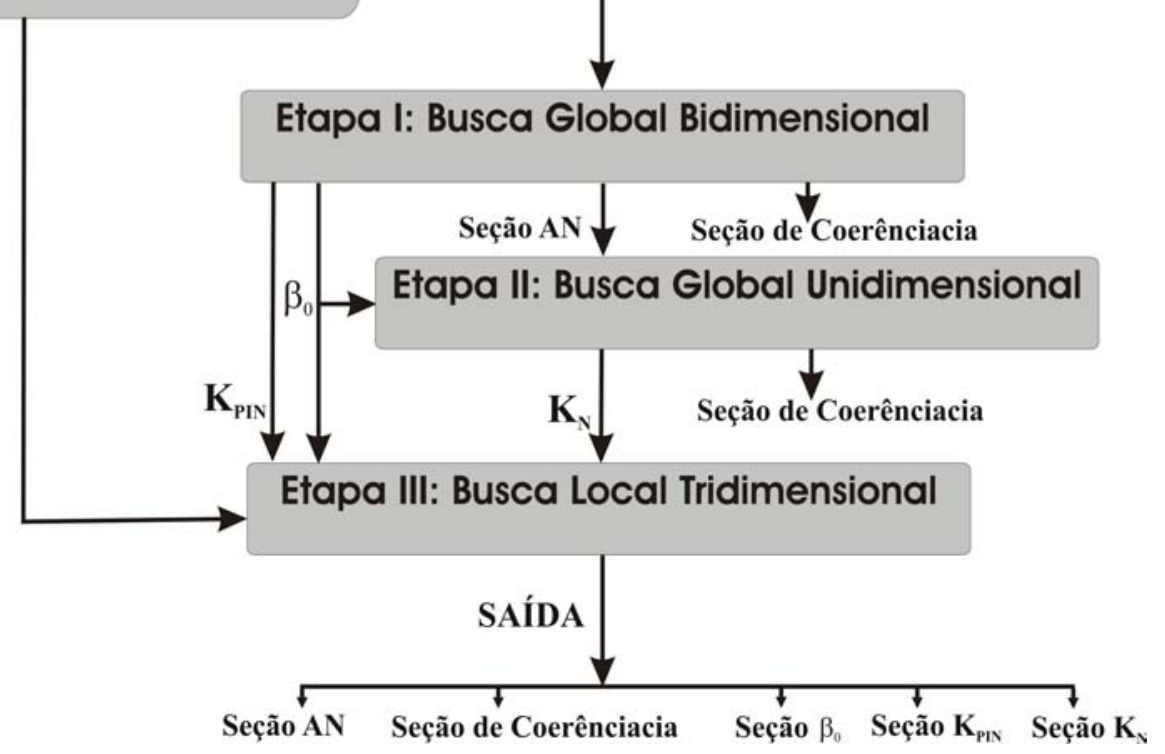

Figura 6.8 - Fluxograma do algoritmo de empilhamento SRC-TR. 


\section{7 - CONCLUSÕES E PERSPECTIVAS}

Neste capítulo são indicadas as conclusões obtidas no desenvolvimento desta dissertação. Também são discutidas perspectivas relacionadas ao algoritmo de empilhamento SRC-TR proposto.

\section{CONCLUSÕES}

Nesta dissertação, foi apresentada uma revisão teórica da teoria paraxial do raio para a obtenção das aproximações dos tempos de trânsito paraxiais considerando uma linha de medição com topografia rugosa e suave, com o objetivo de proporcionar um melhor entendimento para o método proposto nesta dissertação.

Assim, as conclusões descritas a seguir baseiam-se nos resultados obtidos a partir do estudo das fórmulas dos tempos de trânsito de raios paraxiais a um raio central com afastamentonulo (AN) refletido, para o caso de uma linha de medição com topografia suave e rugosa que depende de três parâmetros.

Foram particularizadas as fórmulas dos tempos de trânsito para raios paraxiais na vizinhança de um raio central associado a um ponto difrator em profundidade, bem como para uma configuração afastamento-nulo (AN). Também, para um modelo sintético 2D com topografia rugosa, foram comparados os operadores de empilhamento SRC (reflexões e difrações) para topografia suave e rugosa, demonstrando que os com topografia rugosa são mais apropriados para uma superfície de medição rugosa. Com base nesses resultados foi realizada uma análise de sensibilidade através da perturbação de cada parâmetro visualizado na superfície de empilhamento e da primeira derivada dos tempos de trânsito SRC-TR e SDC-TR, definindo assim, a estratégia de busca dos atributos de frente de ondas com o intuito de implementar futuramente um algoritmo SRC-2D para simular seções AN a partir de dados sísmicos adquiridos numa linha de medição com topografia rugosa.

Portanto, segundo os resultados obtidos da análise de sensibilidade dos operadores SRC-TR e SDC-TR, a futura implementação do algoritmo de empilhamento SRC-TR proposto nesta dissertação, constitui-se numa atraente alternativa, tendo como foco principal, a precisão dos atributos ou parâmetros SRC, além do uso destes parâmetros nas correções estáticas, entre outros. 


\section{REFERÊNCIAS BIBLIOGRÁFICAS}

AKI, K. \& RICHARDS, P. G. 1980. Quantitative Seismology. Theory and Método. Vol. I. New York, W. H. Freeman and Company.

BILOTI, R. 2001 Tempos de Trânsito Multiparamétricos: Estimação e Inversão. Campinas, Universidade Estadual de Capinas (Tese de Doutorado).

BILOTI, R.; PORTUGAL, R.; SANTOS, T. L.; TYGEL, M. 2001. Obtaining AVO and AVA curves from CRS attributes: Journal of Seismic Exploration, 10: 19-29.

BORTFELD, R. 1989. Geometrical ray theory: Rays and traveltimes in seismic systems (seconf-order approximations of the traveltime). Geophysics, 54: 342-349.

BRONSTEIN \& K.A. SEMENDJAJEW. 1991 Taschenbuch der Mathematik. B.G Tubner Verlagsgesellschaft.

CARMO, M. P. do 1992. Differential-geometrie von Kurven und Flächen. Zweite, durchgelesehne Auflage. Wiesbaden, Vieweg Studium Aufbaukurs Mathematik, 263p.

ČERVENÝ, V. 2001. Seismic Ray Theory. Cambridge University Press.

CHIRA, P., 2003. Empilhamento por Superfície de Reflexão Comum 2-D com Topografia e Introdução ao Caso 3-D. Belém, Universidade Federal do Pará (Tese de doutorado).

CHIRA, P. \& HUBRAL, P. 2001. Moveout formulas for a curved 2D measurement surface and near-zero-offset primary reflection. Submitted to Geophysics

CHIRA, P. \& HUBRAL, P. 2003. Traveltime formulas of near-zero-offset primary reflections for a curved 2-D measurement surface. Geophysics, 68: 255-261. 
CHIRA, P.; TYGEL, M.; ZHANG, Y.; HUBRAL, P. 2001. Analytic CRS Stack formula for a 2D curved measurement surface and finite-offset reflections. Journal of Seismic Exploration, 10: 245-262.

DUVENECK, E. 2004. Velocity model estimation with data-derived wavefront attributes. Geophysics, 69: 265-274.

GARABITO, G., 2001. Empilhamento Sísmico por Superfície de Reflexão Comum: Um novo algoritmo usando otimização global e local. Belém, Universidade Federal do Pará (Tese de doutorado).

GARABITO, G.; CHIRA, P; HUBRAL, P., 2003. Algoritmo de Empilhamento SRC-2D com topografia rugosa. SBGF.

GELCHINSKY, B.; BERCOVITCH, A.; KEYDAR, S., 1999a. Multifocussing homeomorphic imaging Part 1. Basic concepts and formulas. J. Appl. Geoph., 42 (Special issue on Karlsryuhe workshop on macro model independent seismic reflection imaging), 229-242.

GELCHINSKY, B.; BERCOVITCH, A.; KEYDAR, S., 1999b. Multifocussing homeomorphic imaging Part 2. Multifold data set and multifocusing. J. Appl. Geoph. 42 (Special issue on Karlsryuhe workshop on macro model independent seismic reflection imaging), 243-260.

GUREVICH, B; KEYDAR, S.; LANDA, E., 2002, Multifocusing imaging over an irregular topography: Geophysics, 67: 639-643.

HUBRAL, P., 1979. A Wave-Front Curvature Approach to Computing Ray Amplitudes in Inhomogeneous Media With Curved Interfaces. Studia Geoph. et Geod, 23:131-137.

HUBRAL, P., 1983. Computing true amplitude reflections in a laterally inhomogeneous earth. Geophysics, 48(8): 1051-1062. 
HUBRAL, P., 1999. Special Issue: Macro-Model Independent Seismic Reflection Imaging. Journal Appl. Geophys., 42: 3- 4.

HUBRAL, P. \& KREY, T., 1980. Interval velocities from seismic reflection time measurements. Soc. Of Exploration Geophysicists. Westem Geophysical Company Houston, Texas.

HUBRAL, P.; SCHLEICHER, J.; TYGEL, M. 1992. Three-dimensional paraxial ray properties, Basic relations. Journal of Seismic Exploration, 1: 265-279.

HUBRAL, P.; SCHLEICHER, J.; TYGEL, M.; HANITZSCH, C.1993. Determination of fresnel zones from traveltime measurements. Geophysics, 58: 703-712.

JÄGUER, R.; MANN, J.; HÖCHT, G.; HUBRAL, P., 2001. Common-reflection-surface stack: Image and attributes: Geophysics, 66(1): 97-109.

MANN, J.; HUBRAL, P.; TRAUB, B.; Gerst, A.; Meyer, H. 2000. Macro-Model Independent Approximative Prestack Time Migration. In: MTG. EUR. ASSN. GEOSCI. ENG., 62. Extended Abstracts, B-52.

MÜLLER, T., 1999. The common reflection surface stack : seismic imaging without explicit knowledge of the velocity model: Der Andere Verlag, Bad Iburg.

POPOV, M. 1996. Ray Theory and Gaussian Beam Method for Geophysicists. Universidade Federal da Bahia.

SCHLEICHER, J. 1993 Bestimmung von Reflexionskoeffizienten aus Reflexionsseismogrammen. Karlsruhe University, (PhD thesis).

URSIN, B. 1982 Quadratic wevefront and traveltime approximations in inhomogeneous layered media with curved interfaces. Geophysics, 47: 1012-1021. 
ZHANG, Y., HÖCHT , G.; HUBRAL, P., 2002, 2D and 3D ZO CRS stack for a complex topsurface topography. In: ANNUAL INTERNAT. MGT., 64., Karlsruhe, Germany. Extended Abstracts. Karlsruhe, Germany, Expl. Geophys. 
APÊNDICES 


\section{APÊNDICE A - DERIVAÇÃO DO TEMPO DE TRÂNSITO PARABÓLICO}

A equação de Hamilton em sua forma vetorial pode ser expressa por:

$$
\mathrm{d} \tau=\overline{\mathbf{p}}_{\mathbf{G}, \mathbf{T}} \cdot \mathrm{d}\left(\overline{\mathbf{x}}_{\mathbf{G}}-\mathbf{x}_{\mathbf{G}}\right)-\overline{\mathbf{p}}_{\mathbf{S}, \mathbf{T}} \cdot \mathrm{d}\left(\overline{\mathbf{x}}_{\mathbf{S}}-\mathbf{x}_{\mathbf{S}}\right)
$$

Assim, substituindo (4.19), (4.19.1), (4.20) e (4.20.1) em (A.1), tem-se:

$$
\mathrm{d} \tau=\left(\begin{array}{c}
\bar{p}_{\mathrm{G}} \\
\mathrm{f}_{\mathrm{x}} \overline{\mathrm{p}}_{\mathrm{G}}
\end{array}\right)\left(\begin{array}{c}
\mathrm{d}\left(\Delta \mathrm{x}_{\mathrm{G}}\right) \\
\mathrm{f}_{\mathrm{x}} \mathrm{d}\left(\Delta \mathrm{x}_{\mathrm{G}}\right)
\end{array}\right)-\left(\begin{array}{c}
\overline{\mathrm{p}}_{\mathrm{S}} \\
\mathrm{f}_{\mathrm{x}} \overline{\mathrm{p}}_{\mathrm{S}}
\end{array}\right)\left(\begin{array}{c}
\mathrm{d}\left(\Delta \mathrm{x}_{\mathrm{S}}\right) \\
\mathrm{f}_{\mathrm{x}} \mathrm{d}\left(\Delta \mathrm{x}_{\mathrm{S}}\right)
\end{array}\right),
$$

agora, negligenciando os termos superiores em (A.2), obtém-se a equação de Hamilton em sua forma escalar, isto é:

$$
\mathrm{d} \tau=\overline{\mathrm{p}}_{\mathrm{G}} \mathrm{d}\left(\Delta \mathrm{x}_{\mathrm{G}}\right)-\overline{\mathrm{p}}_{\mathrm{S}} \mathrm{d}\left(\Delta \mathrm{x}_{\mathrm{S}}\right)
$$

Dessa forma, dadas as equações:

$$
\begin{gathered}
\overline{\mathrm{p}}_{\mathrm{S}}=\mathrm{p}_{\mathrm{S}}+\mathrm{B}^{-1} \Delta \mathrm{x}_{\mathrm{G}}-\mathrm{B}^{-1} \mathrm{~A} \Delta \mathrm{x}_{\mathrm{S}}, \\
\overline{\mathrm{p}}_{\mathrm{G}}=\mathrm{p}_{\mathrm{G}}+\mathrm{C} \Delta \mathrm{x}_{\mathrm{S}}+\mathrm{DB}^{-1} \Delta \mathrm{x}_{\mathrm{G}}-\mathrm{DB}^{-1} \mathrm{~A} \Delta \mathrm{x}_{\mathrm{S}},
\end{gathered}
$$

em seguida, substituindo (A.4) e (A.5) em (A.3) obtém-se:

$$
\mathrm{d} \tau=\left[\mathrm{p}_{\mathrm{G}}+\Delta \mathrm{x}_{\mathrm{S}}\left(\mathrm{C}-\mathrm{DB}^{-1} \mathrm{~A}\right)+\mathrm{DB}^{-1} \Delta \mathrm{x}_{\mathrm{G}}\right] \mathrm{d}\left(\Delta \mathrm{x}_{\mathrm{G}}\right)-\left[\mathrm{p}_{\mathrm{S}}+\mathrm{B}^{-1} \Delta \mathrm{x}_{\mathrm{G}}-\mathrm{B}^{-1} \mathrm{~A} \Delta \mathrm{x}_{\mathrm{S}}\right] \mathrm{d}\left(\Delta \mathrm{x}_{\mathrm{S}}\right) .
$$

Sabendo que $\mathrm{p}_{\mathrm{G}}, \mathrm{p}_{\mathrm{S}}, \mathrm{A}, \mathrm{B}, \mathrm{C}$ e D são escalares constantes e $\Delta \mathrm{x}_{\mathrm{S}}, \Delta \mathrm{x}_{\mathrm{G}}$ as variáveis de integração, podemos aplicar integrais em ambos os membros da equação (A.6), ou seja:

$$
\int \mathrm{d} \tau=\int\left[\mathrm{p}_{\mathrm{G}}+\Delta \mathrm{x}_{\mathrm{S}}\left(\mathrm{C}-\mathrm{DB}^{-1} \mathrm{~A}\right)+\mathrm{DB}^{-1} \Delta \mathrm{x}_{\mathrm{G}}\right] \mathrm{d}\left(\Delta \mathrm{x}_{\mathrm{G}}\right)-\int\left[\mathrm{p}_{\mathrm{S}}+\mathrm{B}^{-1} \Delta \mathrm{x}_{\mathrm{G}}-\mathrm{B}^{-1} \mathrm{~A} \Delta \mathrm{x}_{\mathrm{S}}\right] \mathrm{d}\left(\Delta \mathrm{x}_{\mathrm{S}}\right),
$$

$\mathbf{I}_{1}$

$\mathbf{I}_{2}$

$$
\tau=\mathrm{I}_{1}+\mathrm{I}_{2}
$$

Cálculo de $\mathrm{I}_{1}$

$$
\begin{gathered}
\mathrm{I}_{1}=\int\left[\mathrm{p}_{\mathrm{G}}+\Delta \mathrm{x}_{\mathrm{S}}\left(\mathrm{C}-\mathrm{DB}^{-1} \mathrm{~A}\right)+\mathrm{DB}^{-1} \Delta \mathrm{x}_{\mathrm{G}}\right] \mathrm{d}\left(\Delta \mathrm{x}_{\mathrm{G}}\right)+\mathrm{C}_{1} \\
\mathrm{I}_{1}=\int \mathrm{p}_{\mathrm{G}} \mathrm{d}\left(\Delta \mathrm{x}_{\mathrm{G}}\right)+\int \Delta \mathrm{x}_{\mathrm{S}}\left[\mathrm{C}-\mathrm{B}^{-1} \mathrm{AD}\right] \mathrm{d}\left(\Delta \mathrm{x}_{\mathrm{G}}\right)+\mathrm{DB}^{-1} \int \Delta \mathrm{x}_{\mathrm{G}} \mathrm{d}\left(\Delta \mathrm{x}_{\mathrm{G}}\right)+\mathrm{C}_{1} \\
\mathrm{I}_{1}=\mathrm{p}_{\mathrm{G}} \Delta \mathrm{x}_{\mathrm{G}}+\left(\mathrm{C}-\mathrm{B}^{-1} \mathrm{AD}\right) \int \Delta \mathrm{x}_{\mathrm{S}} \mathrm{d}\left(\Delta \mathrm{x}_{\mathrm{G}}\right)+\frac{1}{2} \Delta \mathrm{x}_{\mathrm{G}} \mathrm{DB}^{-1} \Delta \mathrm{x}_{\mathrm{G}}+\mathrm{C}_{1}
\end{gathered}
$$


Aplicando a Propriedade Simplecticidade

$$
\mathrm{AD}-\mathrm{BC}=1 \text {, }
$$

ou seja, multiplicando ambos os membros por $\mathrm{B}^{-1}$, tem-se:

$$
\mathrm{B}^{-1} \mathrm{AD}-\mathrm{C}=\mathrm{B}^{-1}
$$

Multiplicando (A.13) por (-1), temos:

$$
\mathrm{C}-\mathrm{B}^{-1} \mathrm{AD}=-\mathrm{B}^{-1}
$$

Substituindo (A.14) em (A.11), temos:

$$
\mathrm{I}_{1}=\mathrm{p}_{\mathrm{G}} \Delta \mathrm{x}_{\mathrm{G}}-\mathrm{B}^{-1} \int \Delta \mathrm{x}_{\mathrm{S}} \mathrm{d}\left(\Delta \mathrm{x}_{\mathrm{G}}\right)+\frac{1}{2} \Delta \mathrm{x}_{\mathrm{G}} \mathrm{B}^{-1} \mathrm{D} \Delta \mathrm{x}_{\mathrm{G}}+\mathrm{C}_{1}
$$

Cálculo de $\mathrm{I}_{2}$

$$
\begin{gathered}
\mathrm{I}_{2}=-\int\left[\mathrm{p}_{\mathrm{S}}+\mathrm{B}^{-1} \Delta \mathrm{x}_{\mathrm{G}}-\mathrm{B}^{-1} \mathrm{~A} \Delta \mathrm{x}_{\mathrm{S}}\right] \mathrm{d}\left(\Delta \mathrm{x}_{\mathrm{S}}\right) \\
\mathrm{I}_{2}=-\int \mathrm{p}_{\mathrm{S}} \mathrm{d}\left(\Delta \mathrm{x}_{\mathrm{S}}\right)-\int \mathrm{B}^{-1} \Delta \mathrm{x}_{\mathrm{G}} \mathrm{d}\left(\Delta \mathrm{x}_{\mathrm{S}}\right)+\int \mathrm{B}^{-1} \mathrm{~A} \Delta \mathrm{x}_{\mathrm{S}} \mathrm{d}\left(\Delta \mathrm{x}_{\mathrm{S}}\right)+\mathrm{C}_{2} \\
\mathrm{I}_{2}=-\mathrm{p}_{\mathrm{S}} \Delta \mathrm{x}_{\mathrm{S}}-\mathrm{B}^{-1} \int \Delta \mathrm{x}_{\mathrm{G}} \mathrm{d}\left(\Delta \mathrm{x}_{\mathrm{S}}\right)+\mathrm{B}^{-1} \mathrm{~A} \int \Delta \mathrm{x}_{\mathrm{S}} \mathrm{d}\left(\Delta \mathrm{x}_{\mathrm{S}}\right)+\mathrm{C}_{2} \\
\mathrm{I}_{2}=-\mathrm{p}_{\mathrm{S}} \Delta \mathrm{x}_{\mathrm{S}}-\mathrm{B}^{-1} \int \Delta \mathrm{x}_{\mathrm{G}} \mathrm{d}\left(\Delta \mathrm{x}_{\mathrm{S}}\right)+\frac{\Delta \mathrm{x}_{\mathrm{S}} \mathrm{B}^{-1} \mathrm{~A} \Delta \mathrm{x}_{\mathrm{S}}}{2}+\mathrm{C}_{2}
\end{gathered}
$$

Aplicando integral por partes no termo $-\mathrm{B}^{-1} \int \Delta \mathrm{x}_{\mathrm{G}} \mathrm{d}\left(\Delta \mathrm{x}_{\mathrm{S}}\right)$ da equação (A.19) tem-se:

$$
-\mathrm{B}^{-1} \int \Delta \mathrm{x}_{\mathrm{G}} \mathrm{d}\left(\Delta \mathrm{x}_{\mathrm{S}}\right)=-\mathrm{B}^{-1}\left[\Delta \mathrm{x}_{\mathrm{S}} \Delta \mathrm{x}_{\mathrm{G}}-\int \Delta \mathrm{x}_{\mathrm{S}} \mathrm{d}\left(\Delta \mathrm{x}_{\mathrm{G}}\right)\right]
$$

Substituindo (A.20) em (A.19), obtém-se:

$$
\mathrm{I}_{2}=-\mathrm{p}_{\mathrm{S}} \Delta \mathrm{x}_{\mathrm{S}}-\Delta \mathrm{x}_{\mathrm{G}} \mathrm{B}^{-1} \Delta \mathrm{x}_{\mathrm{S}}+\mathrm{B}^{-1} \int \Delta \mathrm{x}_{\mathrm{S}} \mathrm{d}\left(\Delta \mathrm{x}_{\mathrm{G}}\right)+\frac{\Delta \mathrm{x}_{\mathrm{S}} \mathrm{B}^{-1} \mathrm{~A} \Delta \mathrm{x}_{\mathrm{S}}}{2}+\mathrm{C}_{2}
$$

Finalmente, substituindo (A.15) e (A.21) em (A.8) e assumindo que as constantes $C_{1}$ e $C_{2}$ são quantidades escalares que contribuem para o raio central $\mathrm{SG}$, ou seja, $\mathrm{t}_{0}=\mathrm{t}_{\mathrm{SG}}=\mathrm{C}_{1}+\mathrm{C}_{2}$, fica demonstrado o tempo de trânsito paraxial na vizinhança de um raio central SG com tempo de trânsito $\mathrm{t}_{\mathrm{SG}}=\mathrm{t}_{0}$, ou seja: 


$$
\begin{aligned}
& \tau=\mathrm{t}_{\mathrm{SG}}+\mathrm{p}_{\mathrm{G}} \Delta \mathrm{x}_{\mathrm{G}}-\mathrm{B}^{-1} \int \Delta \mathrm{x}_{\mathrm{S}} \mathrm{d}\left(\Delta \mathrm{x}_{\mathrm{G}}\right)+\frac{\Delta \mathrm{x}_{\mathrm{G}} \mathrm{B}^{-1} \mathrm{D} \Delta \mathrm{x}_{\mathrm{G}}}{2}-\mathrm{p}_{\mathrm{s}} \Delta \mathrm{x}_{\mathrm{S}} \\
& -\Delta \mathrm{x}_{\mathrm{S}} \mathrm{B}^{-1} \Delta \mathrm{x}_{\mathrm{G}}+\mathrm{B}^{-1} \int \Delta \mathrm{x}_{\mathrm{S}} \mathrm{d}\left(\Delta \mathrm{x}_{\mathrm{G}}\right)+\frac{\Delta \mathrm{x}_{\mathrm{S}} \mathrm{B}^{-1} \mathrm{~A} \Delta \mathrm{x}_{\mathrm{S}}}{2}
\end{aligned}
$$

Ou ainda:

$$
\tau\left(\Delta \mathrm{x}_{\mathrm{S}}, \Delta \mathrm{x}_{\mathrm{G}}\right)=\mathrm{t}_{\mathrm{SG}}+\mathrm{p}_{\mathrm{G}} \Delta \mathrm{x}_{\mathrm{G}}-\mathrm{p}_{\mathrm{S}} \Delta \mathrm{x}_{\mathrm{S}}-\Delta \mathrm{x}_{\mathrm{S}} \mathrm{B}^{-1} \Delta \mathrm{x}_{\mathrm{G}}+\frac{1}{2} \Delta \mathrm{x}_{\mathrm{S}} \mathrm{B}^{-1} \mathrm{~A} \Delta \mathrm{x}_{\mathrm{S}}+\frac{1}{2} \Delta \mathrm{x}_{\mathrm{G}} \mathrm{DB}^{-1} \Delta \mathrm{x}_{\mathrm{G}}
$$




\section{APÊNDICE B - PARÂMETROS CINEMÁTICOS DAS AUTO- ONDAS: PONTO DE INCIDÊNCIA NORMAL E ONDA NORMAL}

Hubral (1983) descreveu dois experimentos hipotéticos que demonstraram grande potencial para resolver vários problemas de propagação de ondas com direção normal ao refletor e chamou as ondas associadas a estas experiências onda de ponto de incidência normal (ou onda PIN) e onda normal (ou onda $\mathrm{N}$ ). Neste contexto introduziu também o nome auto-ondas porque estas duas ondas hipotéticas em termos gerais representam matematicamente auto-soluções do problema do raio normal. Do ponto de vista cinemático os parâmetros destas duas auto-ondas são explicados considerando um modelo 2D heterogêneo, explicado a seguir.

A Figura (B.1) representa um meio heterogêneo composto por duas camadas homogêneas com interfaces encurvadas sobre um semi-espaço, onde é ilustrada a propagação das auto-ondas ao longo do raio central com afastamento nulo (AN), desde o ponto de incidência normal R sobre o refletor até o ponto de observação $\mathrm{X}_{0}=\left(\mathrm{x}_{0}, 0\right)$ na linha sísmica. Neste caso, a interpretação dos parâmetros cinemáticos das ondas PIN e $\mathrm{N}$ não é direta e intuitiva como se fosse interpretado em um meio homogêneo, em contra partida, num meio heterogêneo estes três parâmetros $\left(\beta_{0}, \mathrm{R}_{\mathrm{PIN}}, \mathrm{R}_{\mathrm{N}}\right)$ ainda estão associados com a orientação, a distancia (ou posição) e a curvatura (ou forma) do refletor. A Figura B.1 mostra a propagação da onda PIN (cor azul) e onda N (cor vermelha) para diferentes instantes de tempo, e a transmissão das duas auto-ondas de uma camada a outra, no ponto de intercessão $(T)$ do raio central com afastamento nulo (AN).

Depois da transmissão no ponto $T$ as auto-ondas PIN e $\mathrm{N}$ se propagam ascendentemente até atingir o ponto de observação $\mathrm{X}_{0}$. Em meios heterogêneos, as curvaturas $\mathrm{K}_{\mathrm{PIN}} \mathrm{e} \mathrm{K}_{\mathrm{N}}$ medidas no ponto de emergência $\mathrm{X}_{0}$, são aproximações circulares das frentes de ondas PIN e $\mathrm{N}$, respectivamente. 


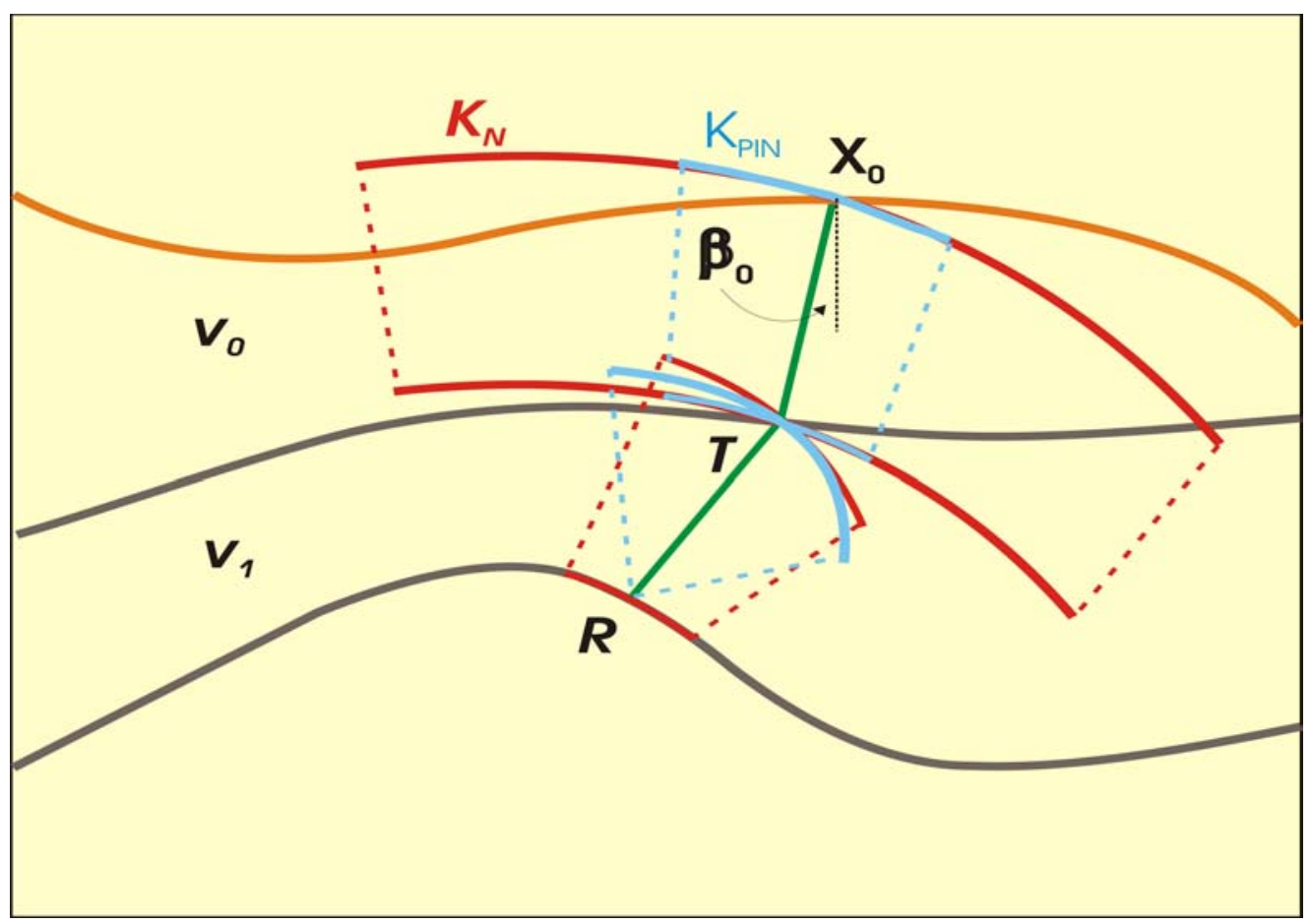

Figura B.1- Representação para diferentes instantes das frentes de ondas hipotéticas PIN (azul) e $\mathrm{N}$ (vermelho) que se propagam associados ao raio normal (verde) em um meio heterogêneo. A onda PIN é originada por uma fonte pontual no ponto de incidência normal R. A onda N propagase a partir de um segmento refletor explosivo ao redor do ponto $\mathrm{R}$, cuja frente de onda inicial tem a mesma curvatura do refletor no ponto R.

\section{B.1 CÁlCULO DOS PARÂMETORS CINEMÁticos DAS AUTO-ONDAS POR MODELAMENTO DIRETO}

Considerando um modelo sintético constituído de camadas homogêneas separadas por interfaces encurvadas e assumindo conhecidas as curvaturas em todos os pontos das interfaces, os três parâmetros cinemáticos $\left(\beta_{0}, \mathrm{R}_{\mathrm{PIN}}, \mathrm{R}_{\mathrm{N}}\right)$ das auto-ondas PIN e $\mathrm{N}$ podem ser calculados por meio do traçamento de raios. $\mathrm{O}$ traçamento de um raio normal com relação a uma determinada interface, fornece o ângulo de emergência $\beta_{0}$ formado com a normal da superfície de aquisição (ou linha sísmica) no ponto de observação $\mathrm{X}_{0}$, que é igual ao ângulo de emergência comum das duas auto-ondas associadas a esse raio normal (Figura B.1). O cálculo das curvaturas das frentes de ondas hipotéticas PIN e N, é realizado na direção ascendente a partir do ponto de incidência normal sobre o refletor e ao longo do raio normal, levando em conta a transformação das frentes 
de ondas pela transmissão de uma camada a outra, isto é, de um lado da interface para o outro lado, até atingir o ponto de observação $\mathrm{X}_{0}$ na superfície de aquisição (ou linha sísmica).

Denotamos $\mathrm{R}_{\mathrm{k} \text {,inicial }}$, como o raio de curvatura inicial de uma frente de onda em um determinado ponto inicial. No ponto de incidência normal, onde as duas auto-ondas se originam, a onda PIN tem um raio de curvatura inicial $R_{k, \text { inicial }}=0$ e a onda $N$ terá um raio de curvatura inicial $R_{k, \text { inicial }}=R_{k, R}$, sendo $R_{K, R}$ o raio de curvatura da interface no ponto de incidência normal. Por outro lado, como mostrado em Hubral e Krey (1980), o cálculo do raio de curvatura de uma frente de onda qualquer que se propaga dentro de uma camada ao longo de um raio normal, mais precisamente desde um ponto inicial localizado numa interface ao ponto final localizado na interface imediatamente superior, é realizado por:

$$
\mathrm{R}_{\mathrm{k}, \text { final }}=\mathrm{R}_{\mathrm{k}, \text { inicial }}+\mathrm{v}_{\mathrm{k}} \Delta \mathrm{t}_{\mathrm{k}}
$$

sendo $\mathrm{R}_{\mathrm{k}, \text { final }}$ o raio de curvatura da frente de onda no ponto final. A distância dada por $\mathrm{v}_{\mathrm{k}} \Delta \mathrm{t}_{\mathrm{k}}$ corresponde ao segmento de raio reto que une os pontos inicial e final dentro da k-ésima camada homogênea, sendo $\mathrm{v}_{\mathrm{k}}$ a velocidade camada e $\Delta \mathrm{t}_{\mathrm{k}} \mathrm{o}$ tempo de trânsito do raio. Também em Hubral e Krey (1980), a determinação da curvatura resultante de uma frente de onda que é transmitida de um lado da interface ao outro lado, é dada por:

$$
\frac{1}{\mathrm{R}_{\mathrm{k}-1, \text { inicial }}}=\frac{\mathrm{v}_{\mathrm{k}} \cos ^{2} \alpha_{\mathrm{k}}}{\mathrm{V}_{\mathrm{k}-\mathrm{l}} \cos ^{2} \beta_{\mathrm{k}-1}} \frac{1}{\mathrm{R}_{\mathrm{k}, \text { final }}}+\frac{1}{\cos ^{2} \beta_{\mathrm{k}-1}}\left(\frac{\mathrm{v}_{\mathrm{k}}}{\mathrm{V}_{\mathrm{k}-1}} \cos \alpha_{\mathrm{k}}-\cos \beta_{\mathrm{k}-1}\right) \frac{1}{\mathrm{R}_{\mathrm{k}-1, \mathrm{R}}},
$$

em que $\alpha_{\mathrm{k}}$ e $\beta_{\mathrm{k}-1}$ são, respectivamente, os ângulos de incidência e transmissão do raio normal na interface ( $\mathrm{k}-1)$. As velocidades $\mathrm{v}_{\mathrm{k}}$ e $\mathrm{v}_{\mathrm{k}-1}$ correspondem, respectivamente, as camadas inferior e superior com relação à interface (k-1), cujo raio de curvatura no ponto de incidência (ou transmissão) do raio é $\mathrm{R}_{\mathrm{k}-1, \mathrm{R}}$. Portanto, usando (B.1) e (B.2) ao longo da trajetória de um determinado raio normal são calculados os raios de curvaturas das frentes de ondas correspondentes as auto-ondas PIN e $\mathrm{N}$, até atingir o ponto de emergência $\mathrm{X}_{0}$. Dessa forma, podem ser determinados os três parâmetros cinemáticos das auto-ondas $\left(\beta_{0}, R_{\mathrm{PIN}}, \mathrm{R}_{\mathrm{N}}\right)$ associados a cada um dos raios normais às interfaces refletoras do modelo sintético considerado. 


\section{APÊNDICE C- MATRIZ PROPAGADORA П ${ }_{\mathrm{AN}}$ EM FUNÇÃO DOS PARÂMETROS CINEMÁTICOS DAS AUTO-ONDAS PIN E N}

Hubral (1983) também relacionou os elementos da matriz propagadora $\Pi_{\mathrm{AN}}$ com as curvaturas das auto-ondas PIN e N. Como descrito anteriormente no Apêndice B, as auto-ondas PIN e $\mathrm{N}$ são ondas hipotéticas medidas no ponto de observação $\mathrm{X}_{0}$ e geradas por um experimento sísmico com afastamento nulo entre as posições da fonte $(\mathrm{S})$ e do receptor $(\mathrm{G})$, ou seja, $\mathrm{S}=\mathrm{G}=$ $\mathrm{X}_{0}$. Červený (2001) mostrou que os vetores vagarosidade inicial $\left(\mathrm{p}^{(\mathrm{q})}\right)$ e final $\left(\mathrm{p}^{(\mathrm{q})^{\prime}}\right)$ da matriz propagadora $\Pi_{\mathrm{AN}}$ podem ser relacionados às curvaturas de frente de ondas $\mathrm{K}_{0}$ e $\mathrm{K}_{0}^{\prime}$ que emergem no ponto $\mathrm{X}_{0}$ na superfície de aquisição por

$$
\mathrm{p}^{(\mathrm{q})}=\mathrm{v}_{0}{ }^{-1} \mathrm{~K}_{0} \mathrm{q}
$$

e

$$
\mathrm{p}^{(\mathrm{q})}=\mathrm{v}_{0}^{-1} \mathrm{~K}_{0}^{\prime} \mathrm{q}^{\prime}
$$

onde nos pontos $\mathrm{S}=\mathrm{G}=\mathrm{X}_{0}$, as velocidades $\mathrm{v}_{\mathrm{S}}=\mathrm{v}_{\mathrm{G}}=\mathrm{v}_{0}$.

Inserindo as equações (C.1) e (C.2) nas equações :

$$
\mathrm{q}^{\prime}=\mathrm{Q}_{1} \mathrm{q}+\mathrm{Q}_{1} \mathrm{p}^{(\mathrm{q})} \quad \text { e } \quad \mathrm{p}^{(\mathrm{q}) \prime}=\mathrm{P}_{1} \mathrm{q}+\mathrm{P}_{1} \mathrm{p}^{(\mathrm{q})},(\text { Červený, 2001) }
$$

tem-se:

$$
\mathrm{q}^{\prime}=\left(\mathrm{Q}_{1}+\mathrm{Q}_{2} \mathrm{v}_{0}{ }^{-1} \mathrm{~K}_{0}\right) \mathrm{q}
$$

e

$$
\mathrm{v}_{0}^{-1} \mathrm{~K}_{0}^{\prime} \mathrm{q}^{\prime}=\left(\mathrm{P}_{1}+\mathrm{P}_{2} \mathrm{~V}_{0}{ }^{-1} \mathrm{~K}_{0}\right) \mathrm{q}
$$

Substituindo o q' da equação (C.5) pela equação (C.4) e eliminando as dependências em q, obtém-se: 


$$
\mathrm{V}_{0}^{-1} \mathrm{~K}_{0}^{\prime}\left(\mathrm{Q}_{1}+\mathrm{Q}_{2} \mathrm{~V}_{0}^{-1} \mathrm{~K}_{0}\right)=\mathrm{P}_{1}+\mathrm{P}_{2} \mathrm{~V}_{0}^{-1} \mathrm{~K}_{0}
$$

Pela definição da auto-onda PIN, as curvaturas de frente de onda $\mathrm{K}_{0}$ e $\mathrm{K}_{0}^{\prime}$ podem ser a curvatura da frente de onda PIN $\left(\mathrm{K}_{\mathrm{PIN}}\right)$ no ponto $\mathrm{X}_{0}$, onde a curvatura $\mathrm{K}_{0}$ se retrai deste o ponto $\mathrm{X}_{0}$ até o ponto refletor $\mathrm{R}$ e a curvatura $\mathrm{K}_{0}^{\prime}$ se expande deste o ponto refletor $\mathrm{R}$ até o ponto $\mathrm{X}_{0}$, ou seja, $K_{0}=-K_{P I N}$ e $K_{0}^{\prime}=K_{P I N}$, substituindo-as na equação (C.6) é determinado, a seguir, a primeira relação entre a curvatura $K_{\mathrm{PIN}}$ e os elementos da matriz propagadora $\Pi_{\mathrm{AN}}(2 \mathrm{D})$ :

$$
\mathrm{P}_{0,1}=\mathrm{v}_{0}^{-1} \mathrm{~K}_{\mathrm{PIN}}\left(\mathrm{Q}_{1}-\mathrm{Q}_{2} \mathrm{~V}_{0}^{-1} \mathrm{~K}_{\mathrm{PIN}}\right)+\mathrm{P}_{2} \mathrm{v}_{0}^{-1} \mathrm{~K}_{\mathrm{PIN}} .
$$

Analogamente, pela definição da auto-onda $\mathrm{N}$ e pela equação (C.6) é obtida, abaixo, outra relação entre a curvatura da frente de onda $N\left(K_{N}\right)$ e os elementos da matriz propagadora $\Pi_{\mathrm{AN}}$, pois semelhantemente, a curvatura $\mathrm{K}_{0}$ se retrai deste o ponto $\mathrm{X}_{0}$ até a interface refletora na vizinhança do ponto refletor $\mathrm{R}$ e a curvatura $\mathrm{K}_{0}$ se expande deste a interface refletora na vizinhança do ponto refletor $R$ até o ponto $X_{0}$, ou seja, $K_{0}=-K_{N}$ e $K_{0}^{\prime}=K_{N}$. Portanto,

$$
\mathrm{P}_{1}=\mathrm{V}_{0}{ }^{-1} \mathrm{~K}_{\mathrm{N}}\left(\mathrm{Q}_{1}-\mathrm{Q}_{2} \mathrm{~V}_{0}{ }^{-1} \mathrm{~K}_{\mathrm{N}}\right)+\mathrm{P}_{2} \mathrm{~V}_{0}{ }^{-1} \mathrm{~K}_{\mathrm{N}}
$$

No entanto, é verificado utilizando a matriz propagadora reversa $\prod_{\mathrm{AN}}^{*}$ para o caso especial $\mathrm{AN} 2 \mathrm{D}$, intrínseco as auto-ondas $\mathrm{PIN}$ e $\mathrm{N}$, que $\mathrm{Q}_{1}=\mathrm{P}_{2}$. Inserindo esta igualdade na relação $\mathrm{Q}_{1} \mathrm{P}_{2}$ $-\mathrm{Q}_{2} \mathrm{P}_{1}=1$, tem-se:

$$
\left(\mathrm{Q}_{1}\right)^{2}-\mathrm{Q}_{2} \mathrm{P}_{1}=1 \Rightarrow \mathrm{P}_{1}=\left[\left(\mathrm{Q}_{1}\right)^{2}-1\right] / \mathrm{Q}_{2} \text {. }
$$

Substituindo a equação (C.9) nas equações (C.7) e (C.8) e reagrupando-as, obtém-se:

$$
\mathrm{Q}_{1}-\mathrm{Q}_{2} \mathrm{~V}_{0}^{-1} \mathrm{~K}_{\mathrm{PIN}}=\mp 1 \text { e } \mathrm{Q}_{1}-\mathrm{Q}_{2} \mathrm{~V}_{0}^{-1} \mathrm{~K}_{\mathrm{N}}= \pm 1
$$

Com o sistema de quatro equações (C.10) são encontrados os elementos da matriz propagadora $\Pi_{\mathrm{AN} \_} \mathrm{Q}_{1}\left(=\mathrm{P}_{2}\right)$ e $\mathrm{Q}_{2}$ em termos das curvaturas $\mathrm{K}_{\mathrm{PIN}}$ e $\mathrm{K}_{\mathrm{N}}$, porém, são escolhidas apenas um grupo de duas equações, uma com a igualdade negativa e a outra, necessariamente, com a igualdade positiva, ou seja, 


$$
\left\{\begin{array} { l } 
{ \mathrm { Q } _ { 1 } - \mathrm { Q } _ { 2 } \mathrm { V } _ { 0 } ^ { - 1 } \mathrm { K } _ { \mathrm { PIN } } = + 1 } \\
{ \mathrm { Q } _ { 1 } - \mathrm { Q } _ { 2 } \mathrm { V } _ { 0 } { } ^ { - 1 } \mathrm { K } _ { \mathrm { N } } = - 1 }
\end{array} \quad \left\{\begin{array}{l}
\mathrm{Q}_{1}-\mathrm{Q}_{2} \mathrm{~V}_{0}{ }^{-1} \mathrm{~K}_{\mathrm{PIN}}=-1 \\
\mathrm{Q}_{1}-\mathrm{Q}_{2} \mathrm{~V}_{0}{ }^{-1} \mathrm{~K}_{\mathrm{N}}=+1
\end{array}\right.\right.
$$

Resolvendo, então, os sistemas de equações (C.11), obtém-se:

$$
\mathrm{Q}_{2}=\mp \frac{2 v_{0}}{\mathrm{~K}_{\mathrm{PIN}}-\mathrm{K}_{\mathrm{N}}} \text { e } \mathrm{Q}_{1}=\mathrm{P}_{2}=\mp \frac{\mathrm{K}_{\mathrm{PIN}}+\mathrm{K}_{\mathrm{N}}}{\mathrm{K}_{\mathrm{PIN}}-\mathrm{K}_{\mathrm{N}}}
$$

Substituindo $\mathrm{Q}_{1}$ e $\mathrm{Q}_{2}$ (equações C.12) na equação (C.9) é determinado

$$
\mathrm{P}_{1}=\mp \frac{2 \mathrm{~K}_{\mathrm{PIN}} \mathrm{K}_{\mathrm{N}}}{v_{0}\left(\mathrm{~K}_{\mathrm{PIN}}-\mathrm{K}_{\mathrm{N}}\right)}
$$

Portanto, inserindo os elementos $\mathrm{Q}_{1}, \mathrm{Q}_{2}, \mathrm{P}_{1}$ e $\mathrm{P}_{2}$, agora, reescritos em função das curvaturas das auto-ondas PIN e $\mathrm{N}$, na matriz propagadora $\Pi_{\mathrm{AN}}$, tem-se:

$$
\Pi_{\mathrm{AN}_{-}}=\left(\begin{array}{ll}
\mathrm{Q}_{1} & \mathrm{Q}_{2} \\
\mathrm{P}_{1} & \mathrm{P}_{2}
\end{array}\right)=\mp \frac{1}{\mathrm{~K}_{\mathrm{PIN}}-\mathrm{K}_{\mathrm{N}}}\left(\begin{array}{cc}
\mathrm{K}_{\mathrm{PIN}}+\mathrm{K}_{\mathrm{N}} & 2 \mathrm{v}_{0} \\
\left(2 \mathrm{~K}_{\mathrm{PIN}} \mathrm{K}_{\mathrm{N}}\right) / \mathrm{v}_{0} & \mathrm{~K}_{\mathrm{PIN}}+\mathrm{K}_{\mathrm{N}}
\end{array}\right) .
$$

